Portland State University

PDXScholar

$1-1-1980$

\title{
An observational study of service provider client dyadic interactions
}

Joan Dayger Behn

Portland State University

Follow this and additional works at: https://pdxscholar.library.pdx.edu/open_access_etds Let us know how access to this document benefits you.

Recommended Citation

Behn, Joan Dayger, "An observational study of service provider client dyadic interactions" (1980). Dissertations and Theses. Paper 880.

https://doi.org/10.15760/etd.880

This Dissertation is brought to you for free and open access. It has been accepted for inclusion in Dissertations and Theses by an authorized administrator of PDXScholar. Please contact us if we can make this document more accessible: pdxscholar@pdx.edu. 
AN OBSERVATIONAL STUDY OF SERVICE PROVIDER/CLIENT DYADIC INTERACTIONS

by

JOAN DAYGER BEHN

A dissertation submitted in partial fulfillment of the requirements for the degree of

\author{
DOCTOR OF PHILOSOPHY \\ in \\ URBAN STUDIES
}

\author{
Portland State University \\ 1980 \\ (c) Joan Dayger Behn, 1980
}


TO THE OFFICE OF GRADUATE STUDIES AND RESEARCH:

The members of the Committee approve the dissertation of Joan Dayger Behn presented May 13, 1980.

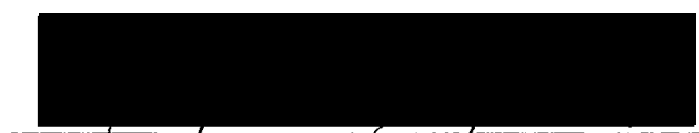

Hugo M. Maynard, Chajrman

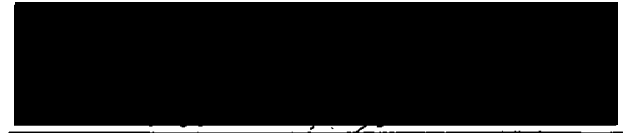

Barbara J. Stéwart
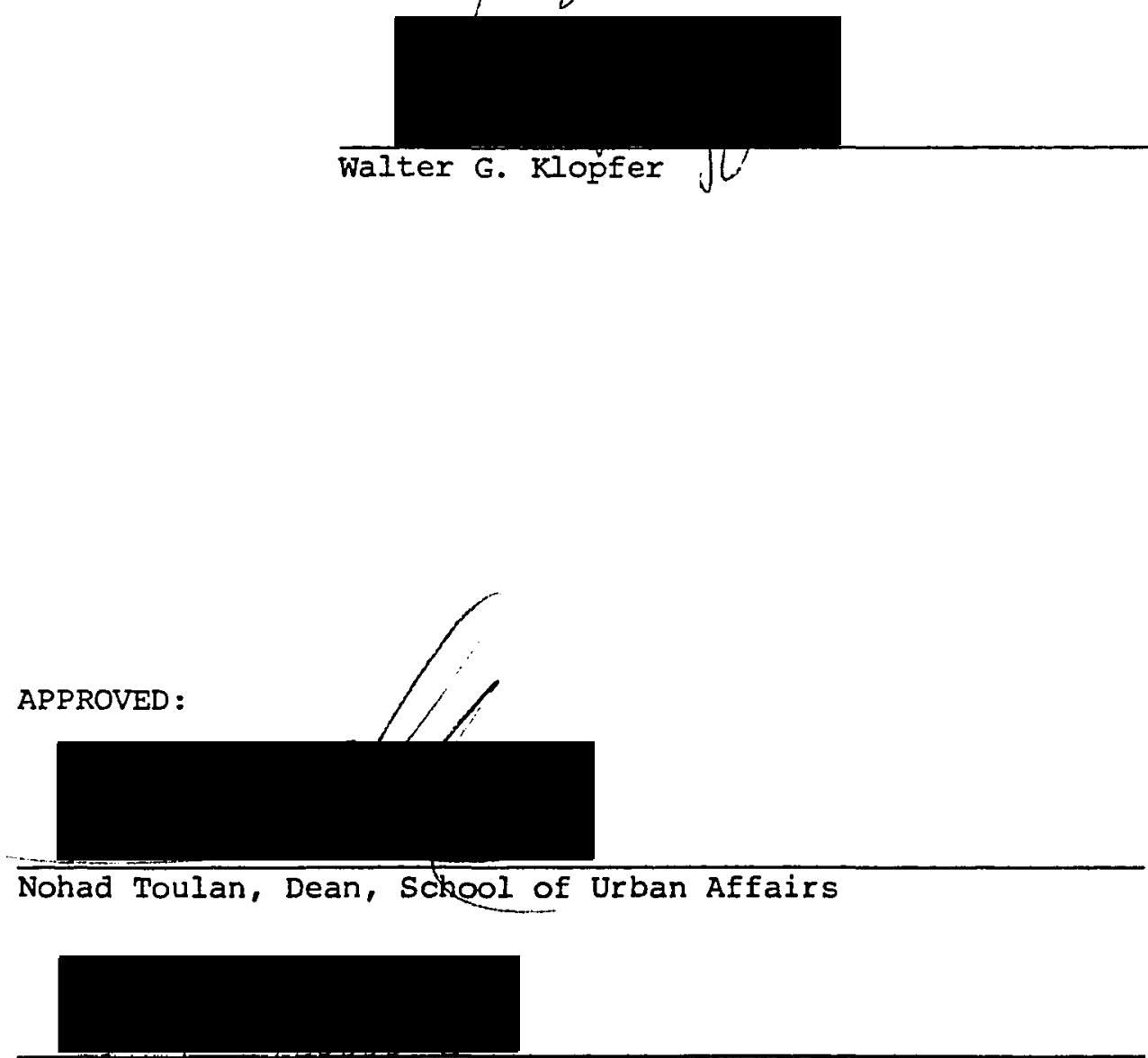

Stanley E. Raúch, Dean of Graduate Studies and Research 
AN ABSTRACT OF THE DISSERTATION OF Joan Dayger Behn for the Doctor of Philosophy in Urban Studies presented May 13, 1980.

Title: An Observational study of Service Provider/Client Dyadic Interactions.

APPROVED BY MEMBERS OF THE DISSERTATION COMMITTEE:
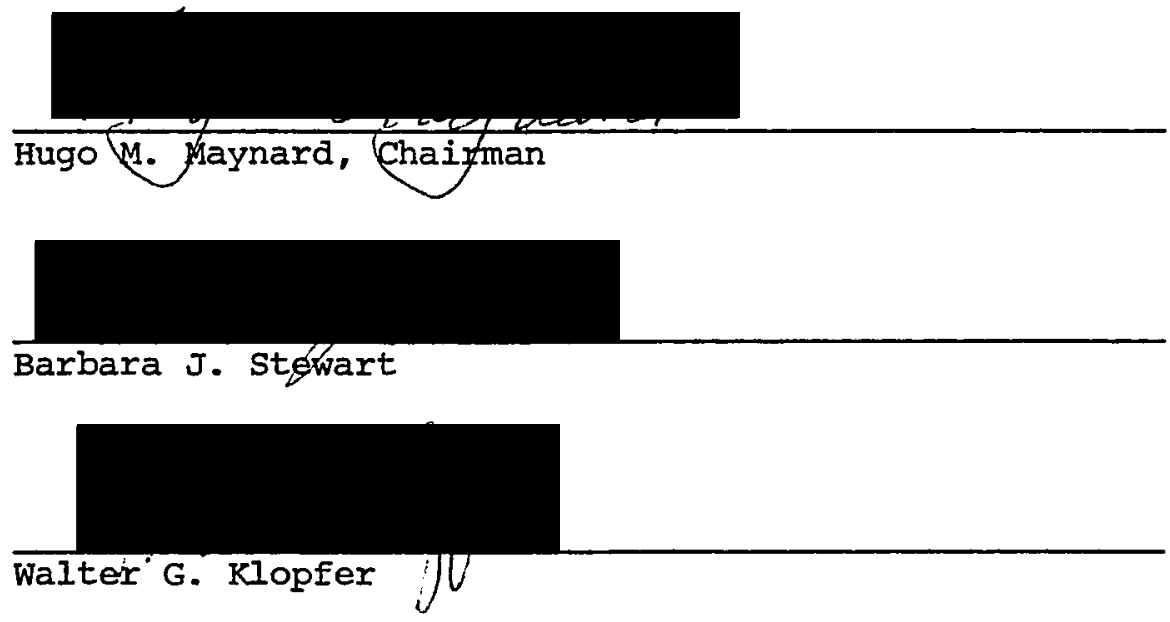

This dissertation reports on the evolution of an observation instrument designed to examine a series of dyadic interactions between service providers and elderly clients. The encounters took place in the physical context of the client's home and under the auspices of two different kinds of urban service agencies. Staff members and elderly clients of In-home Nursing and Interaction agencies participated in the study.

The coding system (Service Provider/Client Dyadic Interaction Coding System or SP/CDICS), is comprised of 28 carefully defined and described behavioral categories. The categories were developed through 
literature reviews and a series of preliminary observations conducted in agencies similar to but not included among the sampled agencies. A majority of the defined behavioral categories require moderate levels of observer judgment. A Field Manual was developed to train the five observers who collected the data. This was supplemented with a videotape constructed to further assist observers in the learning and subsequent use of the code, particularly with non-verbal and paralinquistic aspects of the behaviors.

Fifty-one service providers and 147 clients comprised the sample of observed dyads. The coded observational data were examined in the expectation that there would be recurrent patterns of behavior. Factor analysis resulted in the delineation of ten client and five service provider behavioral patterns that appear to be interpersonally meaningful.

The derived service provider and client behavioral factors were correlated with other measurements available on the same population. These included several service provider personality and attitude measures as well as observer and client evaluations of the encounter. The comparisons, in general, tended to confirm the interpretations given to the described factors, further supporting an assumption that the $\mathrm{SP} / \mathrm{CDICS}$ is a useful and valid instrument.

Recommendations for future research include cross-validation studies. 


\section{ACKNOWLEDGMENTS}

There are three groups of people to whom I owe especial thanks:

Those who assisted me by participating in this research as Subjects. Anyone who investigates behavior under the natural conditions of life, owes a special debt to the people who allowed it: they must remain nameless.

Those who assisted me as mentors. They never flagged in support of me despite considerable provocation: Hugo Maynard, Barbara stewart, and walter klopfer.

Those who suffered with me: Natalie, Robin and Axel. 
TABLE OF CONTENTS

PAGE

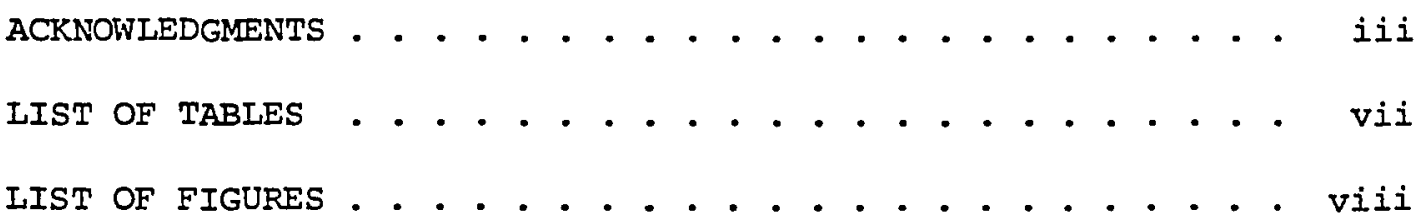

CHAPTER

I INTRODUCTION: THE IMPORTANCE OF THE SERVICE PROVIDER AND ELDERLY CLIENT RELATIONSHIP. . . • . • . . . . . 1

Overview . . . . . . . . . . . . . . . 2

The Iarger Context . . . . . . . . . . . 4

II METHOD I: THE CHOICE OF NATURALISTIC OBSERVATION AS A PREFERRED MODE . . . . . . . . . . . . . . 11

A Brief Review . . . . . . . . . . . . 13

Issues to be Considered . . . . . . . . . 19

Site Selection

Deciding what to observe

Choosing Unit Size for the Behavioral Taxonomy

Observer Training and Limitations

Sampling strategies

Summary

III METHOD II: THE DEVELOPMENT OF AN INSTRUMENT • • • . 32

Site Selection . . . . . . . . . . . 33

The Behavioral Categories . . . . . . . . 37

The Item Pool

Code-T

Code-P

Code-PT

SP/CDICS 
CHAPTER

PAGE

Observer Training . . . . . . . . . . . . 4 47

Recruitment

Screening of Observers

Training of observers

IV AN INITIAI APPICATION: FINDINGS FROM THE FIELD . • • 53

The Observation Sample . . . . . . . . . . 54

Observation Sample Agencies

Observation Sample Service Providers

observation Sample older clients

Procedures and Instruments Used to Collect the

Observation Data

Service Encounter Behavior Frequencies . . . . . 62

Behaviors Affected by Role

Behaviors Affected by Service Type

Patterns of Behavior . . . . . . . . . . . 78

Service Provider Behavior Patterns

Client Behavior Patterns

$V$ RELATIONSHIPS TO OTHER MEASURES: A VENTURE INTO THE

QUESTION OF VALIDITY . . . . . . . . . . . . . . . 102

The Client Factors . . . . . . . . . . 103

Client Factor I (Role Reversal)

Client Factor II (Compliant)

Client Factor III (Direct)

Client Factor IV (Negativistic)

Client Factor V (Complaining)

Client Factor VI (Eager)

Client Factor VII (Friendly)

Client Factor VIII (Assertive)

Client Factor IX (Narcissistic)

Client Factor X (Passive) 
The Service Provider Factors. . . . . . . . 113

Service Provider Factor I (Friendly)

Service Provider Factor II (Nondirective)

Service Provider Factor III (Uninvolved)

Service Provider Factor IV (Authoritarian)

Service Provider Factor V (Task-oriented)

Conclusions . . . . . . . . . . . 120

BIBLIOGRAPHY . . . . . . . . . . . . . . . . 123

APPENDICES . . . . . . . . . . . . . . . . . 129
A Coders Field Manual
B Specific Attitude Questionnaire
C Interpersonal Checklist
D Client Evaluation Interview Schedule
E Observer Impression Sheet
F Observer Evaluation Form 
IIST OF TABLES

TABLE

PAGE

I Naturalistic vs. Iaboratory Research Characteristics . 14

II Social Service Types Included in the General Attitude

Survey $(G A S)$. . . . . . . . . . 54

III Composition of the Observation Sample ........ 55

IV Data Collection Time Table . . . . . . . . 57

V Mean Behavior Frequencies ............. 63

VI A Comparison of Mean Behaviors by Role (Service

Provider vs. Client) .......... 68

VII A Comparison of Service Provider Behavior Means

by Service Type . . . . . . . . . . 74

VIII A Comparison of Client Behavior Means by Service Type. . 75

IX Service Provider Behavior Factors ... . . . . . . 81

X Client Behavior Factors . . . . . . . . . 93

XI Client Behavioral Factors and Contentment Items. . . . 104

XII Client Behavioral Factors and Discontent Items . . . 106

XIII Client Behavioral Factors and Aging and Affect Items and Summary Scales. . . . . . . . . . 108

XIV Service Provider Behavioral Factors Correlated with

Evaluations and Attitudes............ 114

XV Service Provider Behavioral Factors Correlations with

Personality ............... 116 
LIST OF FIGURES

FIGURE

PAGE

1. The SP/CDICS Coding Form . . . . . . . . . . . . . 50

2. Mean Frequencies of Occurrence of the 28 Behavior

Categories for Service providers and Clients . . . . 64

3. Service Provider and Client Mean Behavior Frequencies • 67

4. Range of Behaviors Occurring in Any One Encounter . . . 70

5. Service Provider Behavior Correlations ( $\leqslant .001)$. . . . 80

6. Correlations of Behavioral Items Included in Service

Provider Factor I (Friendly) . . . . . . . . . . . 82

7. Correlations of Behavioral Items Included in Service

Provider Factor II (Nondirective) . . . . . . . . 83

8. Correlations of Behavioral Items Included in Service

Provider Factor III (Uninvolved) . . . . . . . . 85

9. Correlations of Behavioral Items Included in Service

Provider Factor IV (Authoritarian) . . . . . . . . 86

10. Correlations of Behavioral Items Included in Service

Provider Factor V (Directive) . . . . . . - . . . 87

11. Service Provider Factors Plotted on ICL Profile wheel . 89

12. Client Behavior Correlations ( $\mathrm{p} \leq .001)$. . . . . . . . 91

13. Correlations of Behavioral Items Included in Client

Factor I (Role Reversal) . . . . . . . . . . . 93

14. Correlations of Behavioral Items Included in Client

Factor II (Compliant) - . . . . . . . . . . . . 94 
15. Correlations of Behavioral Items Included in Client Factor III (Direct) . . . . . . . . .

16. Correlations of Behavioral Items Included in Client Factor IV (Negativistic) . . . . . . . . 95

17. Correlations of Behavioral Items Included in Client Factor V ((Complaining) . . . . . . . . 96

18. Correlations of Behavioral Items Included in Client Factor VI (Eager) . . . . . . . . . 96

19. Correlations of Behavioral Items Included in Client Factor VII (Friendly) . . . . . . . . . . 97

20. Correlations of Behavioral Items Included in Client Factor VIII (Assertive) . . . . . . . . 98

21. Correlations of Behavioral Items Included in Client Factor IX (Narcissistic) .......... 99

22. Correlations of Behavioral Items Included in Client Factor X (Passive) ............ 100

23. Client Factors Plotted on ICI Profile Wheel ...... 101

24. Client Factors on an Approach-Avoidance Continuum . - 112 


\section{INTRODUCTION: THE IMPORTANCE OF THE SERVICE PROVIDER AND ELDERIY CLIENT RELATIONSHIP}

The conceptualization of this dissertation came as a result of a directed research grant sponsored by the Administration on Aging,* and carried out under the auspices of the Institute on Aging (IOA), Portland State University. The work to be reported in this paper formed a significant sub-section of the larger project. As such, it can be viewed and will be interpreted both as a self-contained study in its own right and as a study nested in the context of a larger, relatec research project.

The focus of the larger investigation was to be on the nature of professional health and social services provided to elderly consumers. The kind of service provided was to be examined particularly as it might be related to service providers' attitudes toward elderly persons; and how this attitude might inadvertently reinforce or create dependency and negative self-concepts in the elderly consumer of those services. The actual encounter situation was seen to be, "the make or break aspect of many types of service provision" (Institute on Aging, 1976). Project objectives, therefore, were to include an understanding of the actual encounter between the provider of services and the elderly recipient of those services. Stated more precisely, this objective was to specify 
the "discrete behavioral components of face-to-face professional interactions with older clients" (Administration on Aging, 1976). This particular objective is the focus of the following dissertation.

\section{OVERVIEW}

The larger study, which came to be known as the Client Relations Project, gathered information on professional staff in agencies that serve elderly clients in the Portland/Multnomah County area of oregon. Six project-defined kinds of services were examined. These included a diversity of services varying from transportation assistance to mental health services. The six service areas considered were named: Health/ Mental Health, Housing, Income, Interaction, Nutrition, and Transportation. Only two of the six service areas or "types" are considered in this study which was identified as the observation Component of the Client Relations project. The observation sample included In-home Nursing agencies (a sub-set of the Health/Mental Health category) and Interaction agencies. Both of these agency types deliver services to the client in a home setting.*

Data collected on the population of service providers in all the six areas included: demographic details related to the service provider such as age, sex, and education; job satisfaction and agency organizational information; and an assessment of the attitudes of service providers toward their elderly clients-as-a-group (named: "General Attitudes"). For the observed group, additional data were collected that included: (1) demographic details related to the client such as

*The reasons for the sample selection are discussed in detail in Chapter III. A description of the sample can be found in Chapter IV. 
age, sex, and length of time served; (2) a description of each client by his or her respective service provider (named: "Specific Attitudes"); (3) a personality measure on each service provider (Leary's Interpersonal Checklist); (4) a coded record of the behaviors emitted by both service provider and client during an observed encounter; and, finally, (5) evaluations of that same observed encounter by (a) the trained coders, and (b) by the elderly recipient of those services. The service provider personality measure was taken at two levels: public (from the observer's point of view); and private (from the service provider's own view). These data together with the observed behaviors were gathered explicitly for this dissertation. The design of a code with which to record the observations is the author's original work and the essential contribution of the dissertation.

The results of the larger Client Relations (CR) Project and the smaller dissertation study are intended to aid in the construction of training materials and orientation programs for the staffs of community human service agencies; and, as such, are expected to contribute to the realization of the national objectives of the older American Act by developing more effective community resources. It is hoped that these efforts will also provide the scientific community with information which can be incorporated in the formation of additional hypotheses for further meaningful research in the area of human behavior. Especially, it is hoped that this research will result in some direct benefit to elderly consumers through an increase in the humaneness of the services they increasingly depend upon and thus impact on the quality of life experienced. 
THE LARGER CONTEXT

A number of related and interacting phenomena can be seen to contribute to the emergence of a special concern with the encounter between elderly individuals and the professionals they must interact with and rely upon. Of particular note is the intersection of (1) the social changes surrounding the historical events of industrialization and urbanization, and (2) the special vulnerabilities of the elderly population.

In 1790, when the first federal census was taken, less than 20 per cent of the American population survived from birth to the age of 70. Today, more than 80 per cent can expect to do so (Fisher, 1978). The 20th Century has witnessed the widespread urbanization of the industrialized nations. Achievements accompanying these developments such as medical discoveries, better nutrition and hygiene, and general technological sophistication, have added years to average life expectancy. In 1900, only 4 per cent of the population were 65 and older, constituting a group of some 3 million. The total elderly population is now in excess of 10 per cent, and in 1970, included over 20 million persons. While further increases in longevity are not expected to occur due to additional advances in medical knowledge, the numbers and proportion of elderly are, nevertheless, expected to increase--in response to the improved delivery of health care and the presently stable or declining birth rate. It is estimated that by the year 2000 , those over 65 will be a group of nearly 29 million people (U. S. Census, 1972). The dramatic increase in numbers has provoked alarm in many service sectors. Economists worry that Social security funds may be in danger 
from the shift in proportion of working (depositing) individuals to retired (withdrawing) individuals. Mental health professionals also warn about the numbers of elderly using and needing services. Wolfe (1963), in a typical emphasis, titles the first chapter of his text: "The Geriatric Patient--A National and International Problem." (See also: Birren, 1959; and Busse \& Pfeiffer, 1973.)

While years have been added to average life expectancy, answers have not been found to many problems facing the growing numbers of elderly in these same industrialized and urbanized countries (Butler \& Lewis, 1978; Hendricks \& Hendricks, 1977). The quality of life experienced by older citizens has not been enhanced to the same degree as the length of life. Concern with the nature and quality of service provision to aging individuals stems not only from this sheer numerical increase in elderly persons in the population, but also from a number of other interacting variables that produced increased dependency.

Early in this century, actually, old age began to be viewed in a new way. It began to be seen as a "social problem" that needed institutional remedies. Responses prompted by this discovery began appearing in the first decade in actions such as the:

appointment of the first public commission on aging (Massachusetts, 1909), and the first major survey of the economic condition of the aged (Massachusetts again, 1910); in the first federal old age pension bill (1909), and the first state old age pension system (Arizona, 1915); in the invention of a new science named geriatrics (1909), and the first published text book in that field (1914) (Fisher, 1978, p. 157).

Old age was not the only newly discovered social problem at the turn of the century. There were many such "discoveries" that reflected a change in the prevailing social ethic that now espoused the idea that 
"government was necessary; planning was good; and regulation was a requirement for order, justice, and even freedom in the modern world" (Fisher, 1978, p. 158).

Migration patterns related to industrialization have had important effects on the elderly. During the early 20th Century, major population relocations occurred as industrial production out-distanced agricultural production. In 1900, 60 per cent of the population resided in rural areas; by 1970, it was only 26 per cent (U. S. Census, 1972). Currently, concentrations of elderly are found either in popular retirement states such as Florida and Arizona where the more affluent segment has moved, or, more commonly, where thy have been left behind by the out-migration of youth. Earlier, this phenomenon occurred in the rural midwest; more recently it can be observed in the central city areas. older, frequently isolated, individuals comprise a significant proportion of the population in urban areas.

Another covarying consequence of urbanization is smaller, nuclear family units. The role of the professional service provider is becoming increasingly important as social and environmental changes work toward. the breakdown of the extended family and the disruption of networks of friends and neighbors. Young \& willmott (1962) have convincingly shown that social mobility and environmental change result in more and more individuals of all ages needing care and support from persons other than immediate family and kin. The interaction between the aging process and these forces operating within the urban and larger societal context, makes older Americans an especially service-dependent group. Against this background of social change which has tended to isolate the older citizen, prevalent concomitants of aging have 
increased repercussions. Elderly individuals are more likely to be isolated by the aging process itself as they are more likely to lose friends and spouses through death; they are no longer in work relationships that provide interactions with co-workers and social status; and they are more likely than the general population to also suffer from the isolating effects of poverty and ill health. The management of life problems once handled by kin or life-long friends is increasingly taken on by organized service agencies. Concerns of financial support are handled by programs such as social security and supplemental security Income. Nutritional support is obtained from food stamps, Meals on Wheels, and Loaves \& Fishes programs. Housing needs are responded to by subsidized housing, old age homes, and nursing homes. Medical support and physical care systems are managed by hospitals, nursing homes, and agencies that come into the person's own hörie. The sharp increase in longevity, for those individuals who attain late maturity, may have profound consequences for personal adjustment as well. When marriage was made a sacrament in the Ninth Century A.D., the prospect of a 25-year marriage lasting into the couple's forties was slight. Elderly individuals are now confronted with increased incidence of late-life divorce, either personally or indirectly in friends and relatives. In the year 1000, or even 1900, the problems of late-life divorce or adjustment to the chronic illness of one's spouse were moot questions at best. Feelings of loneliness, estrangement, and unwanted dependence are added concerns brought to the professional service provider who finds that it is not enough to tend only to specific material or physical needs. Emotional and social support are also crucial for a sense of well-being and they increasingly come from the 
the ministrations of agency personnel.

In the second half of the 20th Century, another change in awareness and social expectation became apparent with the rise of the postindustrial or service society (Bell, 1973). Employment figures in 1950 "showed that there were more service-producing than goods-producing workers" (Gartner \& Riessman, 1974, p. xii). An emerging serviceconsumer society has been developing both because increased industrial productivity has made it possible, and because that same industrial progress has dislocated the means by which individuals solved economic, personal, and social problems--making organized human services a perceived as well as real need.

The booming of the human service sector (the welfare establishment, the professions and paraprofessions of education, welfare, and health) has presented us with the phenomena of highly interpersonal human-oriented activities occurring in the context of large-scale organizations which are characterized by formalism, impersonality, and rigid rules. As stated by Gartner \& Riessman (1974, p. 143), these characteristics which were so efficacious to industrial progress are an "anathema to activities that have humanistic ends and require relational interpersonal processes."

Consumers are beginning to demand more appropriate services. Bell (1973) predicts that the traditional conflict between the worker and the capitalist will be replaced by a conflict between professional and consumer. With the exception of the Gray Panthers, older individuals have not emerged as a strong force. However, with each succeeding cohort of individuals entering the ranks of senior citizens, we can expect an increase in demands and expectations. The "new" elderly are 
increasingly native born, well-educated, politicized, and informed. We can anticipate that they will want more and better services. They will challenge the professionals, who claim to know better than their clients what they need, for control and direction of services.

Services available to elderly today, despite the best intentions, often have the inadvertent deleterious effects of infantilizing and undermining competence and self-esteem (Romaniuk, Hoyer \& Romaniuk, 1977). Poor health, poverty, role attrition, and devaluation in a youth-oriented culture can combine to make the elderly client particularly vulnerable to the negative side effects of human service systems. Without the counterbalancing experiences of being competent at work, physically intact, valued by family, and respected by friends, the elderly individual can be profoundly demoralized by interaction with an organization that amounts to a "total institution" in terms of the degree of impact it can have on an isolated individual (Goffman, 1970). Thus, because of the critical nature of the service system to older people and because of the concentration of older citizens in urban areas, the quality of the urban service systems serving older individuals is of consequence to researchers concerned with the latter stages of the life course.

This dissertation will examine features of that service system at a crucial point. It aims to analyze a set of instances where services are delivered in a dyadic encounter between service provider and elderly client. As noted earlier in this chapter, it is in this faceto-face meeting of professional and client that the service to the elderly either succeeds or fails. A detailed knowledge of these interactions seems basic to the success and improvement of service provision 
to our older citizens.

An understanding of these critical encounters will be attempted through the creation and application of a behavioral observation technique. This will involve the extension of a method which already exists into a new and novel area: the service proviaer/elderly client dyad. 
CHAPTER II

\section{METHOD I: THE CHOICE OF NATURALISTIC}

OBSERVATION AS A PREFERRED MODE

The researcher has an array of possible investigative strategies (each with different methodological assets and weaknesses) from which to choose the one most appropriate for the question at hand; in this instance, what is the nature of the service provider/client interaction? This question, which is focused on a real life situation and the analysis of how the individuals involved actually behave, seems to be one most readily examined through the mode of direct observation.

"The primary feature of such research is that human perceptual and judgmental abilities are necessary to extract quantitative data from the flow of responses" (Sackett, 1978, p. 2). Observational techniques contrast, in this respect, with experimental and testing traditions in which measurement proceeds under as uniform conditions as possible, and every effort is taken to eliminate observer effects and biases from the actual measurement setting. As a consequence, most standardized tests and controlled experiments measure the abilities and skills of people under conditions bearing little relevance to those of everyday life.

There are many situations in which the laboratory or questionnaire is a poor substitute for human sensory, perceptual, and judgmental skills. Observational or naturalistic research focuses on those situations, which are ones in which the observer is seen to be not a 
liability but a definite asset. To quote Sackett (1978) again,

there exists no instrument capable of locating each of 15 group home residents once per 15 minutes during the 24-hour day and deciding which among an almost infinite combination of individual and social behaviors was occurring at the time of observation. However, a human employing predefined categories can accomplish this task with relative ease and reliability (p. 3).

Observation of behavior has been used effectively by naturalists, anthropologists, biologists, and ethologists. However, in the recent past, psychologists* have neglected this method--though it has not been completely abandoned. Although the use of observation has notably gained in recognized usefulness among some groups in the last 20 years, the academic setting has been a notable exception. As late as 1974, in spite of increasingly visible bodies of effective observational research, Raush could still point out in the American Psychologist that most academicians still cling to the laboratory model as the only "scientific" method: "We have all been sold a parochial definition of science, and those of us who are teachers continue to foist it on students" (p. 679). In light of a statement such as this which testifies to an attitude under attack but still prevalent, it seems pertinent to. review briefly the history of this attitude and to state, in general, the reasons for using naturalistic research.

*It should be stated that particular notice is taken of psychology because it is the author's primary field and, most importantly, because it seems the logical place to look for methods to understand individual and dyadic human behavior. "Psychology, which is both biological and social, takes the molar behavior of the individual as its observation unit" (Sells, 1969, p. 15). 


\section{A BRIEF REVIEW}

The most rigorous scientific approach, it has been maintained, is the laboratory experiment in which environment, the stimuli of choice, and the response possibilities have all been examined and are controlled so as to eliminate the confounding of variables that might interfere with the task of interpretation of results. The use of experimental laboratory research is believed by some to be the defining indicator of a science at its most mature, advanced stage. Mussen (1960) in a review of child development studies, for example, is pleased to note that psychology can be seen to be advancing since many more studies are available now than earlier that ask causal questions about the "whys" of behavior, rather than "purely descriptive, normative studies."

The implied disparagement of naturalistic research is not uncommon in psychology. In fact, the disparagement has often been direct and intense and resulted in a polarization that has given us a not easily resolvable dichotomy of research methods into: (1) naturalistic, observational research, versus (2) explicitly arranged, controlled laboratory methods. A list of epithets thrown back and forth between a majority group (advocating the experimental examination of causal connections) and a minority group (advocating the observational examination of correlates or patterns) looks something like the one in Table I. The ascendancy of laboratory research resulted in what willems \& Raush (1969) have called an "imperialization of method" in the field of human behavior. A dramatic example of the schism caused by the endorsement of only one method can be found in the course catalogues of Harvard 
TABLE I

NATURALISTIC VS. LABORATORY RESEARCH CHARACTERIZATIONS

\begin{tabular}{|l|l|}
\hline Naturalistic & Laboratory \\
\hline anecdotal & scientific \\
rich & sterile \\
sloppy & rigorous \\
meaningful & "zoo" behavior \\
"bird-watching" & mature state \\
stage & artificial \\
true-to-life & ideal: physics \\
ideal: biology & \\
\hline
\end{tabular}

University. The department of psychology was, until his recent retirement, B.F. Skinner's exclusive domain. This department offered only five-to-ten courses a year, all of which were of an experimental laboratory type. Other prominent psychologists at Harvard (such as Henry Murray, Jerome Bruner, and Erik Erikson) were housed in a separate building, william James Hall, where they formed a newly created and named department along with what had been the departments of sociology and anthropology. The new department was called the Department of Social Relations.

In the last ten to fifteen years the increasingly substantial minority group has begun to propose a resurgence of direct observation as not only an acceptable mode of research, but one which in some situations is the method "par excellence." Many current writers of this ilk (e.g., Bakan, 1967; Bronfenbrenner, 1977) maintain that scientific endeavors in the field of human behavior suffer from excessive dependence on the laboratory experiment as a source of information. Contrived situations, they point out, often only give information about unnatural behaviors and interactions and have a very limited 
generalizability to real, naturally-occurring behaviors. Even the area of child development which has supported some observational research (e.g., Gesell, 1943), suffers from the results of a disproportionate emphasis on laboratory methods.

...much of contemporary developmental psychology is the science of the strange behavior of children in strange situations with strange adults for the briefest possible period of time. (Bronfenbrenner, 1977, p. 513.)

The empirical recording of what transpires in everyday life is a necessary but much overlooked first task in the systematic building of a precise and also generalizable body of knowledge concerning human nature and behavior.

Hutt \& Hutt (1970a) remind us that the techniques of systematic observation are not new. They have been used scientifically to study behavior at least since the time of Charles Darwin's Expression of the Emotions in Man and Animals published in 1872. In psychology proper, observational studies were frequent from the time of Galton (1822-1911) through the 1920's and 1930's; but they have been steadily replaced with laboratory experiments since that time. The laboratory seductively allows for manipulated control over the situation in which behavior occurs. For psychologists eager that their science attain "maturity," it was more desirable to engage in efforts that attempted to speak to the "whys" of behavior than to slog through the purely descriptive normative studies that usually both preceed and later sustain laboratory experimentation in other natural sciences. Reflection on data collected by means of observations of humans in our usual habitats should precede the formation of hypotheses that can then be tested under more rigorous controls than the field situation provides. The 
noted ethologist Niko Tinbergen has expressed the dilemma of psychology in the following words:

It has been said that, in its' haste to step into the twentieth century and to become a respectable science, Psychology skipped the preliminary descriptive stage that other natural sciences had gone through, and so was soon losing touch with the natural phenomena (1963, p. 23).

Observation was a frequently used technique in the early development of most of the natural sciences. An example of this is astronomy in its pre-telescope era. Careful observations of the movements of the stars and planets are still the basis of astronomy and navigation. The controlled, usually very simplified, context of the laboratory can produce more precise, but sometimes, also spurious results if this kind of field work is not available to provide the researcher with the necessary information to know what questions to ask. Brandt (1972) has stated the over-riding importance of this kind of grounding:

The fundamental basis of any science, of course, is observation. A scientific discipline can be no more rigorous than the techniques it commands for observing the entities and processes that lie within its domain (p. 22).

Astronomy, along with other sciences like biology and chemistry, proceeded with controlled testing of hypotheses in the ccntext of extensive observational work. Barker (1963) expresses the quandry of a science without adequate information about the distribution of its phenomena of interest outside the experimental laboratory:

Every beginning textbook tells the student that failure and frustration are important behavior phenomena, and that rewards and punishment are important attributes of man's environment. But where is the infoimation on the forms, abundance, and the distribution of these important phenomena outside the very limited, specially contrived situation of psychological laboratories and clinics? As a psychologist, what answer should I give a layman seeking information from me, as a scientific expert, on the occurrence among men of frustration, for example? To what handbook of data should I refer him? (p. 2) 
Willems (1969) echoes this concern when he mentions that we,

know little about the distribution of humor, sadness, problem solving, disappointment, frustration, dependency training, cooperation, commitment, initiation of social contacts, cue learning and interval judgment (p. 52).

It would seem clear that naturalistic, observational research has a role in establishing this bank of contextual data. However, the need for direct observation is not limited to a preliminary, early-stage type of reconnoitering.

Some natural sciences, notably astronomy and geography, rely heavily on observation throughout the course of their development as it is typically not possible to control or manipulate the phenomena in question. It should be noted that the strongly observational sciences (astronomy, geology, oceanography, palentology, archeology) continue to make dramatic progress with the methods of field observation. Major revolutions, in fact, have occurred in all these sciences in the past thirty years. In biology, anthropology and comparative psychology new discoveries in the natural history of animals have similarly revolutionized knowledge in the same period. During this same time the new field science of ethology has come into being and claimed its first Nobel prize.

The field of human behavior has whole domains of questions which, by their very nature, are impossible to consider in the laboratory. Many socially relevant questions have been ignored in the past because they did not lend themselves to laboratory study and therefore were deemed not amenable to scientific study. For these questions, or any that relate to what kinds of behavioral achievements persons or animals make when left to their own resources--naturalistic observation is the 
only appropriate mode.

The proper interpretation of studies that are performed in the laboratory is another area in which naturalistic, observational research can serve a unique purpose. Without the context of extensive observational data collection, laboratory experiments may eliminate (unknowingly) natural covariations of variables, or make variables (again, unknowingly) covary in ways that persons never confront in everyday life. This artificial tying and untying of variables can produce results false to the context of actual life. Whatever pattern and organization exist in a given relevant context, may be destroyed in the laboratory and another pattern may be imposed. Without field work, systematic laboratory-acquired results can build a careful body of information on "zoo" behavior. Sells expresses this issue most eloquently in his contribution to Naturalistic Viewpoints in Psychological Research (Willems \& Raush, 1969):

Observations of behavior in its natural setting, without interference or manipulation by the investigator, not only frees psychology from insurmountable limitations due to experimental exclusion of complicating, but ecologically highly relevant variables; it also reduces the equally inescapable difficulty of iatrogenic influences on results, that is, the built-in effects of the experimenter's hynotheses expressed in his particular designs and procedures (p. 25).

The laboratory is itself an environment. Since human adaptation is at least partially dependent on the environment, results may apply to that particular environment--and no other. In some cases, behaviors may be entirely situation specific.

Finally, naturalistic research needs to be included in the repertoire of useful methods because no research method is without bias and, consequently, should not be used alone to build an entire body of 
knowledge. Any method must be supplemented by methods with different methodological weaknesses. Webb (1966) in speaking to this issue, remarks that, "The most persuasive evidence comes through a triangulation of measurement processes" (p.3).

Naturalistic observation has an undisputably important role in the study of human behavior. It can contribute, in a way that laboratory efforts and testing traditions cannot, to an objective, quantitative, and descriptive science of human behavior. A clear consensus exists in the literature, in fact, that indicates complex human interactions occurring in the everyday-life environment is best examined through the mode of direct observation. Utilization of field methods seems the obvious choice of mode for this dissertation, then, which will attempt to understand the service provision encounter. We will consider the behavior of actual service providers interacting with their usual elderly clients in the setting in which the two are accustomed to interact.

\section{ISSUES TO BE CONSIDERED}

In the preceding section, the author has endeavored to show that the research goal in this case (understanding the face-to-face encounters between service providers and elderly clients) is best approached by the method of naturalistic or field observation. Once the congruency between research purpose and research method has been established, attention is drawn to a specification of how the method (in this case, direct observation) is to be implemented. Observation of human behavior is a ubiquitous feature of everyday life and generally functions effectively as an unconscious concommitant of human interaction. When used 
as a data collection method in clinical or field research, however, a heightened awareness and a certain formalization of the process is necessary.

Ordinary language meanings are often not precise enough for reliable recording. This becomes a problem in formal observing because the observer collecting data is usually denied the possibility of checking-out or exploring the meaning of behavior, as is usual in ongoing human interactions. Normally, we are able to respond to the perceived meaning of behavior and receive back information as to our accuracy. Deprived of the usual opportunity for clarifying feedback, it is necessary for the scientific observer to have a specified way to observe--some kind of systematic approach or way to encode the data. Field observing requires a prior delineation of behaviors to be recorded with agreed-upon definitions of those behaviors, and a consistent manner of recording the data.

The creation and use of a coding system for behaviors observed in a natural setting is analogous to the invention and use of the array of tools taken into a natural context in other observational sciences. The telescopes and interferometers of astronomy, the theodolites and seismographs of geology and the binoculars and notation systems of ethologists are all tools of this same sort. They are designed to bring order and consistency into the measurement of naturally occurring events in natural settings.

The choice and definition of what behaviors should be recorded is one of a number of inter-related issues or decision points that must be considered in the course of devising a reliable and valid data 
collection method for a naturalistic observation research effort. The decision as to what degree of observer interpretation to allow in the recording of behavior, what recording devices to utilize, how much training to provide observers, what time sampling strategy to use, and what restrictions to place on the site(s) of observations--are additional questions to be pondered and answered in the course of devising a formal way to observe that can be communicated to and used by others. These decisions mutually affect one another in such a way that they cannot be made in isolation. Nevertheless, they will be discussed separately below, for the purposes of clarity and simplicity, under the headings: Site Selection, Deciding what to Observe, Choosing Unit Size for the Behavioral Taxonomy, Observer Limitations and Training, and Sampling strategies.

\section{Site Selection}

Behavior is widely acknowledged to be situation specific (Hall, 1959; Sommer, 1969; Proshansky, 1969). This "situational specificity" means that the appearance and frequency of occurrence of a given behavior is related to the physical arrangements of the space in which it occurs, and the social context or reason for the gathering of individuals. If the context were a party, for example, one would expect that episodes of "talking between strangers" would be more frequent and the episodes of longer duration than if the context were a physician's waiting room with the same furniture arrangements and physical dimensions. Holding social context constant--let us use a physician's waiting room again--the arrangement of the space can be expected to affect the behavior of interest. For example, if the waiting room were 
long and narrow with chairs lined up along one wall, the episodes of "talking between strangers" would be expected to occur with a lower frequency than would be the case in a square room with chairs arranged on several walls so that the persons could easily make eye contact. An awareness of the situational specificity of behavior has given rise to the field of environmental psychology and has affected architects and interior designers who now readily discuss physical settings which, for example, are likely to promote social interaction versus quiet study, reticence or easy approach. The extent to which this awareness of behavior-environment interaction has penetrated the design community is illustrated by those who refer to a "behaviorcontingent approach" to the design of physical spaces and "behaviorally prosthetic" environments (Stader, 1969).

This malleability of behavior to environment means that even if coding systems exist that have considered the behaviors of current interest, it is usually necessary to devise a new system or at least extensively revise an existing code to fit the occasion. Efforts to avoid this time-consuming task are apparent in attempted "universal" coding systems. Notable examples exist for the behavior of children (McGrew, 1970; Caldwell, 1969) and also for primate social behaviors (Kaufman \& Rosenblum, 1966). "In general, these have not been successful" (Sackett, 1978).

It seems abundantly clear that it is necessary to design an observation coding system that is tailored to setting and research goals. This conclusion leads to the obvious decision that a site must be selected before, or at least concurrently with, the evolution of an observational instrument (code). 
The researcher must not only be aware that his/her setting of interest may vary from that of other studies, but also that conditions may vary within the same study. A Client Relations (CR) Project literature review (Proxemics, Jennings, 1977) along with preliminary field work in agencies similar to those in the CR sample, made it apparent that the behaviors of interest in this study (what transpires between service provider and elderly client) take place in the context of different task-orientations and in a multitude of different environments: hospital rooms, mental health offices, dining rooms, bus interiors, private residences, nursing home day rooms. Some restrictions were clearly imperative. Conclusions derived from the review and field work suggested that, at a minimum, the choice of situation(s) must be such as to insure a relatively uniform physical environment, degree of privacy, and number of participants.

Deciding what to Observe

once some decision has been made as to which setting shall be utilized for the field research, the next logical step involves the decision as to which behavioral categories to abstract from the response secenario in this chosen setting. Many writers (Tinbergen, 1958; Lorenz, 1960; Sackett, 1978) caution that it is important to engage in preliminary or exploratory field work before making these choices. This preliminary stage is often treated superficially, or not at all, resulting in questionable data. Some investigators may have preconceptions of what behaviors ought to occur, rather than a knowledge of what actually occurs and thus are liable to impose a spurious orderliness on data. 
How does one determine what actually occurs and therefore which behaviors to quantify? Clear directions come from experienced field observers who state that the preliminary field observations are to be conducted without preconceptions on the part of the researchers; they are to be held at bay.* Tinbergen (1958) describes this passive attitude as being a state of "open interest." It is important to be patient, to allow time for behavioral "Gestalten" to appear (Lorenz, 1960).

Those who go directly to the field in the attempt to be able, in the end, to record behaviors of importance can feel overwhelmed at first by the flood of information acquired in this state of "open interest." Encouragement to persist is, again, universal from the ethologists, naturalists, and psychologists who use naturalistic research methods. They describe an initial period of acclimating. The naturalist, Darling (1937), describes this orienting stage as being one in which, "an observer has to go through a period of conditioning of a subtle kind" (p. 26). On initial contact, "behavior appears to be infinitely variable; with repeated observation it becomes clear that certain patterns tend to recur" (Hutt \& Hutt, 1970a).

Exploratory field work helps the would-be scientific observer identify what behaviors might be of important content. This preliminary work also gives information as to which behaviors are of frequent or infrequent occurrence as well as those which are of Iong duration versus a momentary nature. This information gives additional guidance as to

*one assumption is maintained: Behavior is not random, but patterned in lawful or meaningful ways. 
what behaviors to include in the projected coding system.

The length of these preliminary observations can be shortened in those cases where past experience suggests which behaviors may be important and/or where a reasonable literature exists relevant to the encounters of concern or where there is some prior interest in certain behaviors. In this case, the ten years of observational experience of Gerald Patterson and his co-workers at the Social Research Institute was found to be extremely helpful. Two coding systems developed by this group (the Family Interaction Coding System and the Marital Interaction Coding System) were closely scrutinized and provided guidance in the choice of behavior categories.

A series of literature reviews conducted by the staff members of the Client Relations (CR) Project were considered at this stage also. A paper on Dyadic Interactions (Behn, 1978) suggested behavioral items that have been found to be of importance by earlier studies. Another review, Service Provider Characteristics (Behn, 1977) brought to light those particular qualities and behaviors that have been found to be facilitative or helpful to clients in counseling situations. The client satisfaction literature was reviewed for the CR Project by Bross (1977) and interviews were conducted with elderly clients in which they were asked to specify behaviors of importance to them (Levkoff and Northrup, 1977). All these sources were examined for information regarding potentially important behaviors that could be included in an initial pool of possible behavioral items along with those derived empirically from the preliminary field work. 
Choosing Unit Size for the Behavioral Taxonomy

Concurrently with the amassing of data as to which kinds of behaviors are likely to occur in the field situation, comes the gradually-made choice of how minute and precise (molecular), or large and complex (molar), or, even global, the items comprising the taxonomy shall be. Some investigators bypass the collection of discrete data and derive conclusions directly from observations. This usually results in global categorizations of interactions as being, e.g., "warm" or "congenial" (see, e.g., Nelson, Masada, and Holmes, 1966). This kind of data is affected by observer limitations to a degree not evident in observations collected by means of more quantifiable units. Patterson (1977b) reports, for example, that observer bias which can be "dramatically reflected" in global judgments is not apparent in more detailed, defined recordings of behavior.

It is assumed here that it is best to move toward quantification whenever possible to minimize observer bias and so that scientific principles can be identified and comparisons with other kinds of data can be facilitated. Hutt \& Hutt (1970b) give a number of examples of attempts to compare physiological data with behavioral information. The level of accuracy in the one area (physiology) points up the very subjective and global nature of the data usually available from the second area (behavior).

It is a curious phenomenon that whilst nearly all physical and physiological data about a patient are measured to at least one decimal place on a parametric scale, behaviour is usually relegated to an ordinal scale whose divisions may be as crude as 'better/worse;' 'good/poor.' At best they contain an odd number of items arranged on a 3-, 5-, or 7-point scale, the mid-point often being treated as an 'optimal' or 'neutral' point from which the variable in question may deviate in either direction. . The non-behavioural measures are not merely 
parametric, they are usually measured with such precision that to correlate them with behavioural measures of the crudity of 'better/worse,' 'more/less' is derisory ( $p .3$ ).

The decision as to how fine a grain the observers' codings shall make, then, seems to be rather easily limited to molecular versus molar levels.

One may choose very finely detailed categories, often specific motor activities such as hit, raise arm, and jump. These are examples of fairly minute or molecular behaviors which are often fruitful in research that focuses on the young child or on primate behaviors where physical activities predominate. Hutt \& Hutt (1970a) used this level or unit size of behavior in their observations of autistic and hyperactive children. They were able to discover in the first instance that autistic children do not make eye contact with adults or their peers; and, in the second case, that the difficulties adults find in working with hyperactive children derive not from an excess of activity but from the inability of these children to sustain attention.

While molecular categories are, in general, more precise in that they require little or no inference or judgment on the part of the observer and may be of a level to match physiological measurements; molecular categories can do damage to situations where complex behaviors are the units of interest. An overly reductionistic approach in the interest of precise quantification, can distort the variables of interest by breaking up behavioral patterns. In these instances, the choice may be made to use more molar categories. Human adult interactions, for example, are usually primarily verbal encounters which may be best captured by molar categories or units. Patterson (1976) found this to be so when observing marital couples and structured his Marital 
Interaction Coding System (MICS) accordingly. Bales (1965) also used a molar-grained system to categorize adult group interactions.

The choice of unit or category size is thus fit to the behaviors of interest. The primary guideline for this determination is that the level (molar or molecular) be appropriate to the kinds of behaviors under scrutiny. It should be said, parenthetically, that while a particular taxonomy is usually predominantly molar or molecular, most are actually combinations of both molecular and molar behaviors. This is the case with both the MICS and the Family Interaction Coding System (FICS) devised by Patterson; and the system to be presented in Chapter III which follows in the tradition of these two systems.

It should be said, finally, that more elaborate definitions are usually needed for categories involving higher levels of abstraction. The degree of observer judgment necessary for assigning behavior to a category is also affected by the choice of unit size.

\section{Observer Training and Iimitations}

Any data collection method using humans is not likely to be accurate as compared with completely mechanized systems such as is found with machine recording of the number of bar presses made by an animal. On the other hand, the machine recording will not collect information as to how the bar was pressed (did the animal use front paw?). What kind of behavior went on during pauses in the bar pressing (did the animal explore the cage)? Efforts in observational research are properly directed toward those situations that capitalize on the judgmental skills of observers and toward the minimization of recording errors. 
Training, along with careful definition of terms, is necessary to enhance the ability of several different observers to make the same categorizations on a regular basis. The extensiveness of training required is dependent upon the degree of judgment required for the categories to be used. In those cases in which molar categories are used, the training must be appropriately rigorous. The degree of judgment and training involved may require the development of an observer's manual for use in learning the categories and for later reference in the field. Videotapes may also be necessary as a training device when observers must note and record non-verbal behaviors, paralinguistic cues, and/or the use of time as a variable. These are best illustrated by a medium which can portray visual, aural, and temporal cues. The size of the code, meaning the number of categories included, is also dependent on the cognitive capacities of human observers, unless film or audio recordings of the observed events are used to allow repeated viewing. It has been found empirically (Patterson, 1977a) that 28 categories are the maximum number that coders can use effectively in the field. With the use of preserved observations (film or videotape), the code can be much larger (see McGrew's Glossary of Motor Patterns of Four-Year-Old Nursery School Children, which has 111 items).

\section{Sampling Strategies}

Time sampling is one method often used in observation research. This can be wasteful, however, if observations are hard to come by. Infrequent behaviors are also more likely to be missed. Continuous observation, on the other hand, requires occasions in which the subjects remain in the setting under consideration for a sustained 
period of time.

The length of the observation session is another choice to be made. Obviously, a longer observation maximizes the opportunity to see the behaviors under consideration. But one must work, again, within the constraints of the natural situation and the limits of observer endurance.

Within the observation time limit, the frequency or density of recording is an additional consideration. Shall the coder record a behavior, for example, once every three seconds? Is this too short or too long an interval? This decision must be made, as are all the decisions discussed in this section, in the context of the situation, the method of recording chosen, the kind of behaviors chosen, the speed and pacing of behavior, the number of subjects viewed, et cetera.

How sophisticated a recording device to use is another variable to consider when deciding how to sample behavior. Video-tape, film, or audio recordings are often the tools of choice. One can use observer consensus, thereby reducing error, with such preserved observations. on the other hand, the use of these or other such "hardware" can be too obtrusive. If alienation of subjects occurs as a result of techniques used, those devices may introduce strong artifacts which detract from the naturalness of the setting.

In any case, even if the interaction is successfully preserved on tape or film, its permanence can be less a virtue than at first it seems, as one has eventually still to decide how to sample this record. The apparent completeness of video or film is another attractive feature, but this too can be at least partly illusion. Sackett (1978) reports that "live recording catches at least $90 \%$ of the information extracted 
from repeated viewing of $16-\mathrm{mm}$ film." He goes on to state that it has even been found by some researchers that, in some instances, data can be missed by film that is not missed by observers on the scene.

Summary

In this section the author has taken the opportunity to discuss, in a very general way, a number of considerations that must be taken into account when undertaking naturalistic research. The formalization of the process of observing raises issues that include: the decision as to what degree of interpretation to include in the categorization of behavior, what recording devices to utilize, how much training to provide observers, what sampling strategy to use, and what restrictions to place on the site of observations.

It is clear that the decisions regarding each of the variables enumerated must be weighed in the context of decisions made in respect to the others. And, in each instance, the particular context of the research to be accomplished is intertwined with all these variables as well. In the next chapter, these decision-points will be discussed as they relate to this particular research and the development of the Service Provider/Client Dyadic Interaction Coding System. 
CHAPTER III

METHOD II: THE DEVELOPMENT

OF AN INSTRUMENT

The particular emphasis of this dissertation is on the construction of an observational coding system and the analysis of subsequently collected field observations. The Service Provider/Client Dyadic Interaction Coding System (SP/CDICS) was developed to objectively record primarily verbal but also paralinguistic and non-verbal behaviors that occur as service provider and client interact with each other in the face-to-face context of service delivery. The main emphasis in the SP/CDICS is placed on the accurate coding of every behavior emitted that can be classified, with these responses being recorded sequentially in 30-second blocks.

The SP/CDICS is similar to coding systems such as Bales' Interaction Process Analysis (Bales, 1965) in that the basic units are molar, rather than molecular codings such as those used for ethograms (Eibl-Eibesfeld, 1975), or in work such as that of Hutt \& Hutt (1970a) with autistic children where categories, e.g., hand-raise, jump, headturn, do not require the same degree of observer judgment. In the SP/CDICS, as in Patterson's Marital Interaction Coding System (Patterson, 1976) and Bales' Scale, the basic unit is the smallest discriminable, meaningful segment of verbal or non-verbal behavior which the coder can classify. It is the skillful discrimination of 28 behavior categories by observers, and their recording of the sequence of these 
units which form the basis of the SP/CDICS. These categories are included with their definitions later in this chapter.

The interrelated tasks involved in the evolution of the coding system will be discussed separately below under three headings: Site Selection, The Behavioral Categories, and Observer Training.

\section{SITE SELECTION}

The observations were originally intended to sample each one of the six service agency types included in the Client Relations (CR) Project attitudinal survey. These six CR-defined agency types included potential observation sites in which the interaction between service provider and client differed on a number of dimensions. Interactions with staff in nursing homes, hospitals, dining rooms, and on buses were often fragmentary; while interactions with physicians, mental health counselors, and other interviewers were likely to be lengthy. Many interactions were public in nature such as in a dining or day room, while others were primarily private as in a mental health worker's office or in a client's home. The number of individuals involved in a service provider/client encounter varied widely from only two in the private settings, to three or four in a nursing home room, to over fifty in a Loaves \& Fishes dining hall.

A wide variety of physical space configurations were also apparent. There were situations in which service provider and client were both seated and interacted with each other across a desk. In other cases there were several clients, each in beds, and a number of different service providers approached and left the scene. In still another case, the service provider was stationary, seated behind the wheel of a bus, 
and a number of clients approached and moved on. Finally, there were those settings (dining rooms and day rooms) in which large numbers of clients were seated and a number of service providers moved about, often without direct approach to any one client.

The early field observations, accomplished to begin the formation of the coding system, led to the not surprising conclusion that one coding system could not effectively handle all the potential observation sites. This empirical result was essentially a confirmation of one of the most widely accepted findings in the psychological and environmental design literature--behavior is situation specific (Barker, 1969). This specificity of behavior greatly affects the probability of observing any chosen behavior in a given setting; more importantly, a different setting may require a different interpretation of the "same" behavior.

While it is theoretically possible to create one coding system that would include all the items that seem to be important to any and all the sites included in the CR Project, this system would be exceedingly large and would effectively eliminate the possibility for in vivo recording. The inverse extreme solution, to include only those items which appear in all situations, threatens to leave items so universal that they will not aid understanding, e.g., breathing, walking, sitting, et cetera.

Another alternative, to devise a system comprised of 28 or less items, each one of which seems important in at least one of the potential sites, would likely decrease the potential power of the system since a high incidence or significant behavior in one setting may not occur at all in another setting. This approach would actually reduce 
the "real" items to a few per setting.

Even if items can be found across settings that appear to be significant, meaningfulness may be compromised if they are equated since the same (apparent) behavior can indicate something quite different in dissimilar settings. An example would be touching: in most settings this is a highly important (Henley, 1977) if infrequently occurring indicator of special concern or warm relationship. But in hospitals, nursing homes, and in-home nursing settings touching was usually only a simple task behavior having no special emotional significance.*

It would seem clear from the above that the more one can control context, the more powerful and precise a coding system becomes. The more usual situation found in the literature is, in fact, to limit the scope of a coding system to only one context. Patterson, for example, devised separate codes to record interactions of: (1) chilaren in their own homes (Patterson, Ray, Shaw \& Bobb, 1969), and (2) marital couples in the laboratory (Patterson, 1976).

It was necessary, however, for comparisons the project manager wished to make in the larger research effort, to consider at least two different service agency types. In considering which kinds of services to select, critical variables that had to be considered were the overall duration of an encounter, and its sustained versus fragmentary or interrupted nature. The duration and continuity of chosen behaviors need to be considered in the time base structure of the coding system.

*For the research under discussion this particular problem was resolved by coding task-related touching as NORMATIVE behavior. Touching that was not required and seemed to have emotional significance was coded as POSITIVE PHYSICAL. 
One cannot, for example, plan to conduct two five-minute observations spaced ten minutes apart if the dyadic encounter lasts only one minute. One would also not choose behaviors that tend to last a minute or more (such as describing the problem at hand) for a code to be used in situations that are very brief.

In nursing homes, for example, interactions between service provider and client were brief, sometimes lasting less than fifteen seconds. Another characteristic of the service encounter in this setting was that the dyadic interaction was public and subject to unpredictable and frequent interruptions. The nurse or aide was often summoned by a peer or supervisor to another room or task. The interaction was also often interrupted by conversations between the patient/ client and another service provider in the room, or another patient. Brief, fragmented, and public interactions were also characteristic of service provider/client encounters in buses, hospitals, and in dining halls.

The kinds of behavior that could be coded from these kinds of interactions tend to be ones such as: how long it takes the service provider to acknowledge or respond to the elderly person (usually a matter of seconds); or, how close does the service provider approach (a distance measurement, again, taking a second or two). These measurements would have to be reapeatedly taken, as the behavior occurred, possibly over the course of an entire day or shift.

It became clear that it was necessary to focus either on sites that were characterized by brief, fragmented interactions or by relatively extended and continuous interactions. While one can make some compromise of settings by using extra items (behaviors) to handle a few 
events singular to a particular situation, as has been illustrated above with "touching," the time base structure of the coding system needs to remain fixed. To put it another way, we had to control context and environment at least well enough to be able to keep one timesampling base. The choice was made in favor of extended, continuous interactions.

Because many factors inherent in physical settings have been shown to influence human behavior, we made a further choice: the research was limited to one physical type of setting (the client's own home) to control some of these complicating influences (Hall, 1959; Sommer, 1969). Considerations of privacy and the ability to limit the interaction to the dyad of interest were additional factors in the final selection of the observation site.

THE BEHAVIORAL CATEGORIES

The primary requirement for any coding system is a clear and workable definition of the behaviors under consideration. When using molar units, the definition of a category rests on homogeneity of content, without regard to its arbitrary syntactical properties or duration. By this, it is meant that the coder would not necessarily code each sentence (a grammatical division), but each change of meaning (which could occur mid-sentence as when a change of tone shifted the meaning of a comunication from, for example, the "describing of a problem" over to "complaining).

As with Patterson's Marital Interaction Coding System (MICS), the code under discussion (SP/CDICS), defined coding as being a task which consists in "first learning to discriminate behavior units by attending 
to changes in content, and then learning to categorize each behavior unit in terms of the 28 behavior codes" (Patterson, 1976, section D, p. 2). The steps leading up to the construction of the SP/CDICS are described below.

The Item Pool

A review of the literature was undertaken as one part of the collection of possible behavioral categories to be considered. Dyadic Interactions (Behn, 1978) and Proxemics (Jennings, 1977) were the two resultant papers; both proved to be of assistance as a source of potential items. HUMOR is one example of a behavioral category that was included in the SP/CDICS because of many references in the literature that suggested it could be a strong indicator of status relationships. Coupled with the many suggested items from the literature search was the inclusion of items found to be relevant to clients in a review of the client satisfaction literature (Bross, 1977), as well as items mentioned by elderly clients in a series of field interviews with elderly consumers (Levkoff \& Northrup, 1977). The two codes developed by Patterson (MICS and Family Interaction Coding System (FICS)) were particularly valuable as item sources (Patterson, 1969; Patterson, 1976).

The final source of items was empirical. Items were gleaned from a series of observations, some of which were collected on video-tape. These encounters (recorded in vivo or on tape) were obtained in the field with actual service providers involved in their usual situations with their own clients. 
Code-T

A trial code was constructed from the likely items amassed through the literature reviews, interviews, and field observations mentioned above. This code was used in the field for the purpose of eliminating, adding, and refining behavioral categories.* Eye contact was a variable that found its way into code-T as it is one of the most potent indicators of interpersonal interest found in the literature on non-verbal behaviors. However, in a field situation it is very difficult to assess. A more general category was constructed; ATTEND. A complex of listening behaviors has been shown to be a reliable and significant variable in the literature on counselor effectiveness (Ivey, 1971)

\section{Code-P}

The trial code was sharpened based on the field usage mentioned above. This version of the code was circulated among the Client Relations staff to read for internal inconsistencies, ambiguities, and other editorial input based on their particular and varying expertise.

\section{Code-PT}

The pre-test version of the code was written incorporating staff criticisms and suggestions. A video-tape training tape was constructed at this point to enable prospective observers to learn the coding system in conjunction with a Field Manual written for this purpose. The tape provided graded learning situations and illustrated non-verbal qualities

*The author and one other staff member did all the preliminary field observing. Sue Levkoff, MSW, made an important and very timeconsuming contribution to the development of the final code. 
of certain behavioral units such as tone of voice. The laboratorytrained observers were then scheduled for field observations as the final segment of their training. This field work also subjected the coding system to one final test of relevance, ease of use, and reliability. The observers were sent into sites similar to those in which the final project data were to be collected: In-home Nursing agencies and Interaction (outreach) agencies.

\section{$\underline{\text { SP/CDICS }}$}

The final, data-collection version, of the developed coding system was composed of 28 behavioral categories or units, each of which had a two-letter designation which the coders used in recording their observations of the frequency and sequence of behavior expressed by both service provider and client. Each observation lasted a total of 10 minutes, with at least one behavior being coded for each member of the observed dyad every six seconds. This provided for a sample of at least 200 behaviors per observation, or 100 behaviors for each participant in the dyadic interactions. The entire Field Manual* which includes examples of behavior as well as definitions is attached as Appendix A. The 28 behavioral categories are listed below.

$\underline{\text { AG--AGREE }}$

Affirmative response which occurs when one person expresses an opinion and the other person's response indicates agreement, or acceptance of their interpretation.

Affirmative responses can be verbal or non-verbal.

*The coder's Field Manual, which includes examples of the defined behaviors and examples of behaviors that would be coded and not coded in a given category, is augmented by the training tape (Behn \& Levkoff, 1978), which gives opportunity for coder's to see and hear examples of non-verbal and paralinguistic behaviors and cues. 
Response can occur after a long or short pause, while other speaker is talking, or at the end of a sentence.

\section{DG--DISAGREE}

Statement in which one person expresses an opinion and the other person's response indicates disagreement.

Can be headshaking if clearly meant for disagreement and with no intention of criticizing.

Often occurs after QUESTION, TALK, PROBLEM DESCRIPTION, PROPOSE SOLUTION, OY CRITICIZE.

\section{AT--ATTEND}

Non-verbal behavior which occurs when one person is speaking and the listener is maintaining eye contact and general orientation toward the speaker, code AT for the listener.

Brief verbal or non-verbal response emitted by listener while speaker is talking, or during a pause in speech.

Responses indicating that the speaker's comments are being Iistened to (not to indicate agreement with the content of the speaker's comments).

Statements where listener repeats short versions of the other's statements, often to facilitate the conversation (paraphrasing).

Responses are made in a neutral or positive tone of voice.

\section{NT--NOT TRACKING}

Non-verbal behavior.

When a listener doesn't maintain eye contact with the speaker for more than 3 seconds, code NT for "listeners."

Do not code NT for the speaker, even if he/she looks away from the listener for more than 3 seconds.

\section{CO--COMPLIANCE}

Code when a person's behavior fulfills the requirements of an immediately preceding command/request with 30 seconds. This behavior can be verbal, indicating the person intends to comply.

Often double-coded with appropriate response. 
NC--NON COMPLIANCE

Code when a person's behavior does not fulfill the requirements of an immediately preceding command/request within 30 seconds. This behavior can be verbal, indicating the person does not intend to comply.

Often double-coded with the appropriate code for the noncomplying behavior of the actor.

\section{CM--COMMAND/REQUEST}

Statement of request for an action, usually followed by a COMPIY or NON COMPLY (within 30 seconds) on the part of the other person.

Statement can be delivered as an imperative.

If delivered in a hostile, irritated way, double-code with CRITICIZE: $\mathrm{CM} / \mathrm{CR}$.

If delivered with a "thank you," "please," etc., code with CIVIIITY: $\mathrm{CM} / \mathrm{CV}$.

"I want you to..." statements and "Let me..." statements are coded: CM.

\section{CP--COMPLAIN}

Statements in which a person bemoans the extent of his/her suffering.

Statements which don't explicitly blame the other person or themselves for their suffering.

At-large statements of dissatisfaction.

Statements expressing feelings of being deprived, wronged, or inconvenienced either through someone else's action or because of external circumstances.

Stafement doesn't propose any solutions.

statement may be delivered in a hurt, irritated or whining voice.

\section{CR--CRITICIZE}

Hostile statements expressing dislike or disapproval with a behavior, attitude, or generalized trait of the other person. 
Unkind comments meant to demean, insult, embarrass, or hurt the other person; or non-verbal indicators of a demeaning nature such as an exasperated sigh.

Any proposal for change made in an irritated or hostile way. Statements can be made in a neutral or sarcastic tone of voice.

\section{CV--CIVILITY}

Simple statements of thanks. Compliments. Statements of Hello/Good-bye.

Excuse me statements, if not spoken in a self-demeaning way. Statements spoken in a friendly or neutral tone of voice.

\section{DR--DISREGARD}

Any behavior that appears to be dehumanizing or objectifying of the other person.

Assumptions that the other person is non-functioning or incompetent, in excess of the actual (apparent) situation. Talking or making judgments about the other person without including them in the evaluation.

Ignoring or disregarding the intent or content of a communication from the other person.

Often used as a double-code, a qualifier of other reactions.

\section{HM--HUMOR}

Statements clearly intended to be humorous and usually light hearted in tone.

Mild and gentle teasing, not to be coded if at all humiliating or critical.

Statements which propose facetious solutions to problems. Often double-coded with ILAUGH. 
$\underline{\text { IN--INTERRUPT }}$

Action taken to disrupt the continuity of ongoing activity.

Breaking into or in upon another person's train of thought, speech, or behavior.

Intrusion may be an attempt to maintain contact (usually initiated by the client), an attempt to gain access to an activity (usually to the conversation), or may be an effort to redirect the conversation or activity of the other person.

\section{I.A--LAUGH}

Coded for each separate occurrence of a laugh.

Often double-coded with HUMOR, SMILE, or SELF PUT DOWN.

NB--NERVOUS BEHAVIOR

Non-verbal behavior.

Coded for any behaviors which seem unnatural or abnormal.

Often double-coded with a verbal response.

NO--NORMATIVE

Non-verbal behavior that is appropriate to the task at hand.

Verbal behavior thus coded includes the reading out loud of forms, applications, or generalized questioning from a form.

NR--NO RESPONSE

Coded when a verbal response is clearly called for from one person, and there is none for at least 3 seconds.

Coded when person $A$ asks person $B$ a direct question and $B$ doesn't respond. Code NR for person $B$.

Coded when both people stop talking in the middle of a discussion for longer than 3 seconds. Code NR for both persons. 
$\underline{\text { PA--PARENTING }}$

Statements where speaker addresses listener as a child (use of words like "dear," "honey").

statements that foster dependence and helplessness.

Moralizing statements as in should, must, ought, always, can't, never, bad, like, let's, we could.

Tone of voice can be neutral or friendly. May be condescending, as one would speak to a child, but not openly critical.

\section{PD--PROBLEM DESCRIPTION}

Statement describing present problem

Statement of clarification, often describing past problems-explaining, elaborating.

Statements must be said in neutral tone of voice. If whining tone, double-code with COMPLAIN.

Statement can be vague or specific but at the same time must refer to a recognizable problem.

PP--POSITIVE PHYSICAI CONTACT

Any positive physical contact which is not NORMATIVE or required by the tasks of the situation.

Anytime any person touches the other in a friendly or affectionate manner.

\section{PS--PROPOSE SOLUTION}

Statement where person describes something $5 /$ he wishes the other person to do or not to do.

Advise, inform, teach statements--or any elaboration on advising, informing, or teaching.

Statements where person suggests, indicates, attempts to persuade the other person of something.

Doesn't require specific and immediate behavior. Said in a neutral or friendly tone of voice. 
QU--QUESTION

Any statement phrased as a question.

Often double-coded with PROBLEM DESCRIPTION, PROPOSE SOLUTION, and CRITICIZE.

\section{SP--SELF PUT DOWN}

Statements which are negative evaluations or criticisms of one's own behavior, appearance, or characteristics.

Defeatist self-evaluations.

Apologetic statements said in a self-abasing manner.

\section{SM--SMILE}

Coded for each separate occurrence of a smile.

often double-coded with HUMOR.

\section{SS--SUPPORTIVE STATEMENT}

Statement which indicates that the speaker personally favors something the other has said or done (does not include praising someone outside the immediate dyad).

Statements which recognize that the other has performed a desired behavior if made in a way to express approval.

Can refer to past, present, or future action.

Double-coded with PARENTING for statements that include both participants in the approval statement.

Code S/SS when the statement is applied to oneself.

TA--TALK

Simple yes/no responses where no opinion or agreement is indicated.

Head-shaking if meant to indicate these simple yes/no statements.

Responses that do not fit any other verbal category.

If coder does not understand what is being said, code TA. 
VO--VOLUNTEER HELP

Statement where help is offered to other person. Personal

effort is involved, an extension of self.

Often double-coded with PROPOSE SOLUTION, QUESTION.

S/SS--SELF SUPPORTIVE STATEMENT

Same definitions as SUPPORTIVE STATEMENT, except the statements are applied to oneself.

OBSERVER TRAINING

Because of the weight given to observer skill and judgment, candidates were screened for prerequisite skills (discussed later in this chapter) and received extensive training in discriminating and categorizing behavioral units in terms of the 28 well-defined categories.

$\underline{\text { Recruitment }}$

Eleven persons initially expressed interest in becoming trained as observers in response to solicitation in a number of portland state University (PSU) psychology classes and a memorandum circulated in the Institute on Aging, PSU. After an initial interview, six students chose to make the time commitment necessary for the training. Four of the recruited trainees worked in exchange for academic credit, two for workstudy salaries. They began preliminary training by acquainting themselves with the pre-test version of the coder's Field Manual (Code-PT). One person dropped out at this stage; the remaining five were screened for prerequisite skills. 
Screening of Observers

Patterson recommends the use of a number of tests for prospective observers and has found that average-or-above scores on the Employee Aptitude Survey tests 6 and 7, and the Minnesota Clerical Test subtests 1 and 2 are satisfactory indicators of an individual able to develop coding skills. All four tests are well-established, easily administered and scored instruments with documented validity and reliability. (They are published by "Psychological Services, Inc." and The Psychological Corporation," respectively.)

The Employee Aptitude Survey (EAS) test 6, subtitled "Numerical Reasoning," is designed to assess an individual's ability to do inductive reasoning, particularly as it is related to figures, and to analyze data in terms of overall trends and not just "merely adding and subtracting or performing simple computations" (EAS Manual, 1963, p. 13). EAS test 7, subtitled "Verbal Reasoning," measures the ability to use logic and judgment, to make good practical decisions, and to be able to work with minimal supervision.

Both of the Minnesota Clerical Tests (MCT) are more specifically clerical in nature. MCT test 1, "Number Checking" and MCT test 2, "Name Checking" are concerned with the ability to recognize similar and dissimilar pairs of items.

All five observers scored at an average (mean) level or above on all the tests and were retained. Scores were as follows:

$$
\begin{aligned}
& \text { (MCT) Test 1: Mean - 112, S.D. }-25 \\
& \text { Observer I - } 137 \\
& \text { " } 2-128 \\
& \text { " } 3-120 \\
& \text { " } 4-148 \\
& \text { " } 5-119
\end{aligned}
$$




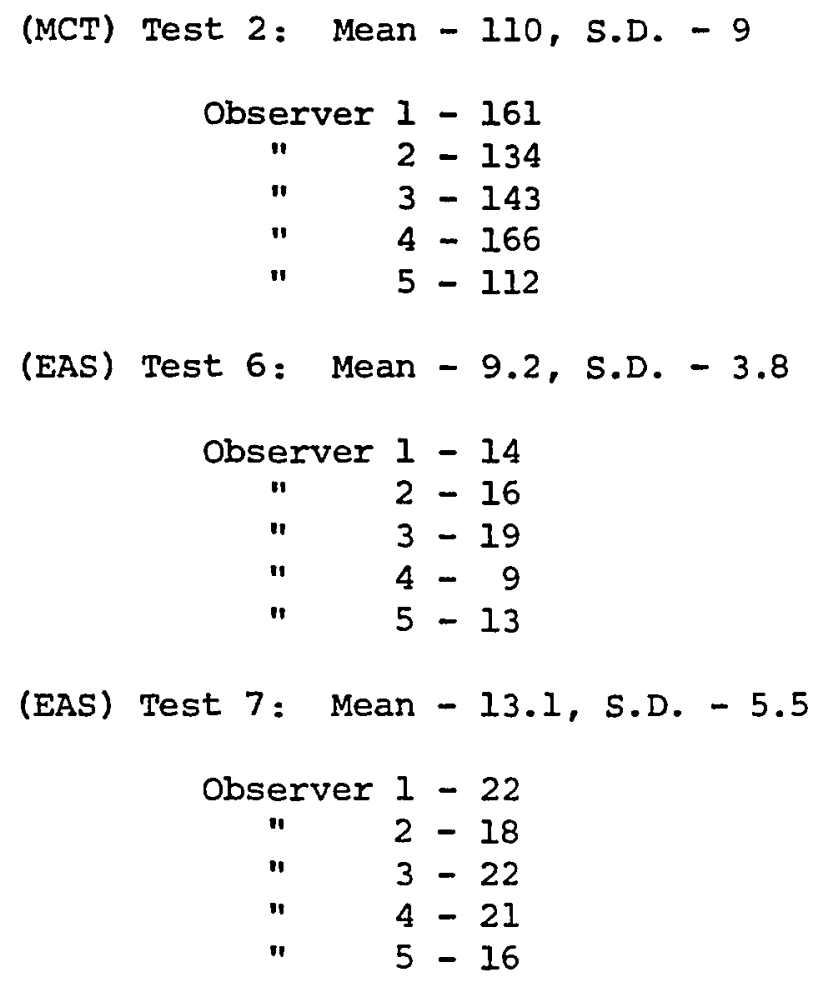

\section{Training of Observers}

Formal training was begun by acquainting each observer with the observation task by reading and discussing the pre-test (Code-PT) version of the coding system and by discussing the overall data collection task the observer was to undertake. Data collection was to include not only the primary task of recording a series of ten-minute observations, but also to record their subjective impressions of the service provider/client encounter and to collect assessments of the observed encounter from both service provider and client.

To make the coder's task as simple as possible a recording form was provided that, along with the time base and the recording methods, are derivatives of Patterson's MICS and FICS. The coding sheet is divided into ten 30-second lines for a total of five minutes of recorded behavior per coding sheet (see Figure 1). Each 30-second line is 
OBSERVER :

DATE :

CP COMPLAIN

CR CRITICIZE

CV CIVILITY

DR DISREGARD

HM EUMOR

IN INTERRUPT

NT VOT TRACKI

CO COMPLIAVICE

NC NONCOMPLIANCE
SITE:

LA LAUGH

NB NERV BEHAVIOR

NO NORMATIVE

PA PARENTING

CM CONMAND/REQUEST
PD PROB DESCRIPTION

PP POSIT PHYSICAL
PAGE:

PS PROPOSED SOLUTION

QU QUESTION

SP SELF PUT DOKN

SS SUPPORTIVE STATEMENT

TA TALK

VO VOLUNTEER HEIP

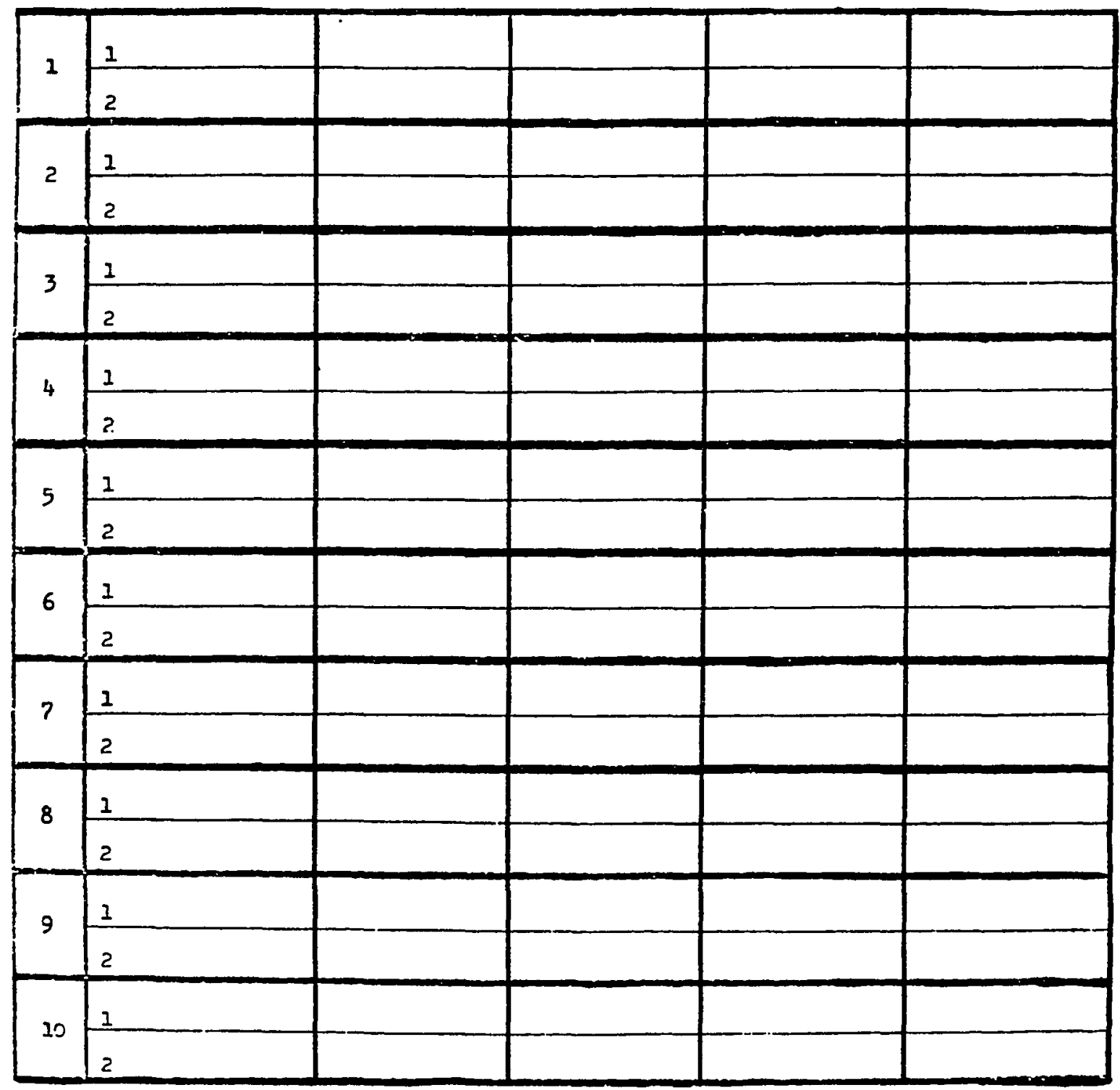

Figure 1: The SP/CDICS coding form.

sub-divided into five 6-second blocks and is also divided horizontally so the coder can record the service provider's behavior on the top half 
of the line and the client's behavior on the lower half of the line. This convention allows the coder to record behavior without the effort of writing in labels to identify which member of the dyad is being recorded.

The problem of timing was handled by using a device developed for the Family Interaction Coding System. Each observer was issued a clipboard that was to be used for holding the recording form during observations. Mounted on the top of the clipboard was a batteryoperated timer that produced an audible beep every 30 seconds. The sound was transmitted to the observer by means of an earplug so the beep would not intrude on the interaction. The 30-second "beeps" signalled the observer to advance to a new line on the coding sheet. Formal learning of the coding system was done on an individual basis with each observer learning at her/his own pace. Five staged video-taped illustrative segments were available which presented the correct coding after each vignette. The segments presented in graded difficulty, several categories in the system, so that observers-intraining were systematically exposed to non-verbal aspects of particular categories (such as tone of voice) as well as to the verbal definitions and examples of each behavioral unit included in their field manuals.

As an individual trainee learned the 28 behavior units or categories, supplementary video-taped materials, taken from documentary interviews, were made available for practice coding. These tapes were graduated in length from $1 / 2$ to 5 minutes. Coded scripts of these same practice tapes were available so that trainees could monitor their learning. When the observer trainees had completed viewing and coding 
all available staged and documentary pre-coded tapes, additional practice material was presented. These final video-tapes were comprised of 10-minute segments of actual in-field service provider/client interactions. Finally, field experience was scheduled so that trainee sbservers would have experience at in vivo coding. This field work was done in the neighboring state of washington in settings similar to those scheduled for the final data collection.

At the conclusion of the field experience, a number of minor changes were made in the coding system based on observer field experiences to form the final Service Provider/Client Dyadic Interaction Coding System (SP/CDICS). A second field experience was scheduled with service providers at the Portland VA Hospital (an organization not included in the $C R$ sample), to give the observers practice with the minor revisions. Inter-rater reliability of coding was assessed in the laboratory through the use of video-tape. Reliability calculated as the proportion of Agreement to Disagreement, * indicated that paired observers were able to code the same 10-minute interaction at an inter-rater reliability level of at least .70 (Range: .73 to .85 ) before they were released for the final field data collection. Learning of the SP/CDICS took place over the course of 14 weeks and represented 75-100 hours of training.

*Events had to be coded correctly by coding category, subject, and in the proper sequence to count as an Agreement. Actually, since only total scores from a coded encounter protocol are the data to be considered, agreement of observers in their total scores by subject would have been an adequate estimate of reliability. No attempt was made to examine the data by means of a sequence analysis. 
CHAPTER IV

AN INITIAI APPIICATION:

FINDINGS FROM THE FIEID

In this chapter, the findings from an initial application of the Service Provider/Client Dyadic Interaction Coding System (SP/CDICS) will be discussed. The behavioral findings will be reported, i.e., descriptive data regarding the frequencies and patternings of behaviors actually observed in the field. Also, the relationships of behavior with other kinds of data will be examined and interpreted as indicators of the validity of the SP/CDICS. These later findings will be reported and discussed in Chapter $v$. To place all these findings in context, the author will first describe the composition of the sample and the procedures used in collecting the data.

The sample of this study (referred to below as the observation Sample) is a subset of a larger sample* which was used to collect data on the attitudes held by service providers toward their elderly clients. This larger sample, the Client Relations (CR) attitudinal sample, was comprised of randomly selected service providers** drawn from a group of forty-two agencies chosen to fit within six CR-defined "types" of

*A detailed account of the larger sample of service providers can be found in Chapter 6 of the Client Relations Project Final Report.

**The term "service provider" refers to individuals in the selected agencies who directly provide services to older clients in either a face-to-face or telephone encounter. For the Observation sample, only face-to-face encounters were considered. 
health and social service agencies in the Portland/Multnomah County area of Oregon (see Table II). The observation sample was drawn from two of these health and social service types.

TABLE II

SOCIAL SERVICE TYPES INCLUDED IN THE GENERAL ATTITUDE SURVEY (GAS)

\begin{tabular}{|l|l|c|}
\hline $\begin{array}{l}\text { Health and } \\
\text { Social Service } \\
\text { Types }\end{array}$ & Examples & $\begin{array}{c}\text { Number of } \\
\text { Agencies } \\
\text { Included }\end{array}$ \\
\hline Health/Mental Health & $\begin{array}{l}\text { hospitals, nursing homes, in-home } \\
\text { nursing, mental health clinics }\end{array}$ & 15 \\
\hline Income & $\begin{array}{l}\text { Social Security, senior employ- } \\
\text { ment agencies }\end{array}$ & 5 \\
\hline Nutrition & $\begin{array}{l}\text { congregate meal programs, home- } \\
\text { delivered meals }\end{array}$ & 1 \\
\hline Transportation & $\begin{array}{l}\text { mass transit, escort programs, } \\
\text { special needs transportation }\end{array}$ & 5 \\
\hline Housing & $\begin{array}{l}\text { public housing, retirement housing } \\
\text { Interaction }\end{array}$ & $\begin{array}{l}\text { senior centers, * information and } \\
\text { oferral services, senior volunteer } \\
\text { grams, friendiy visitor programs, } \\
\text { telephone reassurance } \\
\text { Toral }\end{array}$ \\
\hline
\end{tabular}
Sample.

*Note. These types of agencies were included in the observation THE OBSERVATION SAMPLE

The purpose of the Observation sample was to provide an understanding of the encounter between service provider and elderly client through a detailed description of the dyadic interaction between the two. This sample also allows for a later examination of possible 
relationships between service provider attitudes and their behavior; between client behavior and service provider attitude; and between service provider behavior and client satisfaction.

\section{Observation Sample Agencies}

In all, eleven different social service agencies were involved in the observations. Four of these were In-home Nursing agencies and seven were Interaction agencies. As has been mentioned earlier, these agencies were chosen to be the subject of the observation study since in each case the site of service delivery could be limited to the client's home. From these eleven agencies, 51 service-providing personnel and 147 older clients participated in the data collection (see Table III).

TABLE III

COMPOSITION OF THE OBSERVATION SAMPLE

\begin{tabular}{|l|l|l|c|}
\hline Agency Type & $\begin{array}{l}\text { Number } \\
\text { of } \\
\text { Agencies }\end{array}$ & $\begin{array}{l}\text { Number of } \\
\text { Service } \\
\text { Providers }\end{array}$ & $\begin{array}{l}\text { Number } \\
\text { of } \\
\text { Clients }\end{array}$ \\
\hline In-home Nursing & $4(3) *$ & 32 & 93 \\
Interaction & $7(11)$ & 19 & 54 \\
\hline TOTALS & $11(42)$ & 51 & 147 \\
\hline
\end{tabular}

*Note. Numbers in parenthesis indicate number of agencies of the same type in the GAS sample.

Social service agencies making up the observation Sample, with one exception, were selected from the agencies included in the original General Attitude Survey (GAS) Sample. For a number of reasons (e.g., staff turnover, change in job assignment, not having at least two older clients) there was an insufficient number of service providers available 
for the Observation Sample. Consequently, one agency (in the In-home Nursing category) was added to the original sample of forty-two agencies* in order to provide needed numbers of service providers to observe. In-home Nursing and Interaction services were comprised of a variety of tasks that took from 10-60 minutes and which were carried out in the client's home. During In-home Nursing visits, the taking of blood pressure or other health measurements was likely to be observed as well as interviewing regarding the health status and personal needs of the client. Friendly visiting and assistance with personal hygiene comprised portions of some of the health-related visits also. Interaction services were usually comprised of friendly visiting and interviewing with regard to personal needs such as transportation, shopping, housecleaning, and health concerns. Sometimes services (such as shopping or arranging transportation) were subsequently performed by the outreach worker.

Agency directors were each contacted by telephone to obtain permission to observe service provider/client encounters occurring under the auspices of their respective agencies (see Table IV for a complete

*The added agency, a health clinic, brought to a total of fortythree the agencies on which attitudinal data were available. This agency was classified as an In-home Nursing agency because the service providers to be observed were engaged in conducting medical screening of older clients in the clients' own homes. The general attitudinal data were collected from these personnel before the observations were undertaken. The three original In-home Nursing agencies from the GAS sample all participated in the observation sample.

Seven of the original eleven Interaction agencies also participated. Non participation on the part of the remaining four Interaction agencies resulted from: (a) the refusal of one agency director to allow service providers from that agency to be observed; (b) attrition of personnel over the six month period taken for collection of the GAS data; and (c) a sampling error that included one agency that actually had no personnel with face-to-face encounters with older clients. 
list of procedures and a time table for data collection). This was a necessary first step since the original agreement to participate in the CR Project had been solicited for the collection of organizational and attitudinal data alone and did not include a promise to allow observations. In some cases, the approached In-home Nursing and Interaction

TABLE IV

DATA COLLECTION TIME TABLE

\begin{tabular}{|c|c|}
\hline Time & $\begin{array}{l}\text { Contacts with } \\
\text { Agency Director }\end{array}$ \\
\hline $\begin{array}{l}\text { Weeks 1-7 } \\
\text { (June 12-July 28, 1978) } \\
\text { AS Appropriate }\end{array}$ & $\begin{array}{l}\text { Telephone call and/or visit (using a "script") } \\
\text { to request agency's participation. The "script" } \\
\text { for the telephone calls and visits was formatted } \\
\text { as a letter, which was then also mailed to the } \\
\text { directors contacted by telephone and hand delivered } \\
\text { to the directors contacted by staff visit. } \\
\text { Thank-you letter for agency's participation upon } \\
\text { completion of scheduled observations }\end{array}$ \\
\hline & $\begin{array}{l}\text { Contacts with } \\
\text { Encounter participants }\end{array}$ \\
\hline $\begin{array}{l}\text { Weeks 1-8 } \\
\text { (June 12-July 31, 1978)d }\end{array}$ & $\begin{array}{l}\text { Telephone call (using a "script") to } \\
\text { request service provider's participation } \\
\text { and to schedule observationse }\end{array}$ \\
\hline $\begin{array}{l}\text { Weeks 1-8 } \\
\text { (June 12-July 31, 1978) }\end{array}$ & $\begin{array}{l}\text { To newly sampled subjects, cover letter and } \\
\text { General attitude Questionnaire }\end{array}$ \\
\hline As Necessary & $\begin{array}{l}\text { Telephone calls to service providers to } \\
\text { schedule and confirm observation dates }\end{array}$ \\
\hline $\begin{array}{l}\text { Weeks } 2-10 \\
\text { (June 20-August } 17,1978 \text { ) }\end{array}$ & $\begin{array}{l}\text { Observational visits: } \\
\text { (a) explanation of procedures to service } \\
\text { providers and older clients } \\
\text { (b) recording of service provider and older } \\
\text { client's encounter behaviors for lo } \\
\text { minutes, using Service Provider/Client } \\
\text { Dyadic Interaction Coding System (SP/CDICs) } \\
\text { (c) Encounter Attitude Questionnaire to be } \\
\text { answered by service provider } \\
\text { (d) interview of older client, using Client } \\
\text { Evaluation Interview Schedule } \\
\text { (e) Consent Form to be signed by older client } \\
\text { and letter of appreciation hand-delivered to } \\
\text { older client } \\
\text { (f) observer recorded impressions of service } \\
\text { provider and encounter (using Observer } \\
\text { Impressions and observer Evaluation forms) } \\
\text { (g) Interpersonal Checklist to be answered by } \\
\text { service provider re gelf }\end{array}$ \\
\hline hs Appropriate & $\begin{array}{l}\text { Thank-you letter to service provider upon } \\
\text { completion of scheduled observations }\end{array}$ \\
\hline
\end{tabular}


agency directors requested more extensive information regarding the procedures involved in the observations. Senior CR staff made personal visits to explain our procedures in these instances. Only one agency director refused to allow his agency to participate. All other agency directors agreed that CR personnel could approach service providers to solicit their participation in the observation sample. The final

decisions, in every case, were left to the service providers. When data collection was completed, a thank-you letter was sent to each of the eleven participating In-home Nursing and Interaction agency directors.

Observation Sample Service Providers

Fifty-one service providers* participated in the observed encounters. Of these, thirty-two came from In-home Nursing agencies and nineteen were outreach workers from Interaction agencies. The typical Observation Sample service providers:

(1) were 39 years of age,

(2) predominantly female (44 women; $7 \mathrm{men}$ ),

(3) had an education level that included some college,

*A t-test comparison of means was completed to check for differences between the mean scores, on eleven variables, of the non-observed and observed In-home Nursing and Interaction sample members. The observation sample differs significantly ( $\leq \leq .05)$ from the non-observed personnel of In-home Nursing and Interaction agencies in the GAS sample on five of eleven characteristics. In comparison with their non-observed counterparts, the observed In-home Nursing and Interaction service providers: were younger, more educated, worked more hours per week, were not volunteers, and had a larger percentage of elderly individuals in their clientele. These differences in characteristics appear to be attributable to the fact that no volunteers were included in the observation sample. The volunteers were excluded from the non-observed sample, no significant differences in characteristics were found between the nonobserved and observed In-home Nursing and Interaction service providers. Generalizations from the findings resulting from the observations, then, should be limited to paid personnel and not extended to volunteers. 
(4) worked 37 hours per week,

(5) were paid employees rather than volunteers,

(6) had worked at the sampled agency for 3 years,

(7) spent 61 to 80 \% of their work day with clients,

(8) had a clientele that was 61 to $80 \%$ elderly,

(9) served 8 older clients per day,*

(10) had an older clientele that was 21 to $40 \%$ male, and

(11) were in contact with the same older client on a weekly basis.

Using a prepared "script" to standardize the approach to service providers as much as possible, a telephone call was made to service providers in the selected agencies who had completed the General

Attitude Survey. Permission to observe the service providers in three service encounters with older clients was requested. Forty-five service providers were subsequently observed with three clients; six were observed with two clients each.**

\section{Observation Sample Older Clients}

The older clients who were observed were selected by the service providers themselves. In all, service encounters between service providers and 147 different older clients were observed. Of those 147 service encounters, 93 were for health-related concerns (In-home Nursing) and 54 were with outreach workers (Interaction). Fifty-two of the observed clients were male; 95 were female--a proportion which

\footnotetext{
*The median number of older clients served per day was 6 .
}

**Six service providers were observed with two rather than three older clients because of scheduling difficulties or non-availability of older clients. In only one case, did a service provider refuse to participate. 
reflects the actual preponderance of women in the elderly population. The dyads in 99 cases were composed of service providers and older clients who were of the same sex (usually female service provider with female client): in 48 instances the dyads were of opposite sex pairs (usually female service provider and male client). The ages of the older clients ranged from 48 to 94 years; the mean age was 75 years. Age differences between the observed service providers and their older clients ranged from 0 to 68 years.

Procedures and Instruments Used to Collect the Observation Data

Each service provider to be observed had completed the General Attitude Survey for the CR Project and had been approached, as mentioned above, after their respective agency directors had given permission. The procedures used to carry out each observation were as follows:

(1) The observer informed the service provider and older client of the specific procedures of the observational visit. This included an explanation that the observer would not be participating in conversation during the 10-minute observation period; and the need to have private interviews with both the client and the service provider following the service encounter. Before the observer began recording, a verbal consent was obtained from the client.

(2) For the initial 10 minutes of the service encounter, the behaviors of both the service provider and older client were recorded using the Service Provider/Client Dyadic Interaction Coding System.

(3) Privately, the service provider was requested to report his/her beliefs and feelings about the older client. A checklist of items was developed, paralleling items from the General Attitude 
Survey, that described elderly clients. The resulting twenty-two items allowed for a measure of the service provider's specific attitudes toward the particular elderly clients they were observed with. Each client was, for example, rated as being more or less "fragile," "dependable," or "overly demanding." The specific Attitude Questionnaire can be examined in Appendix B.

(4) The service provider was also asked to complete an Interpersonal Checklist (ICI) on themselves. This personality instrument is a self-report measure of the individual's self-concept and the interpersonal impact they are likely to have on others. The ICI is a wellestablished test with standard scores, enabling us to make some estimate of the homogeneity of the sampled service providers. A copy of the ICL is included as Appendix C.

(5) The older client was interviewed privately, after the service encounter, regarding his/her evaluation of the interaction using the Client Evaluation Interview Schedule (see Appendix D). This structured interview was used to obtain the client's view regarding the service provider, the immediately preceeding encounter, and what was important for them in such encounters.

(6) At the completion of the visit, the older client was again asked for permission to use the collected data for research purposes and this time was asked to sign a written consent form.

(7) A letter of appreciation was presented to the older client along with the observer's spoken remarks. The formal acknowledgement of their helpfulness to the research project was given at this time since the guarantee of anonymity prevented a mailed letter from the Institute on Aging. 
(8) Following the visit, the observer recorded his/her subjective impression of the service provider on the Observer Impression Sheet (see Appendix E) and used the Observer Evaluation Form to give their impression of the encounter--specifically, whether the service provider treated the client with respect and allowed the client to participate (see Appendix F).

(9) After all (two or three) observations were completed with an individual service providex, a written letter of appreciation was mailed to him/her. Invitations to a workshop that presented preliminary findings were also extended after all data were collected and some first statistical information was available.

\section{SERVICE ENCOUNTER BEHAVIOR FREQUENCIES}

As has been described earlier, in Chapter III, the interaction between service provider and client was recorded as it could be coded in terms of the 28 behavioral categories developed for this research. Mean frequencies for each of the behavioral categories tallied during the observation encounter were calculated for the 147 different dyads comprising the observation Sample. The mean frequencies are given in Table $V$ which indicates a wide variability in frequency of occurrence for the 28 different behaviors.

TALK, ATTEND, PROBLEM DESCRIPTION, NORMATIVE, and QUESTION are the most frequent behaviors, being common enough to appear in most of the records.* A first impression gained from an examination of these means

*TALK is the only behavior that occurred in every observed encounter without exception. ATTEND was a close second, occurring in 146 of the 147 observations. 
is that five apparently bland and innocuous behaviors fill up the bulk of the observation protocols. These behaviors seem to describe what is nearly universal in the observed kinds of service provision encounters: the participants talk to each other, question and listen to each other, spend time describing the problems at hand, and take care of routine, task-related matters.

TABLE V

MEAN BEHAVIOR FREQUENCIES

\begin{tabular}{|c|c|c|c|}
\hline BEHAVIOR & $\begin{array}{c}\text { MEAN } \\
\text { FREQUENCY }\end{array}$ & BEHAVIOR & $\begin{array}{c}\text { MEAN } \\
\text { FREQUENCY }\end{array}$ \\
\hline I AGREE & 4.068 & 15 NERV BEHAV & 1.469 \\
\hline 2 DISAGREE & .966 & 16 NORMATIVE & 22.054 \\
\hline 3 ATTEND & 48.871 & 17 NO RESPONSE & .544 \\
\hline 4 NOT TRACKING & 2.381 & 18 PARENTING & 1.061 \\
\hline 5 COMPLY & 1.109 & 19 PROB DESCRIP & 26.354 \\
\hline 6 NON COMPLY & .034 & 20 POS PHYSICAI &, 823 \\
\hline 7 COMMAND & 1.721 & 21 PROP SOLUTION & 4.891 \\
\hline 8 COMPLAIN & 2.864 & 22 QUESTION & 20.408 \\
\hline 9 CRITICIZE & .612 & 23 SMILE & 3.245 \\
\hline 10 CIVIIITY & 1.483 & 24 SELF PUT DOWN & .163 \\
\hline 11 DISREGARD & .150 & 25 SUPPORTIVE STAT & 4.571 \\
\hline 12 HUMOR & 3.966 & 26 TALK & 52.844 \\
\hline 13 INTERRUPT & 1.639 & 27 VOLUNTEER HELP & .837 \\
\hline 14 LAUGH & 7.293 & 28 SELF SUPP STAT & .082 \\
\hline
\end{tabular}

A number of behaviors were much less frequently seen in the space of the 10-minute sample of service provider/client interaction. NON COMPLY, DISREGARD, SELF PUT DOWN, and SELF SUPPORTIVE STATEMENT were the four least frequently seen behaviors. Far from being bland, these behaviors, on the face of it, appear to be rather dramatic ones that may signal an interaction is not a constructive or productive one. The remaining 19 behavioral categories ranged along a continuum between these two extremes, as is illustrated in Figure 2. 
The finding that the least frequent behaviors may also be the most intense, or most information intensive, is consistent with other research. For example, during observations Patterson (1974) conducted in homes of aggressive children, he found that "Hostile" responses (Whine, Disapproval, Yell) and "Immaturity" responses (Destructiveness, Tease, Cry) had summed base rates of only .26 and .06 per minute, respectively. These rates were for children referred for treatment "because of extremely high rates of noxious behaviors."

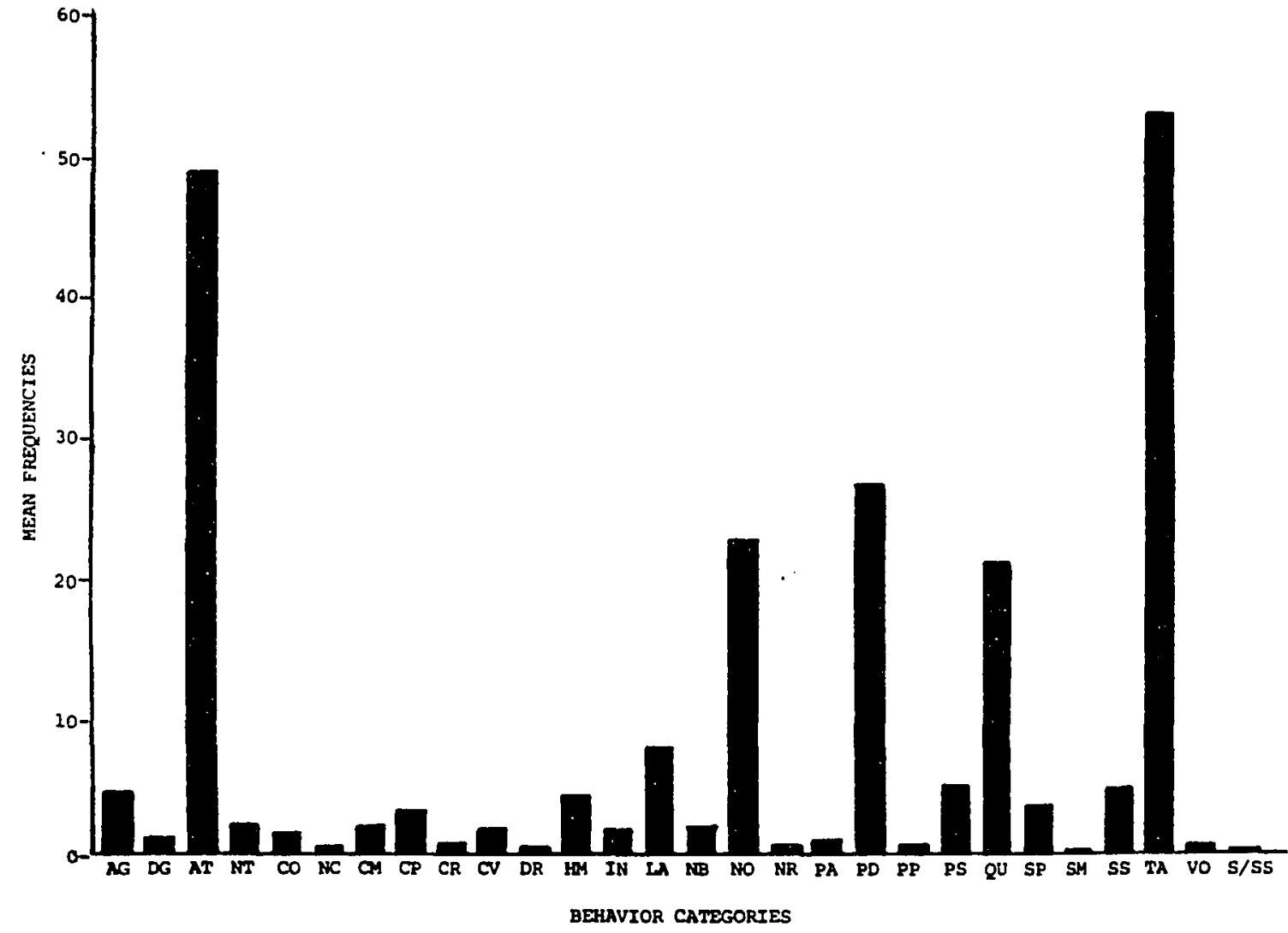

Figure 2. Mean frequencies of occurrence of the 28 behavior categories for service providers and clients combined. 
Later in this paper (Chapter V), analyses will be discussed that were undertaken to examine how an individual's personal characteristics and attitudes may influence the frequency with which a given behavior might be expressed. Prior to those analyses, role will be examined as a possible correlate of behavior since we intend to look at service provider and client behavior separately in the later analyses.

\section{Behaviors Affected by Role}

It was expected that role (whether an individual was the service provider or the client member of the dyad) would be a powerful correlate of behavior. Since the early days of social psychology, roles have been assumed to be of importance as partial determinants of individual behavior. Most definitions of role, in fact, are specifically related to behavior:

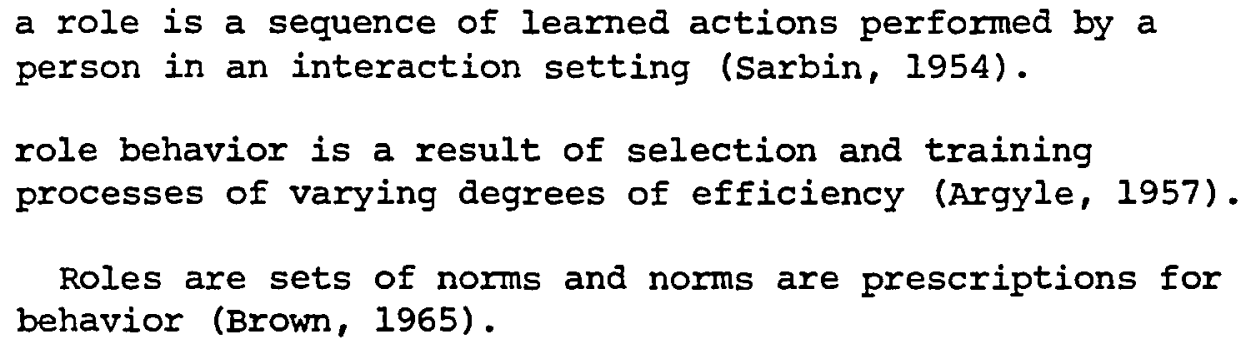

[R]ole: the behavior expected of a person holding a certain position in a given society (Wrench, 1967).

Demonstrations of the assumed important role/behavior link have been apparent since the 1940's. This connection has been shown to be particularly evident in the workplace. Whyte (1948), for example, in his study of Chicago restaurants showed that waitresses cried more frequently than either customers or cooks. Several post world War II studies of servicemen pointed out that role (in this case, service rank) predicted how individuals spent their time, the degree of job 
satisfaction experienced, and frequency of absenteeism (Harrell, 1949; Behrend, 1951; Stogdill, 1953).

Some roles are complementary. Role "A" functions are prescribed in terms of "B." The role of father, for example, cannot be described without reference to the role of child, and vice versa. Goffman's (1970) study of mental hospitals looked at both mental health staff roles and patient roles. He was able to describe in great detail the behaviors characteristically found with each of these roles. Sudnow (1967) further demonstrated in his study of general hospitals that there are subgroups of patients. Iower status or less desirable patients (i.e., those that were poor, old, or terminal) are treated differently. The reciprocity of roles is explained well by Argyle (1957) who states that, "Each person takes a role in response to his perception of the other, to his anticipated role of the other, and the desired role of the other" (p. 116).

To examine the supposed impact of reciprocal roles in the observed service encounter dyadic interaction, the mean frequencies of occurrence for each behavior were calculated separately for service provider and client. The t-tests of differences between the mean frequencies of behaviors emitted by service providers versus clients demonstrated this expected "pull" of role (see Table VI). A total of 22 of the 28 coded behaviors (or 718) were significantly associated with role. The means for the two groups are displayed by histogram to illustrate these differences between the average occurrence of each of the behavioral categories for the providers and recipients of the observed services (see Figure 3 ). This method of presenting the data shows in a more vivid way, that the probabilities of observing a wide variety of 

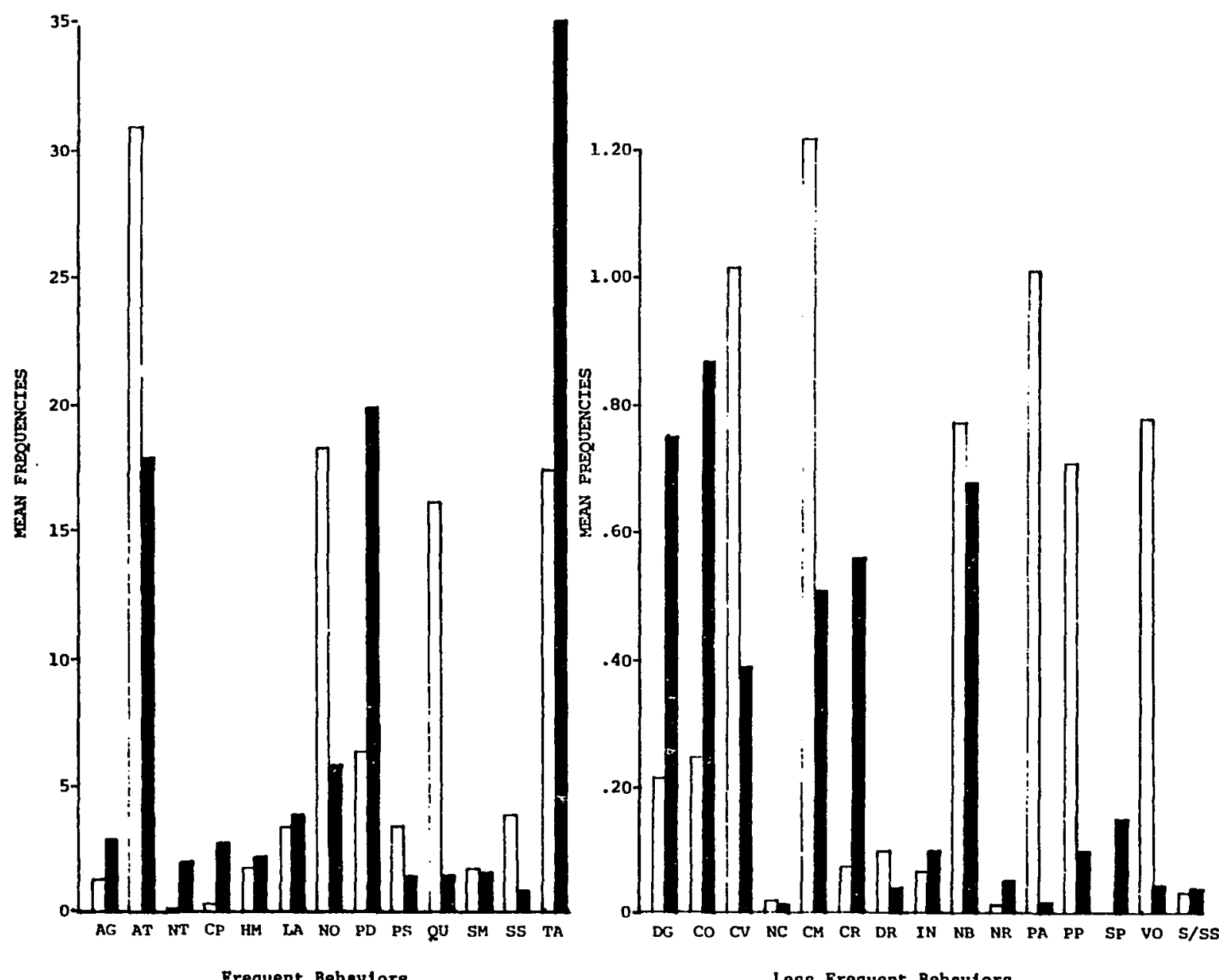

Frequent Behaviors

Less Frequent Behaviors

Figure 3. Service provider and client mean behavior frequencies. Legend: Service Provider $\square$; Client

Note. Because of the wide variation in the magnitude of mean frequencies, the data could not effectively be displayed on the same scale; therefore, the more frequent behaviors graphed above (left) are on a different scale than the less frequent behaviors ( $x$ ight). 
behaviors are significantly influenced by the individual's role in the dyad. This is a finding which may be aramatic in terms of possible

TABLE VI

A COMPARISON OF MEAN BEHAVIORS BY ROLE

(SERVICE PROVIDER VS. CLIENT)

\begin{tabular}{|c|c|c|}
\hline BEHAVIOR & $\begin{array}{l}\text { SERVICE } \\
\text { PROVIDER }\end{array}$ & CLIENT \\
\hline 1 AGREE & 1.3741 & $2.6939 * \star \star t$ \\
\hline 2 DISAGREE & .2109 & $.7551 * * *$ \\
\hline 3 ATTEND & $31.0000 * \star \star *$ & 17.8707 \\
\hline 4 NOT TRACKING & .2449 & $2.1361 * *$ \\
\hline 5 COMPLY & .2381 & $.8707 * \star \star$ \\
\hline 6 NON COMPLY & .0272 & .0068 \\
\hline 7 COMMAND & $1.2245 * \star \star \star$ & .4966 \\
\hline 8 COMPLAIN & .1156 & $2.7483 * \star \star$ \\
\hline 9 CRITICIZE & .0748 & $.5374 * \star$ \\
\hline 10 CIVILITY & $1.0952 * \star \star \star$ & .3878 \\
\hline 11 DISREGARD & .1020 & .0476 \\
\hline 12 HUMOR & 1.7143 & $2.2517 *$ \\
\hline 13 INTERRUPT & .6599 & $.9796 *$ \\
\hline 14 IAUGH & 3.4966 & 3.7959 \\
\hline 15 NERV BEHAV & .7891 & .6803 \\
\hline 16 NORMATIVE & $18.6871 * \star *$ & 3.3673 \\
\hline 17 NO RESPONSE & .1156 & $.4286 \star$ \\
\hline 18 PARENTING & $1.0476 * \star *$ & .0136 \\
\hline 19 PROB DESCRIP & 6.2653 & $20.0884 * \star \star \star$ \\
\hline 20 POS PHYSICAL & $.7143^{\star}$ & .1088 \\
\hline 21 PROP SOLUTION & $3.4082 * * *$ & 1.4830 \\
\hline 22 QUESTION & $16.3605 * \star *$ & 4.0476 \\
\hline 23 SMILE & 1.6599 & 1.5850 \\
\hline 24 SELF PUT DOWN & .0000 & $.1630 *+$ \\
\hline 25 SUPPORTIVE STAT & $3.8912 * * *$ & .6803 \\
\hline 26 TALK & 17.5238 & $35.3197 * * *$ \\
\hline 27 VOLUNTEER HELP & $.7891 * \star *$ & .0476 \\
\hline 28 SELF-SUPP STAT & .0340 & .0476 \\
\hline
\end{tabular}

$\star * * P<.001 \quad * * P<.010 \quad * P<.050$

The significance for this pair of means was calculated by arbitrarily assigning one occurrence of the behavior to the service provider group.

Note. The asterisks are placed by the larger of the two means which are significantly different. 
impact on the elderly client. It would appear that simply being placed in the position of being a receiver of services has a profound effect on what behaviors are likely to be expressed while interacting with a professional.

The role of service provider was characterized by higher scores in ten behaviors. The elderly clients' role was evidenced by more frequent appearance of twelve behaviors.

Service Provider Behavior Frequencies. The service provider was more likely to be observed QUESTIONing than a client--about $16 \%$ of the time versus $4 \%$ of the time, or 4 times as often. Service providers can be expected to ATTEND nearly twice as often as clients, and engage in more NORMATIVE, PARENTING, and polite (CV) behavior than do clients. They also INTERRUPT, make POSITIVE PHYSICAL contact, issue COMMANDS, PROPOSE SOLUTIONS, make SUPPORTIVE STATEMENTS and VOLLUNTEER HELP significantly more often than clients. Except for listening to their clients (AT) and completing routine nursing or interview tasks (NO), service providers as a group seem to be characterized by directive, initiating, proactive behaviors.

Client Behavior Frequencies. It is evident from the graph (Figure 3) that a client, on the other hand, is more likely than a service provider to be observed TALKing. Clients TALK at a mean frequency of 35.32 times per encounter compared to a similar figure of 17.52 for service providers. Alternate ways to state this would be to say that TALKing occurs in at least 35 of the 100 time units comprising the encounter for clients, versus $171 / 2$ times for service providers. Clients also AGREE nearly twice as often as service providers, and they COMPLY more than 3 times as often. They spend significantly 
more time than service providers in PROBLEM DESCRIPTION, HUMOR, DISAGREEment, CRITICIZing, NO RESPONSE, NOT TRACKING, COMPLAINing, and SELF-PUT DOWN. The client seems to have the more passive, or at least more reactive, of the two roles.

Role-Unaffected Behavior Frequencies. A number of behaviors appear not to be influenced by role (at least not in regard to frequency of occurrence). NON COMPLY, DISREGARD, NERVOUS BEHAVIOR, SMILE, LAUGH, and SELF-SUPPORTIVE STATEMENT are behaviors that have nearly equal probabilities of occurring as part of the pattern of behavior for both participants in the service encounter dyad. It should be noted that a consideration of the range of behavior gives much the same impression of the importance of role (see Figure 4).

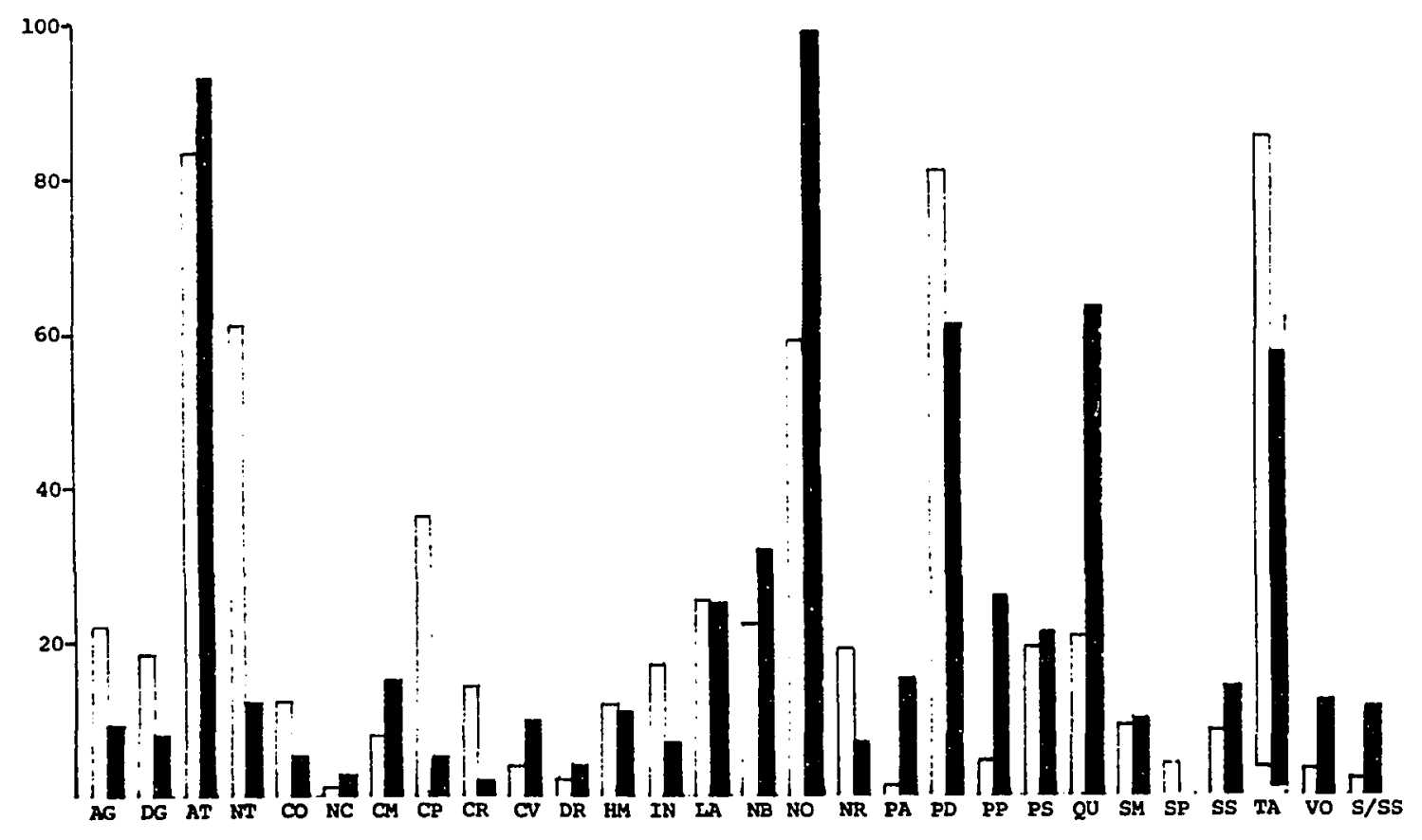

Figure 4. Range of behaviors occurring in any one encounter Service Provider: $\square$ Client: 
Summary. Earlier we stated that TALK, ATTEND, PROBLEM DESCRIPTION, NORMATIVE and QUESTION were behaviors that predominated in the observed dyadic encounters. The examination of behavior by role permits a slightly more refined description. Considering only the more frequent behaviors and those which are significantly related to role, one can say that the typical service provider/client dyadic interaction was one characterized by a good deal of ATTENDing, QUESTIONing, and accomplishment of NORMATIVE tasks by service providers; while their clients TALKed, DESCRIBEd PROBLEMS, and COMPLAINed. On the average, service providers were likely to make more ComMANDing statements while clients were the ones who more often COMPLied. The service providers as a group emerged, not surprisingly, as the dominant figures in most of the observed dyads. For example, POSITIVE PHYSICAI contact, a well-known indicator of power in relationships (Henley, 1977), was most often a service provider behavior, occurring seven times more frequently for service providers than for clients. The professionals also PROPOSED SOLUTIONS, VOLUNTEEREd HELP, made SUPPORTIVE STATEMENTS and PARENTEd more often. The client was more often found in the position of being a reactor or respondent in the average interaction. They AGREEd or DISAGREEd (with the service provider's proposals or interpretations). The more frequently INTERRUPTed, didn't RESPOND (NR), and did not pay close attention (NT). Other responses more typical of clients included CRITICIZing, self-deprecation (S/PD), and the use of HUMOR.

The examination of behavior frequencies by role assists us in the endeavor of understanding the nature of the service encounter, but it is unclear at this point as to whether or not behaviors may also be 
sensitive to the context of type of service delivered; In-home Nursing or Interaction task-related activities.

\section{Behaviors Affected by Service Type}

Behavior is widely acknowledged to be sensitive to setting (Hall, 1966; Sommer, 1969; Sackett, 1978), as has been discussed earlier in this paper. The effect of environment or context is so potent, in fact, that a general criticism can be made of research accomplished in laboratory settings, that the laboratory elicits behavior so artificial (or unique to that particular setting) that one cannot use the findings to predict behavior in different settings (Bronfenbrenner, 1977). This problem is so critical that the effect of context on behavior in the Observation Sample must be examined. In this sample, the context was limited by design: (1) only two of the six social service areas investigated in the larger CR study were sampled; and (2) only one general physical environment was considered (the client's home) from a disparate set that included offices, hospital rooms, dining halls, and buses. It was assumed, for the purposes of this study, that the differing furniture arrangements, room sizes, and configurations within the home environments would be random and not have systematic effects on the observed behaviors. In each case, the older client would be in her own territory, i.e., have the psychological support of being in a place that was not only familiar but also is under the control of the client. Also, the service provider in each set would not be in her own territory but would be, in a sense, a guest. However, since two fairly distinct task-orientations are included in the sample, service type is still a potential systematic effect. 
Through the use of a series of th-tests, type of service (In-home Nursing vs. Interaction) or task-orientation, emerged clearly as a substantial correlate of behavior both for service provider and client.* Sixteen of twenty-seven (or 57\%) of the service provider behaviors differ significantly in frequency of occurrence depending on the type of service being provided;** as are nineteen of the twenty-eight (or 68\%) client behaviors.

In-home settings. In-home Nursing encounters are characterized by much more service provider NORMATIVE behavior than are Interaction encounters (about $25 \%$ as opposed to $8 \%$ of the interaction time). COMMANDing is also more frequently observed in In-home Nursing situations, occurring about three times as often. In-home Nursing staff exhibit more CIVIIITY, PROBLEM DESCRIPTION, and POSITIVE PHYSICAL contact than do the outreach workers of Interaction agencies (see Table VII for a comparison of service provider behavior mean frequencies). Clients, as well as service providers, exhibited different behaviors as a function of the type of service being provided. During In-home Nursing encounters, clients were observed ATTENDing about twice as often as clients in Interaction encounters. Six other client behaviors: DISAGREE, DISREGARD, NOT TRACKING, COMPLY, POSITIVE PHYSICAL, and SELF/SUPPORTIVE STATEMENT had higher mean frequencies for In-home

*It appears not to be a concomitant of different attitudes since: (a) the effect is apparent for clients as well as service providers, and (b) the attitudes for these two service types are relatively homogenous (discussed further in Chapter V).

**Any differences in Tables VII and VIII significant at a level less than .01 are ignored for purposes of this discussion, recognizing that in any series of t-tests a few relationships will be discovered to be significant by chance alone. 
TABLE VII

A COMPARISON OF SERVICE PROVIDER

BEHAVIOR MEANS BY SERVICE TYPE

\begin{tabular}{|c|c|c|c|c|c|c|c|c|c|}
\hline \multicolumn{3}{|c|}{ BEHAVIOR } & \multirow{2}{*}{$\frac{\text { IN-HOME }}{1.2258}$} & \multirow{2}{*}{$\frac{\text { INTERACTION }}{1.6296}$} & \multicolumn{3}{|c|}{ BEHAVIOR } & \multirow{2}{*}{$\frac{I N-H O M E}{.5484}$} & \multirow{2}{*}{$\frac{\text { INTERACTION }}{1.2037 \star \star \star}$} \\
\hline SP & 1 & AG & & & SP & 15 & NB & & \\
\hline$S P$ & 2 & DG & .1398 & $.3333 * \star \star \star$ & SP & 16 & NO & $24.9247 \star \star \star$ & 7.9444 \\
\hline SP & 3 & AT & 27.8172 & 36.4815 & SP & 17 & NR & .0538 & $.2222 \star \star \star$ \\
\hline$S P$ & 4 & NT & .2043 & $.3148 * \star \star$ & SP & 18 & PA & .8065 & $1.4630 \star \star$ \\
\hline$S P$ & 5 & $\mathrm{CO}$ & .2581 & .2037 & $\mathrm{SP}$ & 19 & PD & 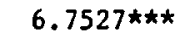 & 5.4259 \\
\hline$S P$ & 6 & NC & .0108 & $.0556 * \star \star *$ & $\mathbf{S P}$ & 20 & PP & $.7609 * *$ & .6364 \\
\hline$S P$ & 7 & CM & $1.6452 * \star \star *$ & .5000 & $\mathrm{SP}$ & 21 & PS & 3.4731 & 3.2963 \\
\hline SP & 8 & $\mathrm{CP}$ & .0538 & 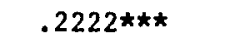 & SP & 22 & QU & $18.1183 *$ & 13.3333 \\
\hline SP & 9 & $\mathrm{CR}$ & .1323 & $.1481 * \star \star$ & SP & 23 & SM & 1.5484 & 1.8519 \\
\hline SP & 10 & $\mathrm{CV}$ & 1.1398 & 1.0185 & SP & 24 & SP & .0000 & .0000 \\
\hline SP & 11 & $\mathrm{DR}$ & .0968 & .1111 & SP & 25 & sS & 3.3011 & $4.9074 \star \star$ \\
\hline SP & 12 & HM & 1.7849 & 1.5926 & SP & 26 & TA & 16.2688 & 19.6852 \\
\hline SP & 13 & IN & .3011 & 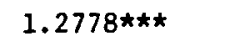 & SP & 27 & vo & .6237 & 1.0741 \\
\hline SP & 14 & LA & 2.7527 & $4.7778 * * \star$ & SP & 28 & s/ss & .0108 & $.0741 * * *$ \\
\hline & & $\begin{array}{l}\text { OME : } \\
\text { ION : }\end{array}$ & $\begin{array}{l}N=93 \\
N=54\end{array}$ & $\begin{aligned} \star \star * & \leq .001 \\
\star * & \leq .01 \\
\star & \leqslant .05\end{aligned}$ & $\begin{array}{l}\text { te: } \\
\text { rger } \\
\text { ntly }\end{array}$ & $\begin{array}{l}\text { The } \\
\text { of } \\
\text { dif }\end{array}$ & $\begin{array}{l}\text { aster } \\
\text { two a } \\
\text { feren }\end{array}$ & $\begin{array}{l}\text { isks are pla } \\
\text { eans which a } \\
\text { t. }\end{array}$ & $\begin{array}{l}\text { ed by the } \\
\text { e signifi- }\end{array}$ \\
\hline
\end{tabular}

Nursing settings (see Table VIII for a comparison of client behavior mean frequencies).

Interaction Settings. In Interaction settings, service provider exhibited eleven behaviors that had higher mean frequencies than they did in In-home Nursing service encounters. CRITICIZing, for example, was likely to occur five times as often on the part of an outreach worker as it did for Nursing personnel. Other behaviors with higher frequencies were: DISAGREE, NOT TRACKING, NON COMPLY, COMPLAIN, INTERRUPT, LAUGH, NERVOUS BEHAVIOR, NO RESPONSE, PARENTING, SUPPORTIVE 
TABIE VIII

A COMPARISON OF CLIENT BEHAVIOR

MEANS BY SERVICE TYPE

\begin{tabular}{|c|c|c|c|c|c|c|c|c|c|}
\hline \multicolumn{3}{|c|}{ BEHAVIOR } & \multirow{2}{*}{$\frac{\text { IN-HOME }}{2.6344}$} & \multirow{2}{*}{$\begin{array}{l}\text { INTERACTION } \\
2.7963\end{array}$} & \multicolumn{3}{|c|}{ BEHAVIOR } & \multirow{2}{*}{$\frac{\text { IN-HOME }}{.5054}$} & \multirow{2}{*}{$\begin{array}{c}\text { INTERACTION } \\
.9815\end{array}$} \\
\hline CL & 1 & AG & & & $\mathrm{CL}$ & 15 & NB & & \\
\hline CL & 2 & DG & $.7957 \star \star \star$ & .6852 & CL & 16 & No & 3.2043 & $3.6481 * \star \star$ \\
\hline CL & 3 & $\mathbf{A T}$ & 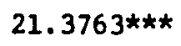 & 11.8333 & $\mathrm{CL}$ & 17 & NR & .4086 & $.4630 * \star$ \\
\hline CL & 4 & $\mathbf{N T}$ & $3.0323 * \pi *$ & .5926 & $\mathrm{CL}$ & 18 & PA & .0108 & $.0185 *$ \\
\hline $\mathrm{CL}$ & 5 & $\mathrm{CO}$ & 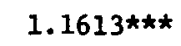 & .3704 & CL & 19 & PD & 18.3333 & 23.1111 \\
\hline $\mathrm{CL}$ & 6 & NC & .0000 & .0185 & $\mathrm{CL}$ & 20 & PP & $.1290 \star \star \star$ & .0741 \\
\hline CL & 7 & CM & .3871 & 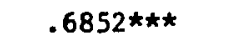 & $\mathrm{CL}$ & 21 & PS & 1.0860 & $2.1667 * \star$ \\
\hline CL & 8 & CP & 2.3011 & $3.5185 * \star$ & $\mathrm{CL}$ & 22 & QU & 4.2473 & 3.7037 \\
\hline CL & 9 & $\mathrm{CR}$ & .2796 & $.9815 * \star \star$ & $\mathrm{CL}$ & 23 & SM & 1.5914 & 1.5741 \\
\hline CL & 10 & CV & .2366 & $.6481 * \star \star$ & $\mathrm{CL}$ & 24 & $\mathbf{S P}$ & .0860 & $.2963 * \star *$ \\
\hline CL & 11 & $\mathrm{DR}$ & $.0538 * \star \star$ & .0370 & $\mathrm{CL}$ & 25 & sS & .4194 & 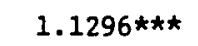 \\
\hline Cl & 12 & HM & 2.1290 & 2.4630 & CL & 26 & TA & 35.1720 & 35.5741 \\
\hline CL & 13 & IN & .3226 & $2.1111 * \star \star \star$ & $\mathrm{CL}$ & 27 & vo & .0215 & 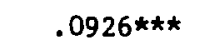 \\
\hline $\mathrm{CL}$ & 14 & IA & 3.0215 & 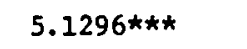 & $\mathrm{CL}$ & 28 & s/ss & $.0538 * \star$ & .0370 \\
\hline IN? & $\begin{array}{l}\text { IN- } \\
\text { ERAC }\end{array}$ & $\begin{array}{l}\text { HOME : } \\
\text { TION : }\end{array}$ & $\begin{array}{l}N=93 \\
N=54\end{array}$ & $\begin{aligned} * \star \star & \leq .001 \\
\star \star & \leq .01 \\
\star & \leq .05\end{aligned}$ & $\begin{array}{l}\text { Note: } \\
\text { larger } \\
\text { cantly }\end{array}$ & $\begin{array}{l}\text { Che } \\
\text { of } \\
\text { dif }\end{array}$ & $\begin{array}{l}\text { aster } \\
\text { two o } \\
\text { feren }\end{array}$ & $\begin{array}{l}\text { sks are plac } \\
\text { ans which ar }\end{array}$ & $\begin{array}{l}d \text { by the } \\
\text { signifi- }\end{array}$ \\
\hline
\end{tabular}

STATEMENT, and SELF/SUPPORTIVE STATEMENT.

During observations in Interaction settings, clients were observed INTERRUPTing nearly seven times as often as clients in In-home Nursing encounters. They CRITICIZEd more than three times as often and COMMANDed more than twice as often with Interaction personnel as they did with nursing personnel. COMPLAIN, CIVILITY, LAUGH, NORMATIVE, NO RESPONSE, PROPOSED SOLUTION, SELF/PUT DOWN, SUPPORTIVE STATEMENT, and VOLUNTEER HELP were also behaviors more frequently observed for clients 
in Interaction encounters.*

Unaffected Behaviors. Service provider behaviors not affected by type of service were AGREE, ATTEND, COMPLY, CIVILITY, DISREGARD, HUMOR, PROPOSED SOLUTION, QUESTION, SMILE, TALK, and VOLUNTEER HELP. CIient behaviors not affected were AGREE, NON COMPLY, HUMOR, NERVOUS BEHAVIOR, PARENTING, PROBLEM DESCRIPTION, QUESTION, SMILE, and TALK. Only five behaviors were unaffected by the type of service for both service provider or client. Those behaviors that did not vary for either participant in the dyad as a function of service are: AGREE, HUMOR, QUESTION, SMILE, and TALK.

Sumary. It is clear, at this point, that any description of the service provider/client encounter must acknowledge the variable of service type or task-orientation. Using the significantly different behaviors, a scenario can be constructed incorporating the added specificity.

The In-home Nursing encounter is one in which the service provider describes the problem at hand (PD) and spends considerable time involved in routine tasks (NO). The nursing personnel are polite (CV) but directive (CM). They use touch to communicate with their clients (PP). The patient or client spends her time reacting to the service provider in either positive or negative ways. The clients can be observed paying attention of not (AT and NT). They DISAGREE, DISREGARD or COMPLY. The clients make SELF/SUPPORTIVE STATEMENTs and respond nonverbally to the service provider (PP). A picture emerges of a mainly task-oriented

*It is possible that differences between In-home Nursing clients and Interaction cleints are not due to service-orientation. It may reflect simply a lowered activity level due to illness on the part of In-home Nursing clients. 
encounter with the service provider dominant or in charge, and the client as reactant. The emotional tone seems to be one similar to an adult-child relationship.

The Interaction encounter is one in which the service provider and client both INTERRUPT, COMPLAIN, CRITICIZE, LAUGH, and make SUPPORTIVE STATEMENTS. The client tends to PROPOSE more SOLUTIONS, is polite (CV), makes requests or commands $(\mathrm{CM})$, and is involved in routine tasks (NO). The service provider in Interaction encounters, displayed NERVOUS BEHAVIOR, and routine activities (NO). They also occasionally did not attend (NT) or comply (NC). These service providers also made self-enhancing remarks $(S / S S$ ) and were patronizing (PA) toward their clients. Clients were sometimes self-deprecating (S/PD) and occasionally reversed roles with the service provider (VOLUNTEER HELP). The range of behaviors in Interaction encounters (of both positive and negatively-toned behaviors) was greater. The client in these encounters appeared to be more active, more a director of what happened. These relationships appear to be ones in which the participants are on a more equal footing than those observed during In-home Nursing encounters. The emotional tone was one of an adult-adult relationship and was also often one of friendship. It is clear that task-orientation is an important second independent variable (role being the first).

Next, the question of patterns of behavior will be raised. That is, for example, does a service provider who QUESTIONs a great deal also listen (AT)? The interrelatedness of behaviors within the service provider role and client role, implied in our sumary discussions up to this point, is largely assumed and needs to be examined more directly. 
PATTERNS OF BEHAVIOR

Once some idea has been obtained of the behavioral response repertoires in the service provision encounter, a natural next step is to focus on recurring patterns of responses--to ask the question: How is behavior organized? It is unclear at this point whether or not behaviors within a role cluster or fall into patterns.

To examine the relationships of behaviors within and between roles, Pearson correlations were computed for Service Provider/Service Provider Behaviors; Client/Client Behaviors; and Service Provider/Client (or Interaction) Behaviors. It was expected that behaviors within and between roles would fall into patterns such that the appearance of one particular behavior would give information as to the likelihood of some other specific behavior occurring. Findings relating to within role patterning will be examined first, and then interaction patterns.

\section{Service Provider Behavior Patterns}

Virtually all (96\%) of the observed behaviors evidence patterning within the service provider role in that they are significantly more likely to occur given the presence, or absence, of some other particular behavior. The single exception occurred with the category POSITIVE PHYSICAI which appeared to occur independently of other observed behaviors with the possible exception of PARENTING, with which there was a positive tendency $(p \leq .08)$. Among the remaining 26 service provider behaviors, * there were 80 significant interrelationships at a level

*The reader is reminded that SELF/PUT DOWN was an empty set, leaving a total of 27 rather than 28 observed behaviors for service providers. 
of .05. Interpretation of such a large number of interconnections proved to be difficult. A reduction of the data was effected by limiting consideration to only those correlations that could be viewed with the highest confidence $(p=.001)$. This procedure resulted in the elimination of two-thirds of the interrelationships (to 27). This is a substantial reduction of the complexity of the data, but it still allows for a considertion of 18 or $67 \%$ of the observed service provider behaviors. These remaining behaviors and their relationships are shown in diagrammatic form in Figure 5. It is apparent that this procedure still does not give an unambiguous picture. INTERRUPT, for example, is significantly related $(p=.001)$ to eight different behaviors. The choice was therefore made to reduce the data by an alternate method; that of a factor analytic search for pattern. This statistical exploration (varimax rotated factor matrix with Kaiser normalization) resulted in the delineation of five useful* factors. These five factors, listed below in Table IX, account for 70.58 of the variance in the data, and involve fifteen (or 55\%) of the service provider behaviors. The factors will be described below and an attempt will be made to interpret the social impact of each group or factor of behaviors.

*The decision rule for usefulness required that: (a) a factor be composed of at least 3 items, (b) each item have a factor loading of at least .30 , (c) the factor did not appear to be due to the extreme behavior of only one person, (d) no factor included one of the 4 least frequent behaviors (SP6, 9, 24 or 28), and (e) the factor was of sufficient range to make comparisons with other variables feasible. 


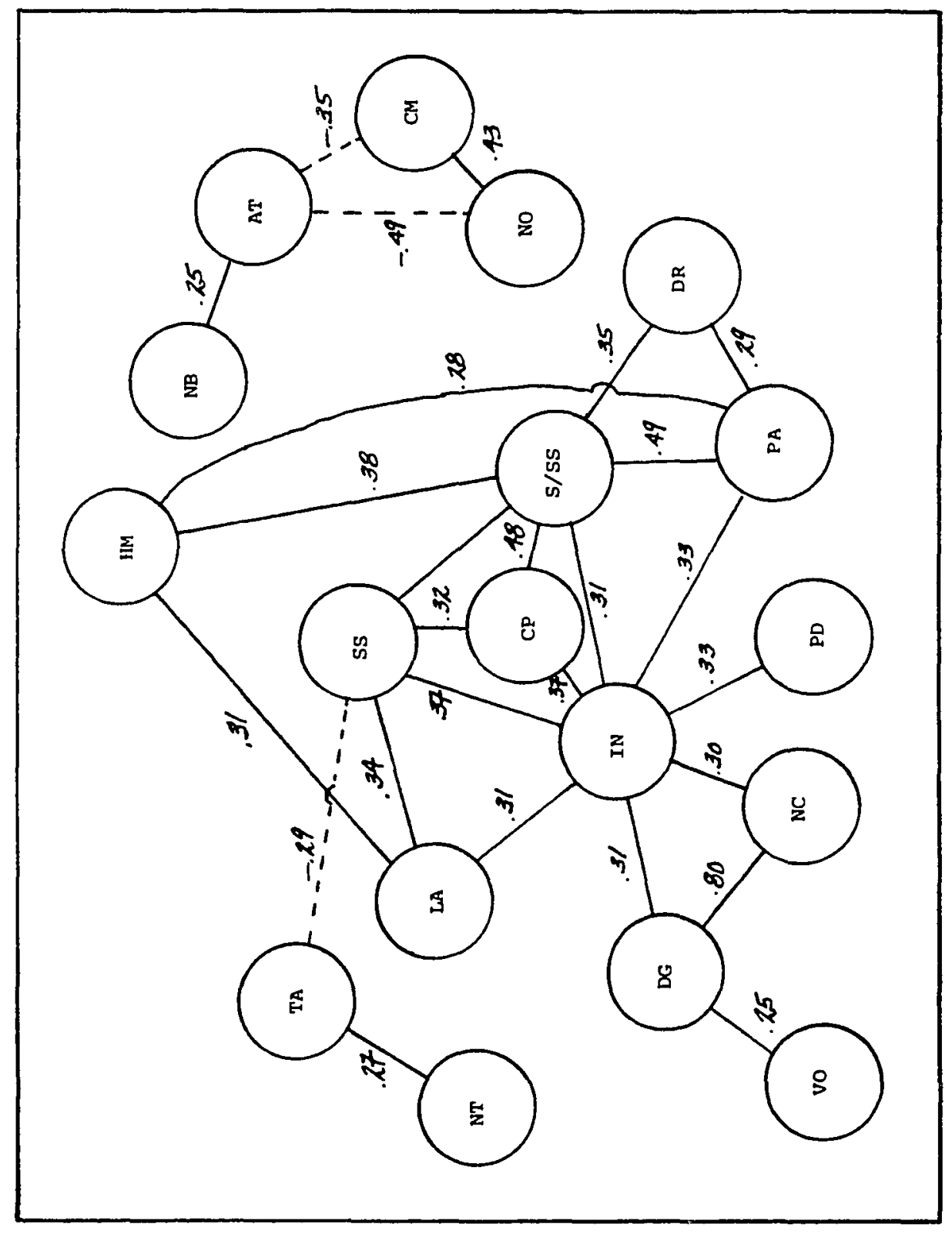

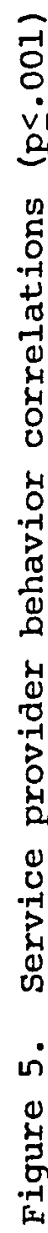


TABLE IX

SERVICE PROVIDER BEHAVIOR FACTORS

\begin{tabular}{|c|c|}
\hline FACTOR & $\begin{array}{l}\text { BEHAVIORS AND } \\
\text { LOADINGS }\end{array}$ \\
\hline $\begin{array}{l}\text { Service Provider I } \\
\text { (Friendly) }\end{array}$ & $\begin{array}{ll}\text { IA } & .66 \\
\text { SS } & .61 \\
\text { IN } & .56 \\
\text { CP } & .52 \\
\end{array}$ \\
\hline $\begin{array}{l}\text { Service Provider II } \\
\text { (Nondirective) }\end{array}$ & $\begin{array}{lr}\text { NO } & -.76 \\
\text { CM } & -.59 \\
\text { AT } & .54 \\
\end{array}$ \\
\hline $\begin{array}{l}\text { Service Provider III } \\
\text { (Uninvolved) }\end{array}$ & $\begin{array}{ll}\text { TA } & -.78 \\
\text { AG } & -.35 \\
\text { NT } & -.33 \\
\mathrm{CV} & .33 \\
\end{array}$ \\
\hline $\begin{array}{l}\text { Service Provider IV } \\
\text { (Authoritarian) }\end{array}$ & $\begin{array}{ll}\mathrm{PA} & .62 \\
\mathrm{DR} & .47 \\
\mathrm{CM} & .35\end{array}$ \\
\hline $\begin{array}{l}\text { Service Provider V } \\
\text { (Task Oriented) }\end{array}$ & $\begin{array}{ll}\text { PD } & .60 \\
\text { QU } & .38 \\
\text { IN } & .33 \\
\end{array}$ \\
\hline
\end{tabular}

Factor I (Friendly). The first factor to emerge accounted for $22.3 \%$ of the common variance and consisted of four behavioral items with loadings above .30 . This factor includes elevated levels of the behaviors: SUPPORTIVE STATEMENT, LAUGH, INTERRUPT, and COMPLAIN. The intercorrelations of these four behaviors is illustrated in Figure 6 . SUPPORTIVE STATEMENT and LAUGH, the two strongest behavioral elements in the factor (loadings were .61 and .66 , respectively), were used in the naming decision of "Friendly." The other behaviors, INTERRUPT and COMPLAIN, were unanticipated items on what is interpreted to be a positive pattern of behaviors. INTERRUPT had been included in the coding System in the assumption that interrupting another person was 


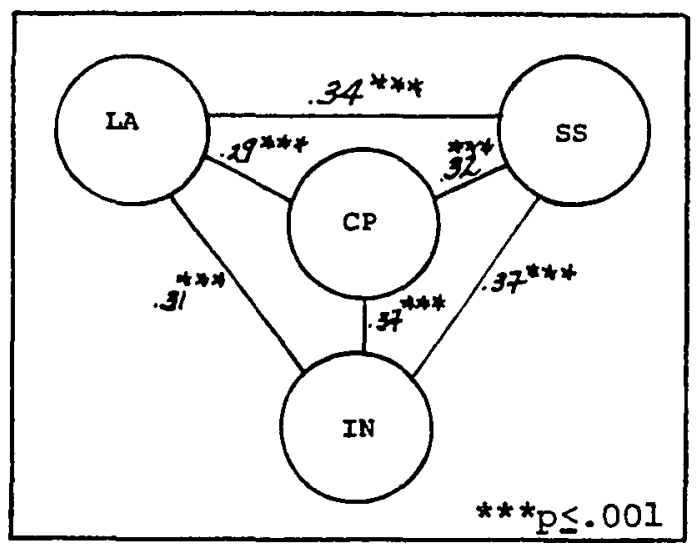

Figure 6. Correlations of behavioral items included in service provider Factor I (Friendly).

rude and would have a generally negative impact; a notion prevalent in polite society. It is clear from the diagram of service provider behaviors (Figure 5) that this assumption is sometimes true, but not always. INTERRUPT is sometimes associated with DISAGREE, NON COMPLY, and DISREGARD, a situation close to the anticipated one in which INTERRUPT could be interpreted as being an unwanted behavior. However, INTERRUPT is a factorially complex behavior that seems best interpreted as a pivotal or redirecting behavior, actually neutral in nature and signifying the service provider's active participation in the interaction (e.g., interrupting to ask for clarification of a statement just made by the client).

COMPLAIN is a behavior that was also included in the anticipation that it would be a universally negative behavior. While this is the situation with clients who usually COMPLAIN in association with PROBLEM DESCRIPTION; service provider COMPLAINing has a different pattern of associations or correlations. Service provider COMPLAIN is not associated with the task at hand (PD). In this context (when concurrent with 
LAUGH, SUPPORTIVE STATEMENT, and INTERRUPT), COMPLAIN can be interpreted as a plea or request for sympathy related to an outside or personal area. One can imagine something like, "My son is having trouble in school," or "My car is going to need an expensive repair." In this configuration with other positive behaviors, the appearance of $\mathrm{CP}$ suggests that the service provider is revealing him/herself as a human being and is allowing a level of reciprocity characteristic of a friendship relation between the two. In summary, these behaviors seem to describe a way of relating to clients that is active, friendly, supportive, and allows for mutuality.

Factor II (Nondirective). The second factor to emerge in the analysis accounts for $17.5 \%$ of the variance in the data and consists of three behavioral items: ATTEND, NORMATIVE, and COMMAND. This pattern is characterized by a negative correlation of ATTEND with the other two behavioral variables: NORMATIVE and COMMAND. (The correlations among these behaviors are diagrammed in Figure 7.)

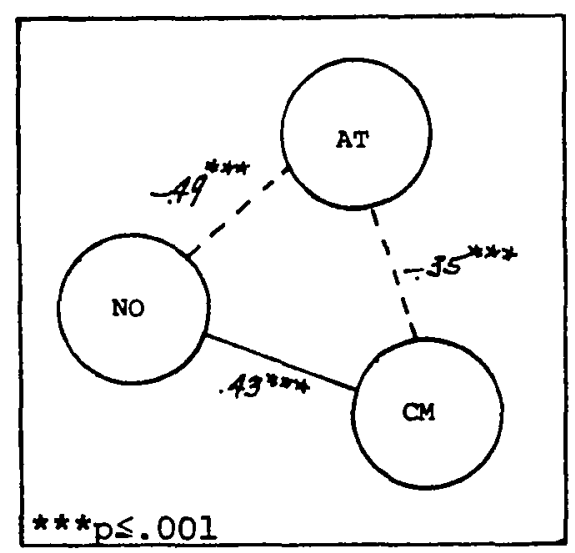

Figure 7. Correlations of behavioral items included in service provider Factor II (Nondirective). 
ATTENDing, a behavioral category which includes eye contact, was included in the coding System as it has correlated in earlier studies (e.g., Ivey, 1971; Mehrabian, 1972) with client satisfaction, feelings of being understood and appreciated. NORMATIVE and COMMAND, on the other hand, were assumed to be indicators of distance or non-involvement. The configuration of behaviors occurring in this factor (AT, -NO, -CM) tends to corroborate these assumptions.

A number of other interesting negative correlations occur with ATTEND. In addition to those with NORMATIVE and COMMAND, negative correlations are found between ATTEND and CRITICIZE, DISREGARD, and PARENTING (all significant at ps.05). This cluster of present and absent behaviors would suggest that while ATTEND is an undramatic-appearing behavior, it is a strong indicator of positive relationship in that it excludes or decreases the probability of negative or aversive behaviors. A plausible interpretation of this pattern seems to be that it characterizes a service provider who is not necessarily an active interventionist, but who clearly pays attention and is careful not to ignore the client's feelings and concerns.

Factor III (Uninvolved). The third factor to be delineated by the analysis accounts for $14 \%$ of the variance and consists of decreased levels of three behavioral items (TALK, AGREE, NOT TRACKING) and an increased level of one behavior (CIVILITY). The pattern of intercorrelations for these four behaviors is illustrated in Figure 8 .

CIVILITY, the only elevated behavior, consists of polite but fairly superficial behaviors, e.g., "Good Morning," "Isn't it a nice day?" or "Thank you," and routine compliments (those not scored as emphathetic: SS) CIVILITY does not appear to be a particularly positive 


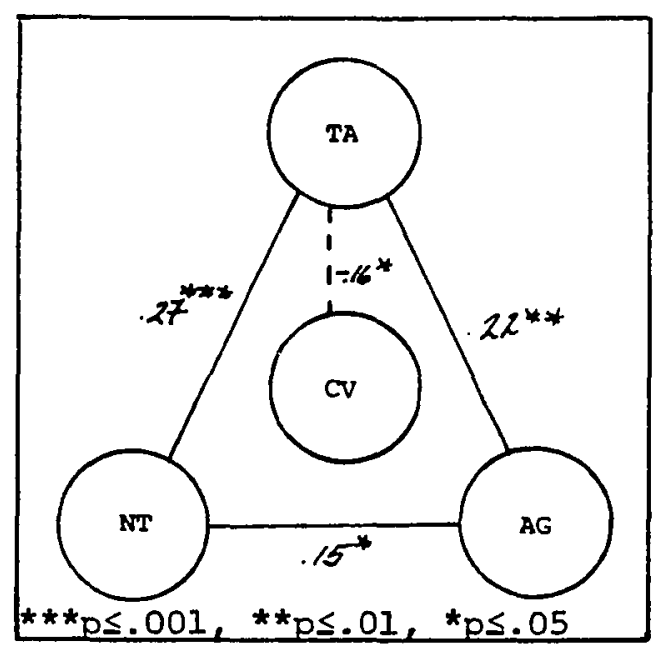

Figure 8. Correlations of behavioral items included in service provider Factor III (Uninvolved).

behavior in that it is often associated with DISAGREE, COMPLAIN, PROPOSE SOLUTION, and SELF/SUPPORTIVE STATEMENT (at $\mathrm{p} \leq .05$ ). This is a group of behaviors that would seem to flag a service provider taking in little information and one who is preoccupied with his/her own interpretations and needs. The appearance of low levels of NOT TRACKING can be interpreted in this context as another indicator (with CV) of politeness. The relative absence of TALK and AGREE are taken to be additional indicators of a general lack of involvement with the client.

Since there are no notably positive behaviors expressed, but also no overtly negative behaviors, one hypothesizes that this "Uninvolved" person monitors their behavior carefully, possibly because they have underlying negative attitudes. This pattern would be consistent with a person repressing negative responses since repression generally inhibits positive behaviors as well as negative; the "Poker Face" response is a notable example. 
Factor IV (Authoritarian). The fourth factor to emerge from the data accounted for 10.88 of the variance and was composed of three behavioral categories with factor loadings greater than .30: PARENTING, DISREGARD, and COMMAND. (The intercorrelations of these three behaviors is illustrated in Figure 9.)

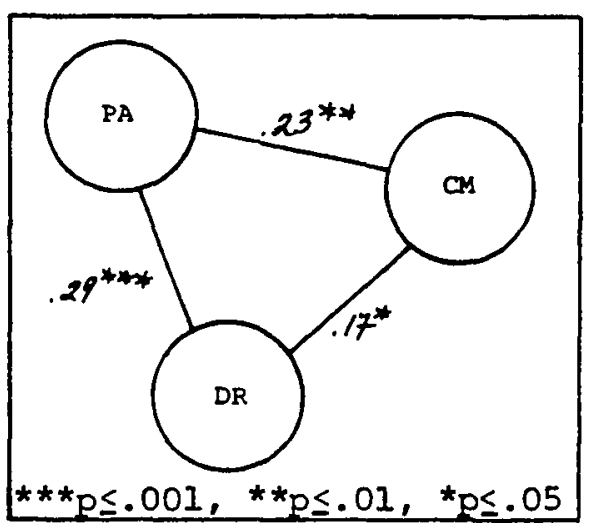

Figure 9. Correlations of behavioral items included in service provider Factor IV (Authoritarian).

The pattern seems to be an overbearing or patronizing one. The service provider engages in PARENTING (e.g., "you should," "you ought to") DISREGARDs the client's feelings, and at the same time makes frequent demands (CM). PARENTING seems to be clearly negative behavior which is often found in configuration with DISAGREE, NON COMPLY, COMPLAIN, CRITICIZE, and SELF/SUPPORTIVE STATEMENT ( $\mathrm{p} \leq .05$ ).

Two of the behaviors in this pattern (PA and $C M$ ) also correlate with decreased ATTENDing ( $\mathrm{p} \leq .05) . *$ The "Authoritarian" service provider appears to operate in the confident belief that she/he knows what is good for the client and does not hesitate to say so--in the

*There is a tendency for the third behavior (DR) to correlate negatively with AT also $(p \leq .10)$. 
absence of any attempt to check out his/her perceptions first. Since no attempt is made to temper aversive behaviors (even in the presence of an observer), one speculates that this service provider is either insensitive to their interpersonal style, or needs to be in control and professes positive attitudes.

Factor V (Task-Oriented).* Factor V accounts for 5.98 of the variance and is composed of three items: PROBLEM DESCRIPTION, QUESTION, and INTERRUPT. (see Figure 10 for the intercorrelations of these behaviors.) While this pattern does not appear to be a particularly warm one, it is not characterized by overt neglect of the client's needs or feelings. This pattern of behaviors seems to reflect a very task-

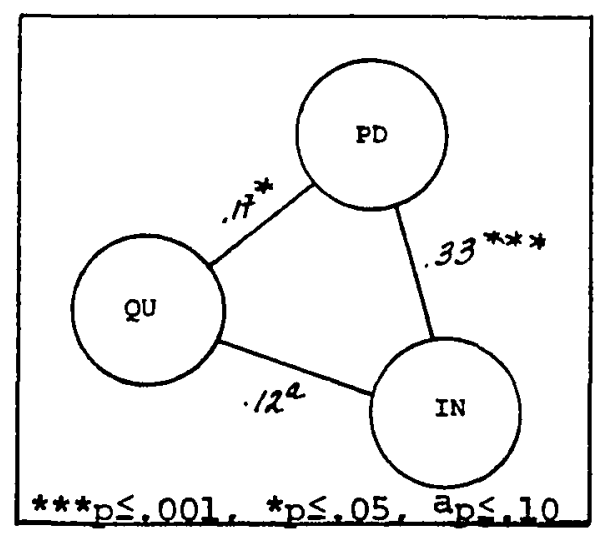

Figure 10. Correlations of behavioral items included in service provider Factor $v$ (Directive).

oriented or businesslike approach that does not offer the client many possibilities for interacting. The three behaviors, together, seem directive and proactive; leaving the client with only respondent

* Two factors were delineated before this one. Since both were single item factors (HUMOR and VOLUNTEER HELP), they did not fit our criteria and were not used. They accounted for 98 and 6.98 of the common variance, respectively. 
behavioral possibilities. PROBLEM DESCRIPTION and QUESTION are both also correlated with PARENTING ( $p \leq .05$ ) suggesting there could be a slight lack of sensitivity to the client.

Summary. Slightly more than half $(55 \%)$ of the 28 service provider behaviors fall into patterns that appear to have interpersonal meaning. Five kinds of behavior patterns were delineated by the factor analysis which can be reduced to two in terms of apparent orientation to the client.

Two of the factors (I and II) seem to describe ways of relating that indicate interest in the client and which are also warm in emotional tone. One can speculate that these two types are expressive of positive attitudes. Together, these two factors account for the largest amount of common variance in the data: $39.8 \%$.

Three other factors seem more self- or task-oriented than clientcentered styles. Two of these factors (III and V) are rather cool, distant styles of interacting which could be masks for negative feelings toward elderly clients, or simple disinterest. This behavior pattern may be characteristic of those who do not realize the impact of their actions or who do not care enough to mask them.* These three factors account for 30.78 of the common variance.

The author has tentatively placed these service provider factors on an Interpersonal Checklist profile wheel, illustrated in Figure 11. This plotting of the factors show Factors I and II as being warm toward others and differing in degree of dominance versus submissiveness.

*It should be noted that these factors reflect behavioral patterns not necessarily individuals. In a particular instance, one individual could well exhibit a combination of patterns. 
Friendly (Factor $I$ ) is seen as being more dominant than Nondirective (Factor II).

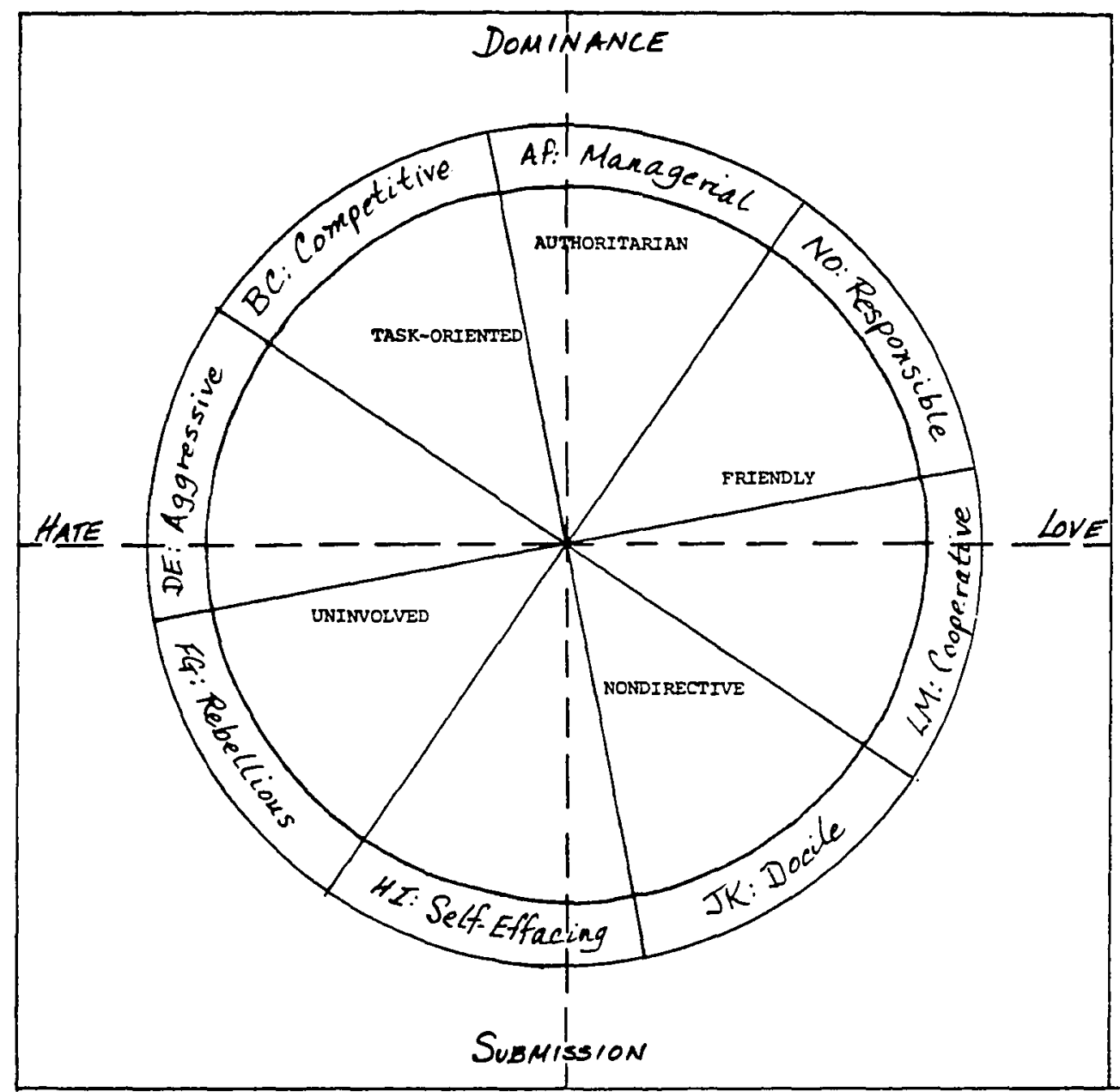

Figure 11. Service provider factors plotted on ICI profile wheel.

The three remaining factors (III, IV, and V) are categorized as lacking warmth and also vary in degree of dominance. Authoritarian (Factor IV) is seen as most dominant, followed by Directive (Factor V) and Uninvolved (Factor III). 


\section{Client Behavior Patterns}

A similar situation exists within the client role, as with the service provider role. Virtually all (96\%) of the observed behaviors evidenced patterning, with one exception, that of POSITIVE PHYSICAL. Again, this was the only observed behavior which had no significant positive or negative relationship with other tallied behaviors. In this case, however, the one tendency was with QUESTION (ps.10) rather than with PARENTING as was the case with service provider behaviors. Among the remaining 27 client behaviors, there were 60 significant interrelationships (ps.05). Again, we have a multitude of interconnecting behavioral ties that are difficult to interpret even if we limit our consideration to those relationships significant at a level of ps.001, as we did with service provider behaviors (see Figure 12). Using only the relationships significant at the higher level of significance, reduces the complexity of the data to eighteen interrelationships, but still allows for a consideration of twenty-one (or 758) of the observed client behaviors. It would appear from a comparison of these simple tabulations of client and service provider behaviors, that client behavior is not as tightly organized and involves a larger scope of behavioral possibilities. One might say that the client has a wider range of behaviors from which to select than does the service provider even though that range is largely (but not exclusively) drawn from the reactive repertoire.

This impression of wider range is reinforced by the results of a factor analysis of client behavior. While the service provider factor analysis resulted in five factors which incorporated fifteen different behaviors, the factor analysis of client behavior resulted in ten 
factors which incorporated twenty-two behaviors.* The ten factors are listed in Table $x$, and together account for a total of 96.28 of the variance.

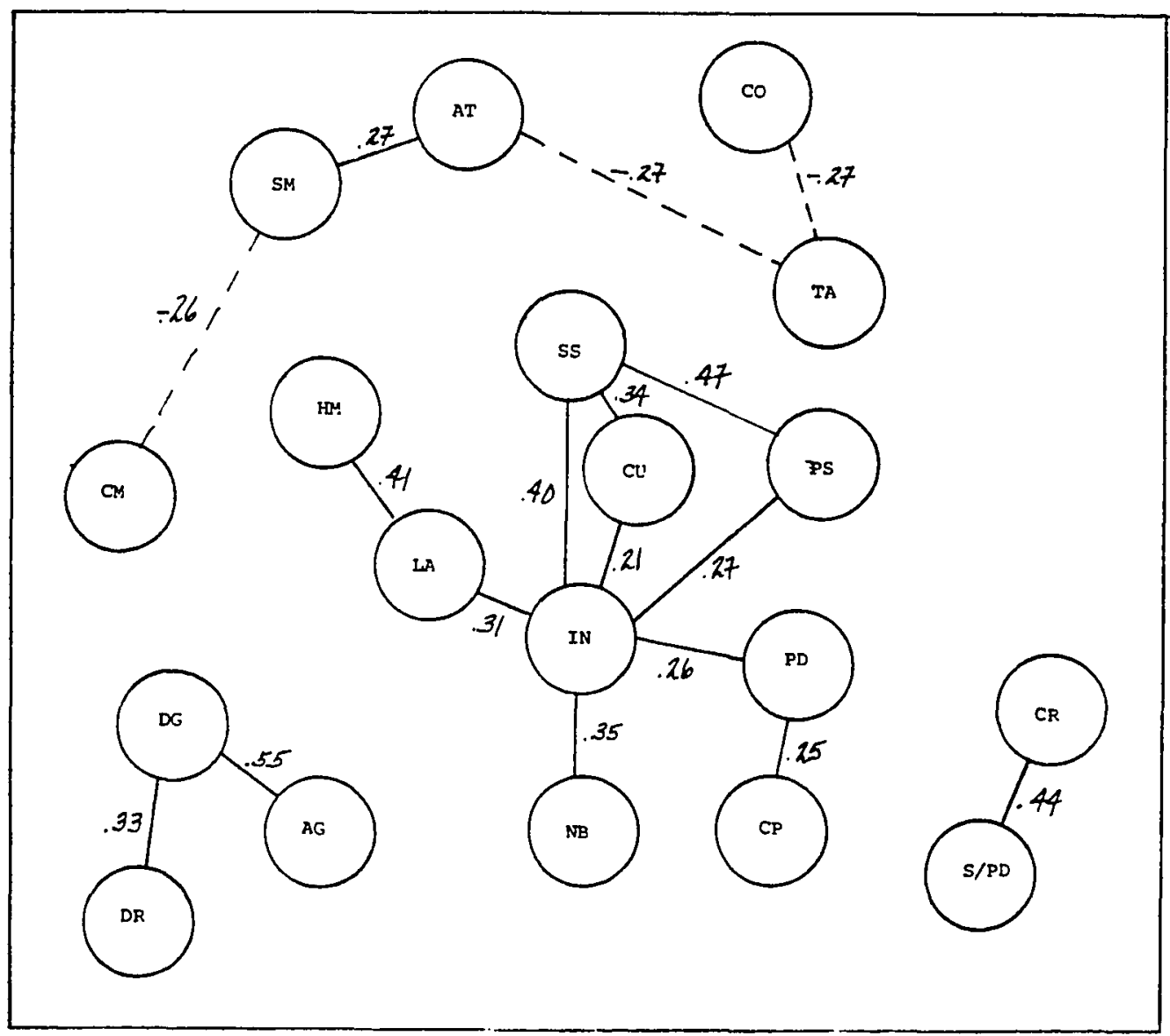

Figure 12. Client behavior correlations (ps.001)

\section{Client Factor I (Role Reversal). The first factor to emerge}

accounted for 20.98 of the variance and consisted of four items with

*The decision rule for useful factors was the same as that used earlier for service providers except that the four least frequent behaviors in this case were CL $6,11,18$, and 28; and the factors required at least two rather than three behaviors due to the increased variety of combinations. Had the requirement of three items been maintained, the increased range would still have been apparent with six factors and sixteen behaviors. 
loadings equaling . 30 : SUPPORTIVE STATEMENT, CIVILITY, PROPOSED SOLUTION, and INTERRUPT. It is clear from a comparison of Figures 5 and 11 , that INTERRUPT is functionally equivalent for service providers and clients in that, in both cases, it is a pivotal behavior highly dependent on context for meaning. We will, therefore, interpret INTERRUPT, as we did earlier for service providers, as being an active, initiating behavior and one which is positive in this context with other positively toned behaviors. CIVILITY seems ambiguous in meaning, as it sometimes occurs with CRITICIZE $(p \leq .01)$. By virtue of its appearance on this factor it is apparently also sometimes positive. PROPOSE SOLUTION is another active initiating behavior. One guesses that these proactive behaviors (INTERRUPT and PROPOSE SOLUTION) or role reversal kinds of behaviors, may be accepted or viewed positively by the service provider when they occur in the context of CIVILITY and SUPPORTIVE STATEMENT. These latter behaviors may serve a placating function. In summary, this factor seems to describe a behavior pattern that is warm, active, and diplomatic. The intercorrelations of the four behaviors are shown in Figure 13.

Client Factor II (Compliant). The second delineated factor consists of three behavioral items and accounts for 14.28 of the data variance. This factor is characterized by a positive correlation between ATTEND and COMPLY together with a negative correlation between ATTEND and TALK (see Figure 14). This individual could be weak or ill, judging from the low level of verbal activity. In any case, the pattern seems to describe a rather passive and docile manner. 
TABLE $X$

CLIENT FACTORS

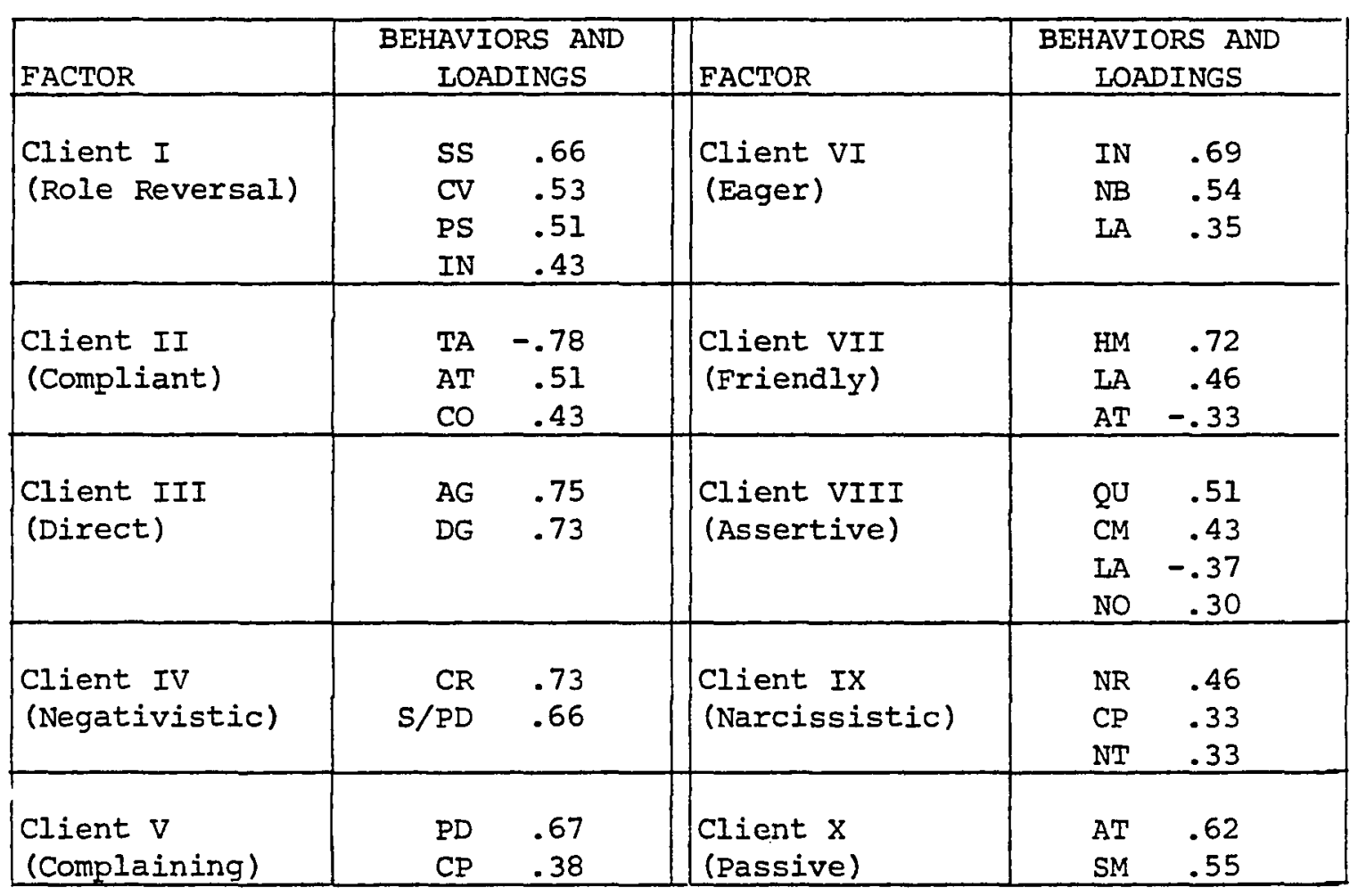

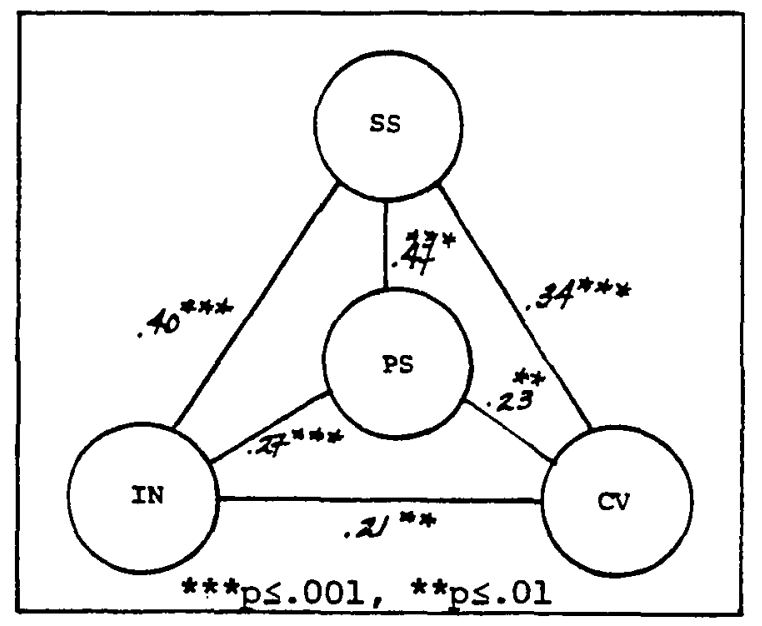

Figure 13. Correlations of behavioral items included in client Factor I (Role Reversal). 


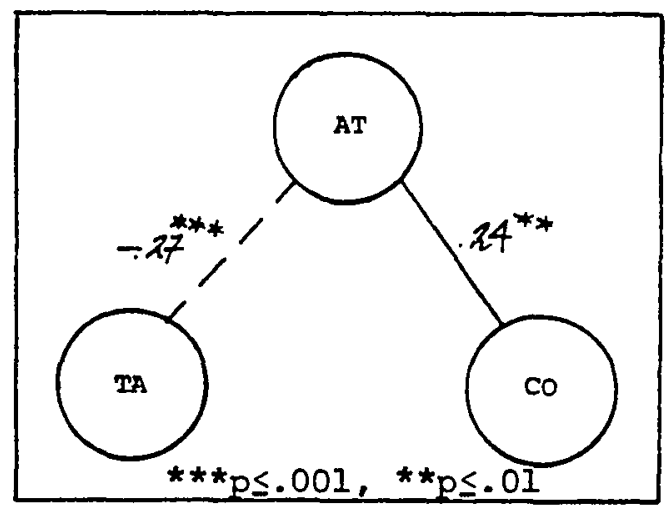

Figure 14. Correlations of behavioral items included in client Factor II (Compliant).

Client Factor III (Direct). This factor consists of only two items, AGREE and DISAGREE. These two behavioral categories correlate very highly with each other (see Figure 15) and have very high factor loading ( $A G=.75 ; D G=.73$ ). No other behavior loads on this factor at anything but a trivial level $(=.12)$ although both behaviors are correlated with PROPOSE SOLUTION ( $\mathrm{p} \leq .05)$ and DISREGARD (with AGREE ps.05, and with DISAGREE pS.001).

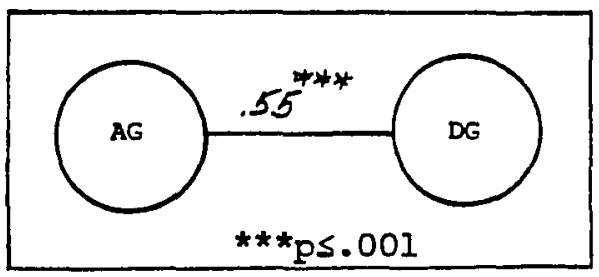

Figure 15. Correlations of behavioral items included in client Factor III (Direct).

While both AGREE and DISAGREE are respondent behaviors, they appear to express self-reliance, and a certain definiteness of stance, which the association with PROPOSE SOLUTION and DISREGARD would tend to corroborate. This factor accounts for 12.38 of the common variance. 
Client Factor IV (Negativistic). This factor is similar to Client Factor III in that it also consists of only two items with high factor loadings: CRITICIZE $=.73 ;$ SELF/PUT DOWN $=.66$. These behaviors also correlate with each other at a high level (see Figure 16).

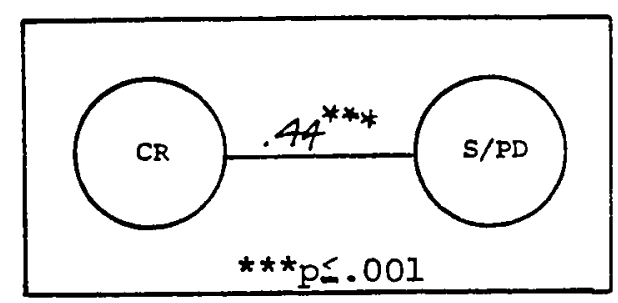

Figure 16. Correlations of behavioral items included in client Factor IV (Negativistic).

This factor appears to be one of anger and hostility. CRITICIZE and SELF/PUT DOWN are also both correlated with COMPLAIN (ps.05) and with INTERRUPT $(p \leq .05)$. These associations would tend to confirm the picture of discontent. The two behaviors comprising Factor IV are directed both outwardly or extra-punitively (CRITICIZE) and inwardly or intra-punitively (SELF/PUT DOWN). This factor, "Negativistic" accounts for $10.4 \%$ of the total variance.

Client Factor V (Complaining). This factor accounts for 9.98 of the common variance and is, again, composed of two of the behavioral categories: PROBLEM DESCRIPTION and COMPLAIN. These behaviors are moderately correlated with each other (see Figure 17) and both are also correlated with INTERRUPT $(p \leq .05)$, PROPOSE SOLUTION $(p \leq .05)$ and are negatively correlated with ATTEND (with PD $\mathrm{P} \leq .01$; and with CP $\mathrm{p} \leq .10$ ). This fifth factor is named "complaining" because of the distaste service providers have for this behavior and it is a frequent stereotypic adjective used to describe elderly individuals. This factor 
accounts for $9.9 \%$ of the total variance.

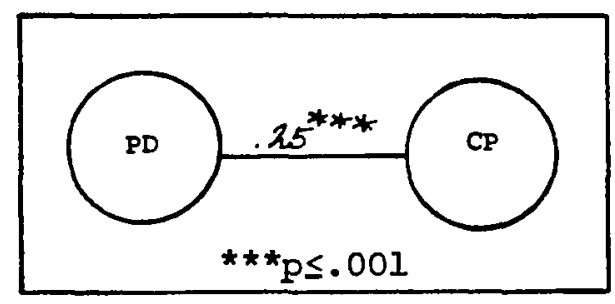

Figure 17. Correlations of behavioral items included in client Factor $\mathrm{V}$ (Complaining).

Client Factor VI (Eager). The sixth factor to emerge from the data includes three behavioral items with factor loading greater than .30. It accounts for $7.3 \%$ of the common variance. The items (INTERRUPT, NERVOUS BEHAVIOR, and LAUGH) are shown with their intercorrelations in Figure 18. They seem to describe an uncertainness of interaction. INTERRUPT is, in most cases, an effort to re-direct or attempt to change the interaction. Coupled, as it is here, with NERVOUS BEHAVIOR and LAUGH, it would seem to indicate that the individual wants to be active but may be unsure as to what to do; or possibly, is ambivalent.

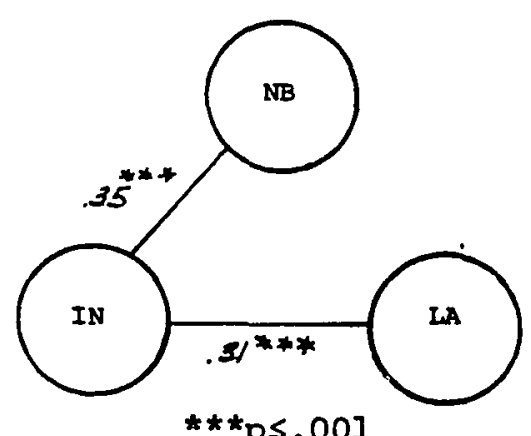

$* * * \mathrm{p} \leq .001$

Figure 18. Correlations of behavioral items included in client Factor VI (Eager). 
INTERRUPT and NERVOUS BEHAVIOR Occur, in some cases, in association with SELF/PUT DOWN. LAUGH is often negatively associated with QUESTION and COMMAND (two assertive behaviors). This additional information tends to support the characterization of this pattern as being unsure or ambivalent.

Client Factor VII (Friendly). The seventh factor to emerge from the data accounts for $6.7 \%$ of the variance. It includes three behavioral items that have factor loadings exceeding .30. Two are positively correlated with the factor: HUMOR and IAUGH; one is negatively correlated with the factor: ATTEND (see Figure 19 for the correlations of these three behaviors).

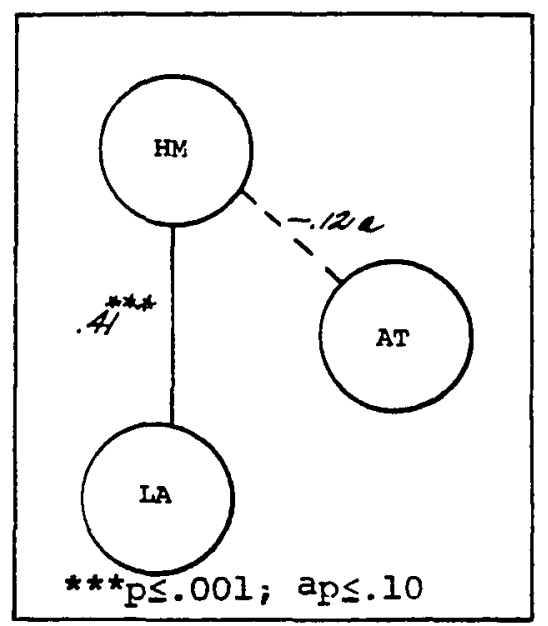

Figure 19. Correlations of behavior items included in client Factor VIII (Friendly).

Elevated levels of HUMOR and LAUGH seem to indicate a joking, good-natured approach to the service interaction. The negative correlation of HUMOR and ATTEND is perplexing. With service providers, lowered ATTENDing seemed a definite negative sign. With clients it may only signal a more active, less passive individual since clients 
typically ATTEND much more than service providers do anyway. In any case, the association is slight.

Client Factor VIII (Assertive). This factor consists of four behavioral categories that load at or beyond a level of .30. Three behaviors show positive loadings: QUESTION, COMMAND and NORMATIVE; LAUGH shows negative loading in this pattern. This eighth factor accounts for $5.7 \%$ of the variance. This looks like a group of behaviors designed to take control of the situation. Both QUESTION and COMMAND are very directive behaviors, usually more characteristic of the service provider role. The negative correlation of LAUGH with the other behaviors and the appearance of NORMATIVE suggest a lack of anything more than a business transaction. The absence of mollifying behaviors (e.g., CIVILITY, SUPPORTIVE STATEMENT) suggests a rather independent individual (see Figure 20).

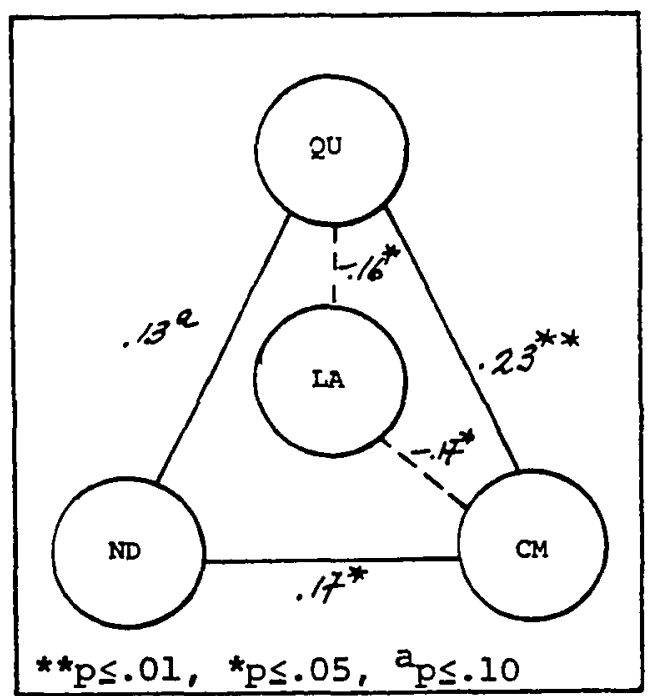

Figure 20. Correlations of behavioral items included in client Factor VIII (Assertive). 
Client Factor IX (Narcissistic). This factor, composed of three behavioral items (NO RESPONSE, COMPLAIN, NOT TRACKING) accounts for $4.7 \%$ of the common variance. This factor combines CoMPLAINing, not paying attention (NT) and ignoring (NR). The next highest loading on this factor is ATTEND (loading, -.25). This is a confirming detail that would seem to describe a pattern of behavior possibly indicative of an individual who does not make any attempt to accommodate to the needs of the other member of the dyad for even minimal interaction. It is not clear if the client does not want to interact, or cannot (too ill). The presence of COMPLAIN, however, would indicate that the individual is capable of some verbal interaction, and also a negative emotional tone. (The behavior correlations are shown in Figure 21.)

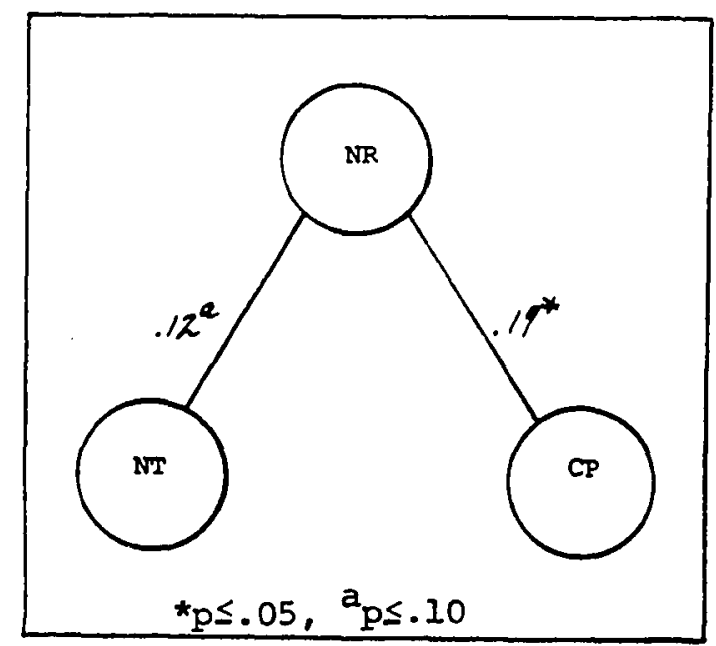

Figure 21. Correlations of behavioral items included in client Factor IX (Narcissistic).

Client Factor $X$ (Passive). This final factor consists of two of the behavioral categories: ATIEND and SMILE. These two behaviors are correlated $p \leq .001$ and have factor loadings of .62 and .55 , respectively. Factor $X$ accounts for $5 \%$ of the variance. It appears to be exceedingly 
passive (again, this is possibly indicative of a debilitated individual; however, it expresses an orientation towards the service provider (see Figure 22).

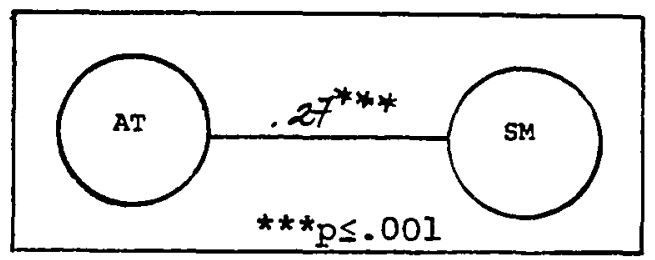

Figure 22. Correlations of behavioral items included in client Factor X (Passive).

Summary. Slightly more than three-quarters (twenty-two, or 78.5\%) of classified client behaviors fall into patterns that appear to have interpersonal significance. Ten patterns of client behavior emerged from the analysis.

An attempt to categorize the patterns in terms of interpersonal impact is illustrated below in Figure 23. As compared to service provider behavior, client behavior is more varied or individualistic. Half of these behavior patterns seem oriented toward the service provider, or emotionally warm, and vary on degree of dominance or submissiveness. The remaining five patterns seem oriented away from or against the service provider--again, in varying degrees of dominance or submissiveness. 


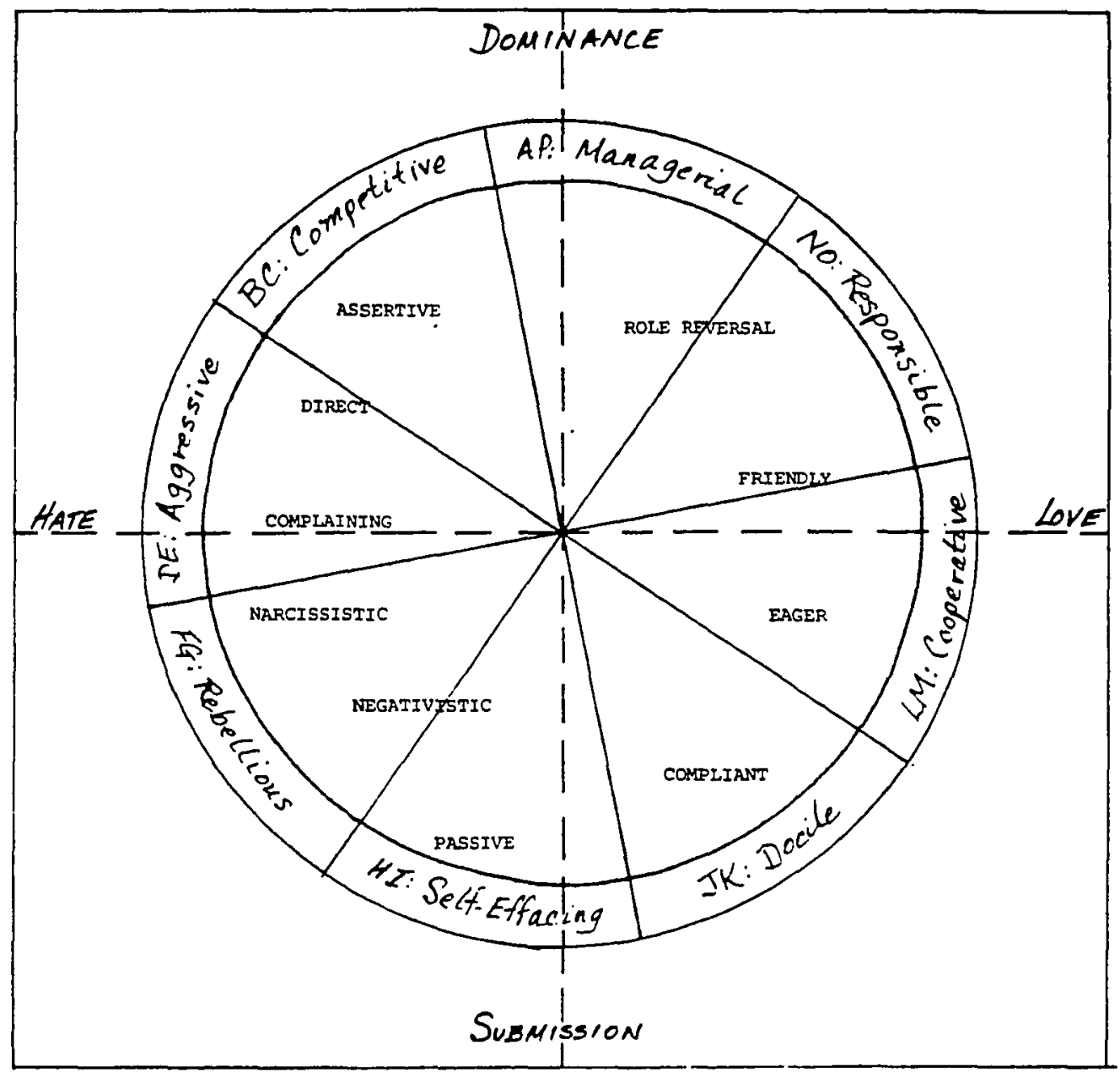

Figure 23. Client factors plotted on ICL profile wheel. 
CHAPTER V

\author{
RELATIONSHIPS TO OTHER MEASURES: A VENTURE \\ INTO THE QUESTION OF VALIDITY
}

In the last chapter, it was demonstrated that the 28 behavioral categories used to collect data on the service provider/client encounter, could result in meaningful information. Behavior was found to fall into a number of recurrent patterns for both members of the dyad. This is one indicator of the usefulness of the developed instrument.

Another way to examine the functional usefulness and validity of the Service Provider/Client Dyadic Interaction Coding system is to see if the derived factors relate to the other kinds of data that are available: i.e., information relating to service provider personality and attitudes; client and observer evaluations of the encounter. We can ask the questions: Are the delineated behavior patterns associated with personality characteristics? General attitudes toward elderly clients? Specific attitudes held in respect to a particular client? To the view an observer has of the encounter? To client satisfaction?

While full-scale analyses remain to be accomplished with this wealth of information, a preliminary examination of possible interrelationships can suggest interesting possibilities for future research efforts. The comparisons between data collected by means of the developed coding system (SP/CDICS) and other levels of data on the 
same population, will give some indication as to the kinds of inferences that can be made from behavioral data collected in this manner.

THE CLIENT FACTORS

Correlations were run between the ten client factors and the service provider's specific attitudes (description of a particular client) at two levels. Client behavior factors were compared with the discrete specific attitude $\underline{\text { items }}$ as well as with four summary scales constructed from these items.* These correlations allow for a comparison between the way the service provider views a particular client, and the way that same client behaved during the observed encounter. These correlations between the client behavior factors and specific attitudes are displayed in Table XI (factors and Contentment items); in Table XII (factors and Discontentment items); ard in Table XIII (Aging and Affect items and summary scales). All relationships mentioned in the following discussion are based on significant correlations $(p \leq .05)$ unless otherwise noted.

\section{Client Factor I (Role Reversal)}

This behavioral pattern (SUPPORTIVE STATEMENT, CIVILITY, PROPOSED SOLUTION, and INTERRUPT) correlates with descriptions of clients who

*Four summarizing scales were constructed from the service provider's responses to the specific Attitude instrument. The Contentment scale is an averaged sum of service provider responses to the positively toned descriptors or items; the Discontentment scale is constructed in a similar manner from the negatively-toned items. The overall contentment scale reflects the difference between the Contentment and Discontentment scales and is, thus, a reflection of the service provider's attitude on balance. The construction of these scales as well as the design of the original measuring instrument is the work of Marilyn Petersen, Institute on Aging, Portland State University. These scales are discussed in detail in the client Relations project Final Report. 
TABLE XI

CLIENT BEHAVIORAL FACTORS AND CONTENTMENT ITEMS

\begin{tabular}{|c|c|c|c|c|c|c|c|c|c|}
\hline & & & PECIFIC & TTITUDE & ONTENTI & IT ITEMS & & & \\
\hline \multicolumn{10}{|l|}{ Client Factors } \\
\hline I Role Reversal & $.14^{\mathrm{a}}$ & $.14^{a}$ & & $.19 \star$ & & $.16 *$ & $.18 *$ & & \\
\hline II Compliant & $-.20 * \star$ & $-.22 \star \star$ & & & & $-.23 \star \star$ & $-.12^{a}$ & $-.11^{a}$ & $-.12^{a}$ \\
\hline III Direct & & & & $.15 *$ & & & & & \\
\hline IV Negativistic & $-.12^{a}$ & $-.16 *$ & $-.12^{a}$ & & & & & & \\
\hline $\mathrm{v}$ Complaining & $-.18^{\star}$ & & & $-.14 a$ & & & & $-.20 * *$ & \\
\hline VI Eager & $.21 * \star$ & & $.12^{a}$ & $.22 \star \star$ & $.13^{a}$ & & & $.18^{\star}$ & $.15 *$ \\
\hline vII Friendly & $.22 \star \star$ & & & $.18 *$ & $.14 *$ & $.13 a$ & $.17 \star$ & $.18 *$ & $.11^{a}$ \\
\hline VIII Assertive & & $.14 *$ & & & & $.15 *$ & & & \\
\hline IX Narcissistic & $-.34 \star \star \star \star$ & $-.15 *$ & $-.22 \star \star$ & & $-.19 \star$ & $=.16 *$ & & $-.32 \star \star \star$ & $-.25 * \star \star$ \\
\hline$x$ Passive & & $-.19 \star$ & & & & $-.22 k *$ & $-.18 *$ & & \\
\hline $\begin{array}{l}\text { a } p \leq .10 \\
p \leq .05\end{array}$ & & $\mathbf{N}=$ & & & & & & & \\
\hline
\end{tabular}


are at peace with themselves, dependable, and who have interesting stories to tell. They are seen as fragile, but not angry individuals. The specific attitude summary scores indicate that for clients who display this role reversal pattern, the service provider endorses positive items to a significant degree. The service provider's view of the client who displays this pattern of behaviors appears somewhat consistent with that assigned earlier by an analysis of the behaviors that comprise the pattern, "warm, active, and diplomatic."

\section{Client Factor II (Compliant)}

The "Compliant" factor (ATTEND, COMPLY, TALK) correlates with service provider descriptions of clients who do not have a positive outlook, do not have a wealth of experience, or interesting stories to tell. These individuals, according to the service provider, refuse to help themselves, have given up on life, are overly demanding, slow, and have serious emotional problems. The summary scales indicate that the service provider is unequivocal in assigning a negative description to the individual displaying this "Compliant" behavior. There is a significant positive correlation between this behavior pattern and the Discontentment scale, and significant negative correlations with both Contentment and overall contentment scales.

The lack of verbal interaction appears to be interpreted by the service provider as a hostile, uncooperative manner, in spite of the increased levels of ATTENDing. The interpretation of this pattern (which was that it reflected passivity or docility, possibly from an ill client) is consistent with descriptors such as "given up on life," but did not include the hostile or self-destructive tone described by the service provider. 
TABLE XII

CLIENT BEHAVIORAL FACTORS AND DISCONTENT ITEMS

\begin{tabular}{|c|c|c|c|c|c|c|c|c|c|}
\hline & & & & SPECIFIC & ATTITUDE & DISCONTE & TTMENT $\mathrm{I}$ & EMS & \\
\hline \multicolumn{10}{|l|}{ Client Factors } \\
\hline I Role Reversal & $-.14^{a}$ & & $.12^{a}$ & & & $-.16 *$ & & & \\
\hline II Compliant & & $.24 \star \star$ & & & $.16 *$ & & $.14 *$ & $.22 \star \star$ & \\
\hline III Direct & & & & $-.16 \star$ & & & $-.13^{a}$ & & $-.22 \star \star$ \\
\hline IV Negativistic & & & $.15^{\star}$ & $.15^{\star}$ & & & $.20 \star \star$ & & \\
\hline$v$ Complaining & $.14^{a}$ & & & $.14 *$ & & $.23 \star \star t$ & & & $.26 * \star \star \star$ \\
\hline VI Eager & & & & & & $-.21 \star \star$ & $-.11 a$ & & \\
\hline vII Friendly & & & & & $-.14 a$ & $-.23 * \star$ & $-.14 *$ & $-.12^{a}$ & $-.12^{a}$ \\
\hline VIII Assertive & & & & & & $.13^{a}$ & & & \\
\hline IX Narcissistic & $.22 \star \star$ & 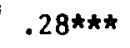 & $.22 * \star$ & $.27 \star \star \star$ & $.26 * \star \hbar$ & $.23 \star \star$ & $.20 * \star$ & & $.26 * \pi \star$ \\
\hline$x$ Passive & & $.15 *$ & & & & & & & $-.11 a$ \\
\hline $\begin{array}{l}\mathrm{a} \leq .10 \\
\mathrm{p} \leqslant .05\end{array}$ & $\begin{array}{l}.01 \\
.001\end{array}$ & $\mathbf{N}=$ & & & & & & & \\
\hline
\end{tabular}


Client Factor III (Direct)

Factor III is composed of the behaviors AGREE and DISAGREE. The service provider sees the individual displaying this pattern as being one who is at peace with him/herself, and neither hostile nor a chronic complainer.* The service provider also reports that the individual has good eyesight.

The service provider's description (specific attitudes) seem to be consistent with the "self-reliant" label given earlier in depicting a calm, self-assured manner; apparently neutral in emotional tone.

Client Factor IV (Negativistic)

"Negativistic" is a behavioral pattern that includes the behaviors CRITICIZE and SELF PUT DOWN. The service provider characterizes the individual displaying this pattern as not having a wealth of experience, and as being hostile, ungrateful, and overly demanding.

The hostility of this pattern was anticipated ("angry," "hostile") in the factor description given in Chapter IV.

\section{Client Factor V (Complaining)}

Factor V, composed of the behaviors PROBLEM DESCRIPTION and COMPLAIN, is correlated with service provider descriptions of an individual who does not have a positive outlook or a sense of humor. He/she is seen as angry and a chronic complainer. The individual exhibiting these behaviors is also described as fragile, and is (admittedly) disliked by the service provider. The definiteness of service provider opinion

*That the "Direct" individual is seen as being neither hostile nor complaining suggests that an assertive client can be well tolerated by most service providers when there is no hint of attack. 
TABLE XIII

CLIENT BEHAVIORAL FACTORS AND AGING AND AFFECT ITEMS AND SUMMARY SCALES

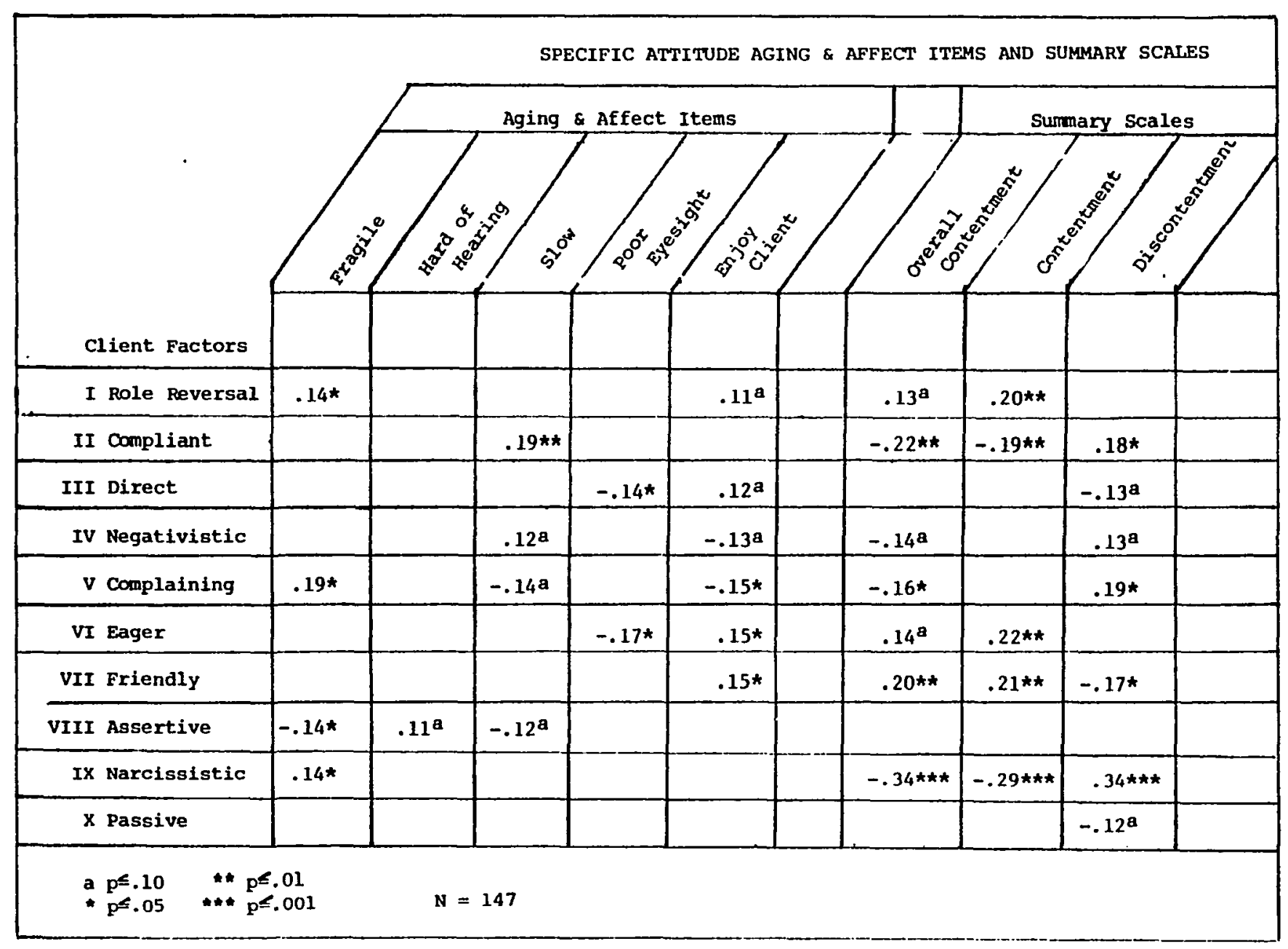


or attitude in this instance, is reflected in the summary scores as well. This factor correlates positively with the Discontentment scale and negatively with overall contentment.

The earlier analysis of the "complaining" factor led to the assumption that a client who exhibited these behaviors would be viewed with distaste by the service provider (see page 95).

\section{Client Factor VI (Eager)}

Service providers describe individuals with this behavior pattern (INTERRUPT, IAAUGH, and NERVOUS BEHAVIOR) as having a positive outlook, being at peace with themselves, having a sense of humor, and as being warm. They are not seen as being either angry or as having poor eyesight.

Service providers say they like this individual, and the sumary scale Contentment reflects the preponderance of positive designations. The behavior pattern alone had not been interpreted as having a positive impact ("active," "unsure," "ambivalent"). Possibly, the behaviors are interpreted by the service provider as being expressive of a desire to please.

\section{Client Factor VII (Friendly)}

The "Friendly" behavior pattern (HUMOR, LAUGH, ATTEND) is one correlated with service provider characterizations that include: positive outlook, at peace with self, dependable, has sense of humor, and is not angry or overly demanding.

The individual with this behavior pattern is, not surprisingly, liked. This was anticipated ("good-natured," "active," "joking"). The specific attitude summary scores indicate a negative correlation of 
this pattern with Discontentment, and positive correlations with both Contentment and overall Contentment scales.

\section{Client Factor VIII (Assertive)}

The eighth client factor (QUESTION, COMMAND, and NORMATIVE) is correlated positively with the service provider's report that such an individual has a wealth of experience, has interesting stories to tell, and is not fragile. There seems to be no particular designation of individuals behaving in this manner as having predominantly positive or negative characteristics. The pattern was described earlier as "independent," "able to take control."

\section{Client Factor IX (Narcissistic)}

In Chapter IV, this factor was described as a pattern "possibly indicative of an individual who does not make any attempt to accommodate to the needs of the other member of the dyad for even minimal interaction." It was not clear whether this was an intentional behavior pattern or merely reflected an inability to interact $(\mathrm{e} . \mathrm{g} .$, because of illness).

The service provider sees this behavior as hostile. The individual who displays these behaviors (NO RESPONSE, COMPLAIN, NOT TRACKING) is described by the service provider as uncooperative, someone who refuses to help him/herself, ungrateful, hostile, someone who has given up on life, angry, overly demanding, and a chronic complainer. They are further described as fragile, not having a positive outlook, no wealth of experience, not considerate, not appreciative, without interesting stories to tell, no sense of humor, and not warm. 
The summary scales are strongly correlated with this pattern: positively with Discontentment, negatively with both Contentment and overall Contentment (all at $\mathrm{p} \leq-001)$. The service provider clearly does not like "Narcissistic" behavior--it is the most aversive client behavior pattern in the sample.

Client Factor X (Passive)

The client displaying "Passive" behaviors (ATTEND, SMILE) elicits no positive descriptions from the service provider who depicts this individual as refusing to help him/herself, not having a positive outlook, does not have interesting stories to tell, and is not dependable. Surprisingly, the service provider on balance has neither positive nor negative attitudes toward the person with this behavior pattern. There are no significant relationships with the summary scales. The service provider characterizations were apparently of very low magnitude. The earlier designation of "exceedingly passive," seems fitting except that it does not also include what seems to be a mild disphoric quality.

\section{Client Factors: Summary}

The comparisons of (I) meanings assigned to the client factors in Chapter IV with (2) the service provider's perception of that same client, suggests that tentative generalizations about the interpersonal impact of those behaviors can be made from behavioral data alone. The added information gained from service provider specific attitudes does not alter the placement (interpersonal meaning) of client factors on the ICI profile wheel (see Figure 23). However, in half of the cases the service provider attitudes were important in assessing the intensity of a behavior pattern. 
The client behavioral factors can be viewed in an alternate, but not competing way, by placing the factors on a rough approachavoidance continuum (see Figure 24) using both sources on information. In general, there was agreement between factor "meanings" and service provider descriptions with increased confidence as either extreme of the continuum is reached. Five factors are neutral-to-positive (approach). All these client behavior patterns seem to be rather active. Those patterns which are, in addition, warm--are clearly preferred by service providers. The remaining five factors which are neutral-to-negative (avoid) in impact, had been weighted in an overly conservative manner in the interpretations assigned in Chapter IV. Several of these patterns provoked more powerful aversive reactions than had been anticipated. It is possible the clients exhibiting these patterns muted their behavior in the presence of the observer. This possibility brings to the fore a major limiting aspect of the client factors: they are based on only one observation.

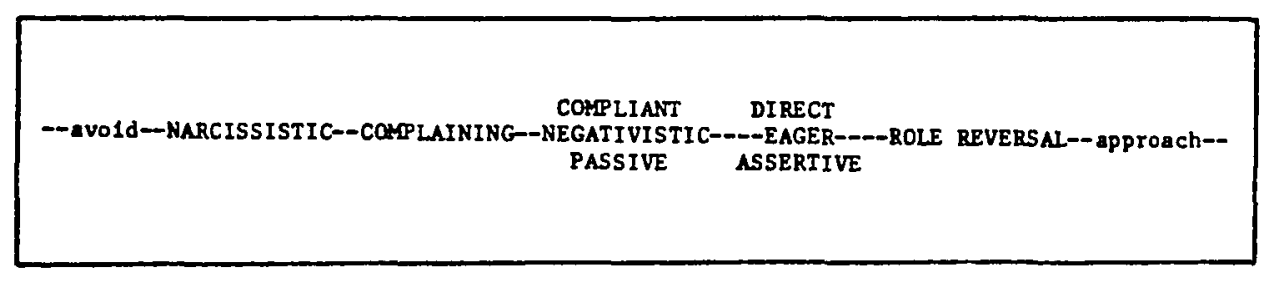

Figure 24. Client factors on an approach-avoidance continuum.

Another limitation of the client behavioral data is that it is not likely that the behavioral factors operate in isolation. Any given person probably exhibits more than one pattern. A consideration of persons which would take into account more than one pattern is an effort that would be interesting for future investigation. 
In summary, the correlations between client behavior and service provider descriptions (specific attitudes) are promising. Continuing with more sophisticated analyses of this sample, however, is probably not warrented since the single observation of each client is a serious limitation. Should additional sampling be done, moving toward the establishment of client profiles could enhance understanding of the service encounter. A conservative conclusion, regarding the SP/CDICS, would be that these findings do not reveal any major lacks in the code. A more optimistic interpretation is that the findings are supportive though hardly conclusive.

THE SERVICE PROVIDER FACTORS

Correlations were run between the five service provider factors ard a number of other variables to see if the descriptions of behavioral patterns that were derived from the internal relationships of discrete behaviors, would be meaningful when compared with other kinds of information related to the service provider: (1) the observer's estimate of whether or not the service provider had been respectful, or had over-serviced the client; (2) the client's evaluation of the service provider; (3) the service provider's general attitudes toward elderly clients-as-a-group, * (4) the service provider's personality as seen by the observer; and (5) the service provider's self-reported personality. Table XIV displays the significant correlations between service provider behavioral factors and (I) observer and client evaluations, and (2)

*The general attitude summary scales are derived in the same manner as the specific attitude summary scales. General Attitudes reflect the service provider's beliefs about or opinions of elderly clients-in-general, rather than adescription of a particular person. 
TABLE XIV

SERVICE PROVIDER BEHAVIORAL FACTORS CORRELATED WITH EVALUATIONS AND ATTITUDES

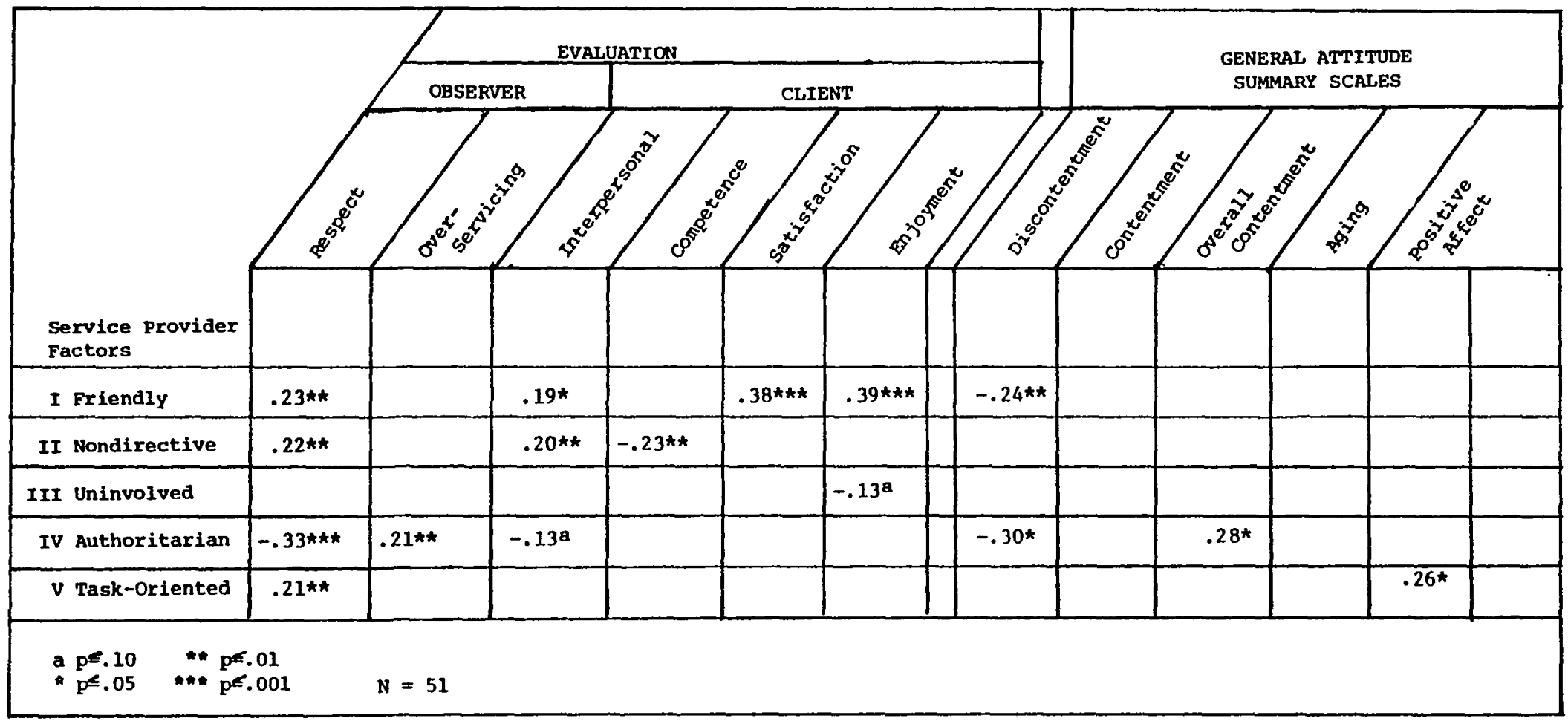


general attitudes. Table XV includes the significant correlations between service provider factors and observer/Public self (ICI-I) and Service Provider/Private Self (ICL-II) reports of personality. All relationships between factors and other variables which are discussed below reflect significant relationships unless otherwise noted.

\section{Service Provider Factor I (Friendly)}

The "Friendly" factor was described as a pattern which is "active," "friendly," "supportive," and permits "mutuality" between service provider and client. Observers judged that service providers expressing this pattern treated their clients with respect. Clients mentioned that they value the interpersonal aspects of relating with such a service provider, enjoy him/her, and are very satisfied with the overall service relationship. The pattern (SUPPORTIVE STATEMENT, IAUGH, COMPLAIN, and INTERRUPT) has a negative correlation with general attitudes that reflects negative beliefs (Discontentment) about elderly clients. The observer describes "Friendly" service providers as having a wide range of modes of relating (ICI-II scores). They are seen, by the observers, as being able to act cooperatively, nurturantly, and even at times, self-effacingly with clients. This orientation towards the needs of others is matched by the ability to also be directive and even agressive (businesslike) when appropriate. There are no correlations between this pattern and the service provider's self-description $(I C L-I I)$.

Service Provider Factor II (Nondirective)

A "Nondirective" behavioral pattern (ATTEND, -COMMAND, and -NORMATIVE) correlates, as did "Friendly," with the observer's estimate 
TABLE XV

SERVICE PROVIDER BEHAVIORAL FACTORS CORRELATIONS WITH PERSONALITY

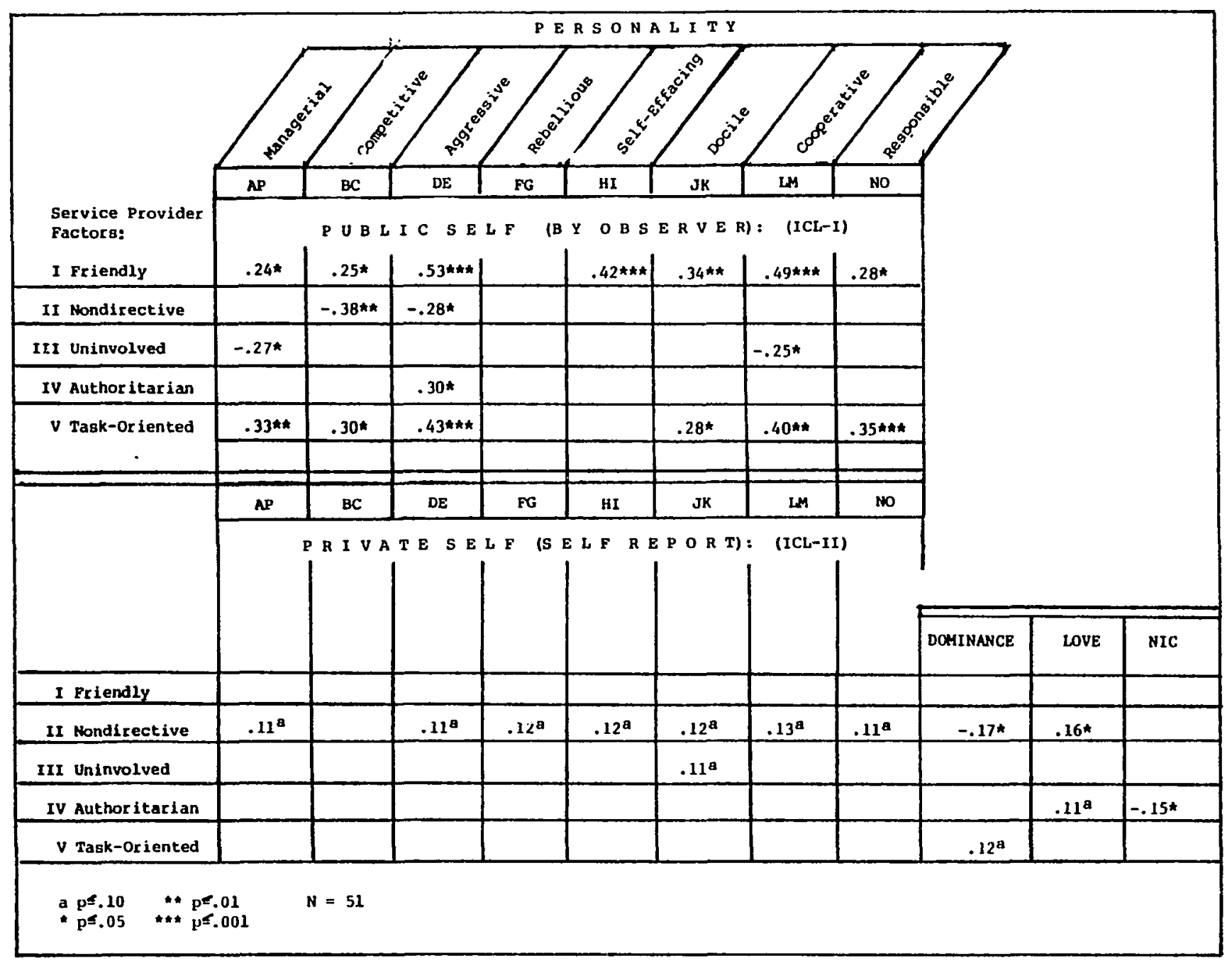


of a respectful manner toward the client. Clients mentioned liking the intexpersonal aspects of interacting with service providers displaying these behaviors. The "Nondirective" set of behaviors is negatively correlated with a client mentioning competence as being the thing they like about their service provider. The general attitudes of the service provider toward elderly clients do not correlate with this factor. Observers describe the personality of the "Nondirective" service provider as being one that is low in businesslike manner, and not aggressive. "Nondirective" service providers see themselves as being loving (warm) toward people and not dominant in personality.

Service Provider Factor III (Uninvolved)

The third factor, comprised of behaviors CIVILITY, -TALK, -AGREE, -NOT TRACKING, correlates significantly with no observer evaluations, no client evaluations, and no general attitudes. There is a tendency for clients to be dissatisfied with the service provider expressing "Uninvolved" behaviors, but this did not reach a significant level. observers describe the personality of the service provider exhibiting these behaviors as being low in managerial qualities and also low in cooperativeness. There are no significant correlations with selfdescribed personality; (one tendency $(p \leq .10)$ appeared with docile). The interpretation of this pattern as being one of disguise, a "poker face" response, seems particularly apt.

\section{Service Provider Factor IV (Authoritarian)}

The behavioral pattern (PARENTING, DISREGARD, and COMMAND) labeled "Authoritarian," correlates with the observer's estimate that such a service provider over-serviced the client and was not respectful. There 
is a tendency (but only that) for clients to omit any mention of positive interpersonal relationships with a service provider displaying "Authoritarian" behavior. The individuals exhibiting this behavior pattern express (the most) positive general attitudes regarding elderly clients and also deny negative descriptors. The observers interpret the "Authoritarian" pattern as being aggressive. No personality items in the self-description are significantly correlated with behavioral factors. It is interesting to note that service providers with "Authoritarian" behaviors endorse few items of any kind about themselves (NIC). This is perhaps, in indicator that they are reluctant to be selfrevealing. This pattern seems to express the motive of disguising negative attitudes through the means of being overly solicitous. While the Uninvolved pattern seems to express the lack of doing as little as possible to avoid revealing negative attitudes, the Authoritarian expresses the "reaction-formation" approach of protesting (and doing) too much as a cover or camouflage.

\section{Service Provider Factor V (Task-Oriented)}

The behaviors, QUESTION, PROBLEM DESCRIPTION, and INTERRUPT, comprise the fifth factor. The service provider exhibiting "Task-Oriented" behaviors is seen to be respectful toward the client, in the observer's opinion. No client evaluations are significantly correlated with this pattern. This pattern is significantly correlated with a liking for elderly clients in general. The observer's description of the personality of the service provider who is "Task-Oriented," is very like that for the "Friendly" pattern. The description differs, slightly, in that there is an absence of self-effacing kinds of behaviors, and a slight 
increased weighting of managerial qualities. No significant relationships are found between this factor and self-description (there is a tendency toward Dominance).

Service Provider Factors: Summary

The comparisons of (1) meanings attributed to the service provider factors with (2) five other kinds of data focused on the same individuals, is supportive of the assumption that the designed behavioral coding system taps important interpersonal variables. The multiple observations on each service provider possibly enhanced the preciseness with which the service provider's intexpersonal impact was described. It is also possible, however, that the service provider role allows for less variability in behavior and therefore is more easily "typed." The way observers and clients evaluate the service provider is not at variance and is suggestive that a trained observer could effectively function as an evaluator in settings where client satisfaction cannot be assessed directly (e.g., due to client incapacity). If this concordance can be refined through additional analyses, the resultant instrument could be very useful in improving services to elderly clients.

The service provider data seem good enough to recommend moving ahead to a consideration of multiple pattern combinations. A cluster analysis, not possible because of data limitations, would have produced this information. A possible alternative route is to construct individual profiles which give a score to each service provider on each of the five factors. This approach is under current investigation.

The correlations between the factors and ( 1 ) attitudes (general and specific), and (2) personality (private self and public self) 
indicate that more general qualities do not correlate, for the most part, with behavior expressed in this particular situation (the service encounter). This finding is consistent with a large body of research, reviewed by Stewart (1977), which indicates that behavior is best predicted by instruments that assess less general/more specific variables. Possibly, additional observations with the same service provider across more clients would reveal the more subtle relationships that exist between general qualities and behavior. Additional areas for future investigation are: (1) to examine additional variables (e.g., age, sex, education) that may relate to both service provider and client behavior; (2) examine the correlations between service provider and client behavioral patterns; (3) an analysis of the data which would consider sequences of behavior rather than simple totals--a treatment of the data which could elucidate "triggering" behaviors that begin aversive or pleasant interactions; and (4) replications are, of course, of interest and importance with any new instrument.

\section{CONCLUSIONS}

This research effort was begun with the aim of examining the features of service provision to the elderly at a crucial point: the face-to-face meeting of professional and client. The investigative strategy chosen to examine a set of such encounters, was that of naturalistic observation. A field observation coding system, the Service Provider/Client Dyadic Interaction Coding System (SP/CDICS), was devised to allow for the systematic collection of data in this real life situation. The data resulting from the 147 coded dyadic interactions were considered from two perspectives: first, the collected 
behavioral data were examined for recurrent behavior patterns and second, the derived patterns were compared to other variables associated vith the participants of the interactions.

It appears from the data that the SP/CDICS proved to be a reasonably effective instrument for use in the context for which it was designed. Recurrent patterns of behavior did emerge that appear to have meaning, i.e., the ten client and five service provider behavioral patterns that emerged seem to have predictable interpersonal impact. There are indications that the client role itself permits only (relatively) reactive--rather than proactive--behaviors. However, passivity may be accepted as the "proper" stance to an unnecessary degree by the individuals currently among the ranks of the elderly population (approximately the cohorts of 1890 to 1920). Service providers, however, definitely do not like very passive clients. They are drawn to elderly clients who are active rather than passive, and particularly like clients who are also friendly, warm persons. The preference for an active client and the dislike of passive (particularly passive-aggressive) individuals, suggests that encouraging elderly clients to be direct and assertive concerning their wants and needs, would be beneficial at a number of levels. Since many clients are passive, techniques for eliciting more direct behaviors from this kind of client may well be a useful skill to include in service provider training.

While elderly clients do not complain about a service provider as long as he or she is competent in his or her most professional tasks, they clearly appreciate and prefer a service provider who has more than a businesslike, strictly professional relationship with them. There was 
no indication that elderly clients were "disengaging" and, therefore, not seeking personal attachments. The situation appears to be quite the opposite and, therefore, the regular rotation of staff seems not to be advisable. The slow building of a personal, mutual feeling between service provider and client requires continuity. Moving closer to a peer/friend interaction may well allow the elderly client to feel that a more assertive stance is permissible--a situation that seems to be preferred by both service provider and client.

The slight and very subtle relationships between general attitudes and behavior, and self-reported personality and behavior, are disappointing although not unexpected. This finding suggests that there is no easy, inexpensive substitute for the time-consuming procedure of observing behavior in the setting in which it is to occur. With such small relationships between general measures and behavior, it seems clear that neither an attitude questionnaire such as the General Attitude Survey nor a personality measure such as the Interpersonal checklist can be used to select service providers to work with the elderly. There is a suggestion in the data, however, that very positive expressions of attitude accompany an "authoritarian" interpersonal style which does not accord the client respect and possibly even undermines self-sufficiency through over-servicing. An agency director would be well advised to be wary of individuals professing unusually positive orientation.

The difficulties of predicting behavior from more general instruments would indicate that refinement of the SP/CDICS would be a worthwhile task. Revisions that could possibly make the coding system 
smaller and easier to learn by using only those behavioral categories that appeared in the factors, is one possible direction to take. (The efforts involved in cross-validation of the instrument would, of course, be also necessary.

An examination of two different task-orientations (In-Home Nursing and Interaction outreach Services) revealed the potent effects of context and confirms the widely-held assumption that setting or context determines behavior to a large extent. Consequently, the SP/CDICS should not be used in settings other than those for which it was intended without (probably extensive) revisions. The reasonably close parallels between client and observer evaluations of the encounter raises the hope that well-trained observers could effectively be used in situations such as nursing homes where client satisfaction may not be easily obtained. For this reason, further research design to adjust the SP/CDICS for observations in additional settings is recommended.

Additional areas for future investigation are: (I) to examine other variables (e.g., age, sex, education) that may relate to both service provider and client behavior; (2) examine the correlations between service provider and client behavioral patterns for a better understanding of the interaction; (3) an analysis of the data which would consider sequences of behavior rather than simple totals--a treatment of the data which could elucidate "triggering" behaviors that begin aversive and/or pleasant interactions; and (4) the replications that are, of course, of interest and importance with any new instrument. 


\section{BIBLIOGRAPHY}

Administration on Aging. Guidelines for preparation of grant applications: Research and development projects in aging, Title IV-B of the Older American Act. Washington, D.C.: Department of Health, Education, and Welfare, 1976.

Argyle, M. The concepts of role and status. Sociological Review, $1952,44,39-52$.

Argyle, M. The scientific study of social behavior. London: Methuen and Co. Ltd., 1957.

Bakan, D. On Method: Toward a reconstruction of psychological investigation. San Francisco: Jossey-Bass, 1967.

Bales, R., Hare, A., \& Borgatta, E. (Eds.). Small groups: Studies in social interaction. New York: Knopf Publishing, 1965.

Barker, R. The stream of behavior. New York: Appleton-Century Crofts, 1963.

Barker, R. (Ed.). Ecological psychology: Concepts and method for studying the environment of human behavior. Stanford, California: Stanford University Press, 1969.

Behn, J. Characteristics of service providers. Unpublished working paper. Portland, Oregon: Portland State University, Institute on Aging, 1977.

Behn, J. Dyadic behaviors. Unpublished working paper. Portland, Oregon: Portland State University, Institute on Aging, 1978.

Behn, J. \& Levkoff, s. Observer training tape. Video-tape, in author's library. 1978.

Behrend, H. Absence under full employment. Birmingham, England: University of Birmingham Press, 1951.

Bell, D. The coming of the post-industrial society: A venture in social forecasting. New York: Basic Books, 1973.

Birren, J. (Ed.). Handbook of aging and the individual. Chicago: University of Chicago Press, 1959.

Brandt, R. Studying behavior in natural settings. New York: Holt, Rinehart \& Winston, 1972. 
Bronfenbrenner, $U$. Toward an experimental ecology of human development. American Psychologist, 1977, 32, 513-531.

Bross, N. Client satisfaction. Unpublished working paper. Portland, Oregon, Portland State University, Institute on Aging, 1977.

Brown, R. Social psychology. New York: The Free Press, 1965.

Busse, E. \& Pfeiffer, E. (Eds.). Mental illness in late life. Washington, D.C.: American Psychiatric Association, 1973.

Butler, R. \& Lewis, M. Aging and mental health. St. Louis: Mosbey Press, 1978.

Caldwell, B. A new 'approach' to behavioral ecology. In J. P. Hull (Ed.), Minnesota Symposia on Child Psychology, Vol. 2. Minneapolis: University of Minnesota Press, 1969.

Darling, F. A herd of red deer. New York: Oxford University Press, 1937.

Eibl-Eibesfeld, I. Ethology: The biology of behavior. New York: Holt, Rinehart \& Winston, 1975.

Employee Aptitude Survey Manual. Los Angeles, California: Psychological Services, Inc., 1963.

Fisher, D. Growing old in America. New York: Oxford University Press, 1978.

Gartner, A. \& Riessman, F. The service society and the consumer vanguard. New York: Harper \& Row, Publishers, 1974.

Gesell, A. Infant and child in the culture of today. New York: Harper \& Brothers, Publishers, 1943.

Goffman, E. Asylums: Essays on the social situations of mental patients. Chicago: Aldine Publishing Company, 1970.

Hall, E. The silent language. Connecticut: Fawcett Publishing, Inc., 1959 .

Harrell, T. Industrial psychology. New York: Rinehart Publishing, 1949.

Hendricks, J. \& Hendricks, D. Aging in mass society: Myths and realities. Cambridge, Massachusetts: Winthrop Publishing, Inc., 1977.

Henley, N. Body politics. Englewood Cliffs, New Jersey: PrenticeHall, Inc., 1977. 
Herbert, J. \& Attridge, C. A guide for the developers and users of observation systems and manuals. American Educational Research Journal, 1975, 12, 1-20.

Hutt, S. \& Hutt, C. Direct observation and measurement of behavior. Illinois: Charles C. Thomas, Publishers, 1970. (a)

Hutt, S. \& Hutt, C. Behavior studies in psychiatry. Oxford, England: Pergammon Press Ltd., 1970. (b)

Institute on Aging. Attitudes toward older persons on the part of service delivery professionals. Grant proposal. Portland, Oregon: Portland State University, 1976.

Ivey, A. Microcounseling. Illinois: Charles C. Thomas, Publishers, 1971.

Jennings, R. Proxemics. Unpublished working paper. Portland, Oregon: Portland State University, Institute on Aging, 1977.

Jones, R., Reid, J., \& Patterson, G. Naturalistic observation in clinical assessment. In McReynolds (Ed.), Advances in clinical assessment. San Francisco: Jossey-Bass, Inc., 1975.

Kaufman, I. \& Rosenblum, I. A behavioral taxonomy for $M$. nemestrina and $M$. radicata. Primates, 1966, I, 205-258.

Leary, T. Interpersonal diagnosis of personality. New York: The Ronald Press, 1957.

Levkoff, S. \& Northrup, L. Interviews with elderly clients. Unpublished working paper. Portland, Oregon: Portland State University, Institute on Aging, 1977.

Lorenz, K. Methods and approach to the problems of behavior. The Harvey Lectures (1958-59). New York: Academic Press, 1960, $60-103$.

Mussen, P. Handbook of research methods in child development. New York: Wiley \& Sons, 1960.

McGrew, W. Glossary of motor patterns of four-year-old nursery school children. In S.J. Hutt \& C. Hutt, Direct observation and measurement of behavior. Illinois: Charles C. Thomas, Publishers, 1970.

Mehrabian, A. Nonverbal communication. Chicago: Aldine-Atherton Publishing, 1972.

Nelson, G., Masada, M., \& Holmes, T. Correlation of behavior and catecholamine metabolite extration. Psychosomatic Medicine, $1966,28,216-226$. 
Patterson, G., Ray, R., Shaw, D., \& Cobb, J. A manual for coding of family interactions. Document \#01234. Eugene, Oregon: Oregon Research Institute, 1969.

Patterson, G. Some procedures for assessing changes in marital interaction. Eugene, Oregon: Oregon Research Institute Bulletin, $\underline{16}(7), 1976$.

Patterson, G. Personal communication. Author's visit to Oregon Social Learning Center, Eugene, Oregon, 1977. (a)

Patterson, G. Naturalistic observation in clinical assessment. Journal of Abnormal Child Psychology, 1977 (b), 5(3), 68-73.

Proshansky, H. (Ed.). Environmental psychology. New York: Holt, Rinehart \& Winston, 1969.

Raush, H. Research, practice, and accountability. American Psychologist, $1974, \underline{29}(9), 678-681$.

Romaniuk, M., Hoyer, F., \& Romaniuk, J. Helpless self-attitudes of the elderly: The effect of patronizing statements. Paper presented at the Annual Meeting of the Gerontological Society, San Francisco, 1977.

Sackett, G. (Ed.). Observing behavior, Vol. 2. Baltimore, Maryland: University Park Press, 1978.

Sarbin, T. Role theory. In G. Lindzey (Ed.), Handbook of social psychology. Cambridge, Massachusetts: Addison-Wesley, 1954.

Sells, S. Ecology and the science of psychology. In E. P. Willems \& H. L. Raush, Naturalistic viewpoints in psychological research. New York: Holt, Rinehart \& Winston, 1969.

Sommer, R. Personal space. New Jersey: Prentice-Hall, Inc., 1969.

Stader, R. The dynamics of behavior-contingent physical systems. In H. M. Proshansky (Ed.), EnvironmentaI psychology. New York: Holt, Rinehart \& Winston, 1969.

Stewart, B. Attitudes and behavior. Unpublished working paper. Portland, Oregon: Portland State University, Institute on Aging, 1977.

Stogdill, R. Patterns of leadership behavior. Journal of Psychology, $1953,25,35-71$.

Sudnow, D. Passing-on. New Jersey: Prentice-Hall, 1967.

Sullivan, H. The interpersonal theory of psychiatry. New York: W.W. Norton \& Company, Inc., 1953. 
Tinbergen, N. Curious naturalists. New York: Doubleday \& Company, Inc., 1958.

Tinbergen, N. On aims and methods of ethology. Zeitschrift Fuer Tierpsychologie, 1963, 20, 410-433.

U.S. Government. Census of population: 1970 (general population characteristics). Washington, D.C.: U.S. Government Printing Office, 1972 .

Webb, E. (Ed.). Unobtrusive methods. Chicago: Rand McNally \& Company, 1966.

Whyte, w. Human relations in the restaurant industry, New York: MCGraw-Hill, 1948.

Willems, E. Naturalistic method and the clinical approach. In E. P. Willems \& H. L. Raush (Eds.), Naturalistic viewpoints in psychological research. New York: Holt, Rinehart \& Winston, 1969.

Willems, E. \& Raush, H. Naturalistic viewpoints in psychological research. New York: Holt, Rinehart \& Winston, 1969.

Wolfe, K. Geratric psychiatry. Illinois: Charles C. Thomas, Publishers, 1963.

Wrench, D. Psychology: A social approach. New York: McGraw-Hill Book Company, 1969.

Young, M. \& Willmott, P. Family and kinship in East London. England: Penguin Books, 1962. 
APPENDIX A

CODER'S FIEID MANUAL

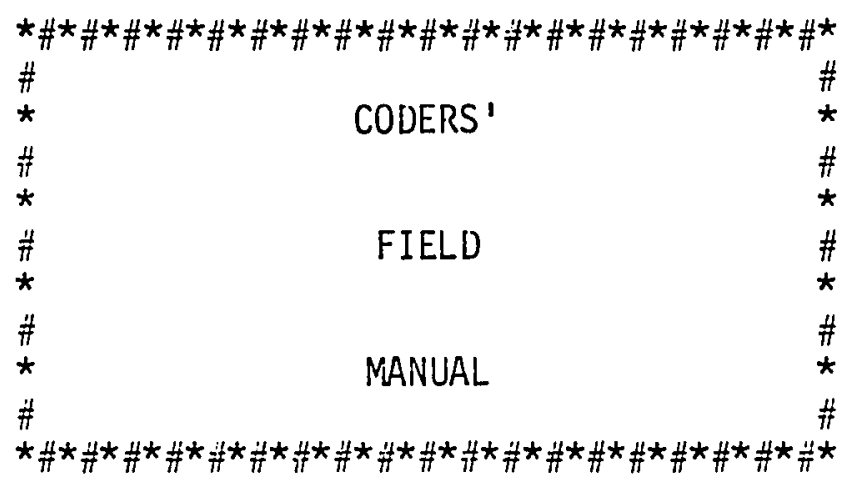

Data Collection Version

CAUTIONARY NOTE: This manual is not intended for use except in conjunction with a set of video-tapes that further assist observers with definitions, examples, and controlled experience.

Institute on Aging

May 16, 1978 


\section{TABLE OF CONTENTS}

1. AGREE

2. DISAGREE

3. ASSENT/TRACKING

4. NOT TRACKING

5. COMPLIANCE

6. NONCOMPLIANCE

7. COMMAND/REQUEST

8. COMPLAIN

9. CRITICIZE (Put Down)

10. CIVILITY

11. DISREGARD

12. HUMOR

13. INTERRUPT

14. LAUGH

15. NERVOUS BEHAVIOR

16. NORMATIVE

17. NO RESPONSE

18. PARENTING

19. PROBLEM DESCRIPTION

20. POSITIVE PHYSICAL

21. PROPOSED SOLUTION

22. QUESTION

23. SMILE

24. SELF PUT DOWN

25. SUPPORTIVE STATEMENT

26. TALK

27. VOLUNTEER HELP

28. SELF/SUPPORTIVE STATE
AG $\quad 1$

DG 2

AT 3

NT 4

CO 5

NC 6

CM 7

CP 8

CR 10

CV 11

DR 12

HM 13

IN 14

LA 15

NB $\quad 16$

NO 17

NR 18

PA 19

PD 21

PP 23

PS 24

QU 26

SM 27

SP 28

SS 29

TA 30

Vo 31

S/SS 32


AG-AGREE

Affirmative response which occurs when one person expresses an opinion and the other person's response indicates agreement, or acceptance of their interpretation.

Affirmative response can be verbal or non-verbal.

Response can occur after a long or short pause, while other speaker is speaking, or at the end of a sentence.

\section{EXAMPLES}

I think we have a problem getting there in the rain. Don't you?

Yes, I do. (AG)

I know there must be a better way to do this. (PD) Your're right.

You should go to the Social Security Office before the first. (PA) Yes, I know I should. (AG)

I think you would be better off to stay at home in this rainy weather. You're right. (AG)

NOT TO BE COINFUSED WITH:

AT-- ATTEHD

TA-- TALK

I was going to come in...(PD) YES...(AT)

Hould you please bring your medicare card in when you come to the office. (CM/QU) Yes, I will. (TA)

Did you already speak with a counselor here? (QU) Yes, I did, yesterday. (TA) 


\section{$\underline{\text { DG--DISAGREE }}$}

Statement in which one person expresses an opinion and the other person's response indicates disagreement.

Can be headshaking if clearly meant for disagreement and with no intention of criticizing.

Often occurs after a QUESTION, TALK, PROBLEM DESCRIPTION, PROPOSE SOLUTION, OR CRITICIZE.

\section{EXAMPLES}

I think you must be having problems understanding your doctor. Don't you? (PD/QU) No, I don't think so. (DG)

Don't you think it's time to go home now? (QU/PS) lio, not yet.

I didn't come too early, did I? (QU) Yes, you did. (DG)

You never see me on time. (CR) Yes, I do. (DG)

HOT TU BE COINUSED WITH

TA--TALK

CR--CRITICIZE

Did I come too early today? (QU) Yes, a little bit. (TA)

Did I come too early? (QU) Yes, you could call two hours a bit early. (CR) 


\section{AT--ATTEND}

Non-verbal behavior which occurs when one person is speaking and the 1 istener is maintaining eye contact and general orientation toward the speaker: Code AT for the listener.

Brief verbal or non-verbal response emitted by 1 istener while speaker is speaking or during a pause in speech.

Responses indicating that the speaker's comments are being listened to (not to indicate agreement with the content of the speaker's comments).

Statements where listener repeats short versions of the other's statements, often to facilitate the conversation (paraphrasing).

Responses are made in a neutral or positive tone of voice.

\section{EXAIPLES}

head nods (AT) (if made while speaker is speaking to indicate that the listener is following what is being said.)

uh huh

yeah

Imm

HOT TO BE COIFUSED WITH

AG--AGREE

TA--TALK

I think you did a good job! (SS) Yes, I did. (AG)

Can you come in tomorrow? (QU) Yes, that's ok. (TA) 


\section{NT--NOT TRACKING}

Non-verbal behavior.

When a listener doesn't maintain eye contact with the speaker for more than 3 seconds, code NT for "listeners."

Do not code NT for speaker, even if he/she looks away from the listener for more than 3 seconds.

\section{EXAMPLES}

You look so nice today, Mrs. J., and by the way I found out about your checks. You should be getting them starting this next month. (CV/PD) [If listener looks away for 3 seconds or more while speaker is talking, code NT for listener.]

NOT TO BE CONFUSED WITH

NR--NO RESPONSE

Do you want me to speak to the aide for you? (QU/VO) [...at least 3 seconds wi thout a reply...(NR)] 
CO--COMPLIANCE

Coded when a person's behavior fulfills the requirements of an immediately preceding command/request within 30 seconds. This behavior can be verbal, indicating the person intends to comply.

Often double-coded with appropriate response.

\section{EXAMPLES}

Why don't you go and sit over there? (CM/QU) [If person does over and sits down, code CO.]

Please, come and sit here. (CM/CV) Thank you. [Person does go and sit down.] (CO/CV)

Be sure to call the social security office to find out about that. (Cii) I will do it this afternoon. (CO)

NOT TO BE CONFUSED WITH

AG--AGREE

You ought to balance your checkbook. (PA) I know I should. (AG) 


\section{NC--NON COMPLY}

Code when a person's behavior does not fulfill the requirements of an immediately preceding command/request within 30 seconds. This behavior can be verbal, indicating the person does not intent to comply.

Often double coded with the appropriate code for the noncomplying behavior of the other person.

\section{EXAMPLES}

Why don't you go sit over there? (CM/QU) [If person doesn't go and sit, code $(N C)$.]

Tell the aide not to use so many towels. (CM)

No, I can't talk to her. (NC/PD) 


\section{CM--COMMAND/REQUEST}

Statement of request for an action usually followed by a COMPLY or NON COMPLY (within 30 seconds) on the part of the other person.

Statement can be delivered as an imperative.

If delivered in a hostile, irritated way, double-code with CRITIZE: $\mathrm{CM} / \mathrm{CR}$.

If delivered with a thank you, please, etc., double-code with CIVILITY: $\mathrm{CM} / \mathrm{CV}$.

"I want you to" statements and "let me..." statements are coded: CM.

\section{EXAMPLES}

Come here and sit down. (CM)

Would you sit over here and wait? (QU/CM)

Come and do this... if you can. (CM/CR)

Please, have a seat and wait til someone can see you. (CM/CV)

I want you to be here by $12: 00$. (CM)

Let me have the forms. (CM) 


\section{CP--COMPLAIN}

Statements where person bemoans the extent of his/her suffering.

Statements which don't explicitly blame the other person or themselves for their suffering.

At-large statements of dissatisfaction.

Statements expressing feelings of being deprived, wronged, or inconvenienced either through someone else's action or because of external circums tances.

Statement doesn't propose any solutions.

Statement may be delivered in a hurt, irritated, or whining voice.

\section{EXAMPLES}

Everything is so miserable, I could just cry. (CP)

I wish I weren't so poor. (CP)

I always get the raw end of the deal. (CP)

If I didn't do it, it wouldn't get done. (CP)

Who wouldn't be miserable, naving to live with a husband/wife like mine. (CP)

NOT TO BE CONFUSED WITH

CR--CRITICIZE

SP--SELF PUT DOWN

PD--PROBLEII DESCRIPTIOIN 
CP--COAPLAIN (Continued)

You really made me feel terrible when I came in yesterday. (CR)

You sure know how to make a person fee] good [sarcastic tone]. (CR)

I really shouldn't go out looking like this. (SP)

Yesterday my mother was getting angrier and angrier ajout my not being home [neutral tone of voice]. (PD) 


\section{CR--CRITICIZE}

Hostile statements expressing dislike or disapproval with a behavior, attitude, or generalized trait of the other person.

Unkind comments meant to demean, insult, embarrass, or hurt the other person; or non-verbal indicators of a demeaning nature such as an exasperated sigh.

Any proposal for change made in an irritated or hostile way.

Statements can be made in a neutral or sarcastic tone of voice.

\section{EXAMPLES}

You are never here on time. (CR)

You can't do anything right. (CR)

When are you going to start taking care of yourself? (Sarcastic tone) (QU/CR)

Grimaces, exasperated sighs, rolling eyes upward, shaking head in disgust. (CR)

\section{NOT TO BE CONFUSED WITH}

CP--COMPLAIN

PD--PROBLEM DISCRIPTION

I get so nervous and uncomfortable when my mother is around [whining]. (CP)

I find it hard trying to get my family to see that I want to stay home instead of going to that nursing home. (PD)

I forgot my medicine again. (PD) [Exasperated sigh.] (CR) 


\section{CV--CIVILITY}

Simple statements of thanks. Compliments.

Statements of Hello/Goodbye.

Excuse me statements, if not spoken in a self-demeaning way.

Statements spoken in a friendly or neutral tone of voice.

\section{EXAMPLES}

Thanks for the cookies you made me. (CV)

I like the dress you're wearing today. (CV)

Sorry, I didn't mean to bump into you. (CV)

He110, Irs. J., what can I do for you today? (CV/VO)

Goodbye. Have a good day. (CV)

NOT TO BE COHFUSEU WITH

SS--SUPPORTIVE STATEMEITT

SP--SELF PUT DOWN

It was nice of you to think of calling me at home.

I like it when you call me by my real name. (SS)

I think it's great that you're always here on time. (SS)

I'm sorry I bumped into you. I'm just so clumsy. (SP)

I really am a stupid person. (SP) 
DR--UISREGARD

Any behavior that appears to be dehumanizing or objectifying of the other person.

Assumptions that the other person is nonfunctioning or incompetent, in excess of the actual (apparent) situation.

Talking or making judgments about the other person without including them in the evaluation.

Ignoring or disregarding the intent or content of a communication from the other person.

Often used as a double-code, a qualifier of other reactions.

\section{EXAMPLES}

The skin looks better, the sheep skin must be making it feel better. (DR)

You should take your medicine more often, I don't think you feel well. (PA/DR)

My medication isn't taking care of the problem. (PD) Oh, you're just impatient. (DR) 
HM--HUMOR

Statements clearly intended to be humorous and usually lighthearted in tone.

Mild and gentle teasing, not to be coded if at all humiliating or critical.

Statements which propose facetious solutions to problems.

Often double-coded with LAUGH.

\section{EXAMPLES}

We could have taken a canoe to work today, it was raining so hard. (HM)

You are a card! (HM) 


\section{IIN--INTERRUPT}

Action taken to disrupt the continuity of ongoing activity.

Breaking into or in upon another person's train of thought, speech, or behavior.

Intrusion may be an attempt to maintain contact (usually initiated by the client), an attempt to gain access to an activity (usually to the conversation), or may be an effort to redirect the conversation or activity of the other person. 


\section{LA--LAUGHI}

Coded for each separate occurrence of a laugh.

Often double-coded with HUMOR, SMILE, or SELF PUT DOWN.

\section{EXAMPLES}

I was yoing to take a boat to work today [Laugh]... it was raining so hard. (LA/HM)

I'm just stupid [Laugh]. (SP/LA) 


\section{HB--NERVOUS BEHAVIOR}

Non-verbal behavior.

Coded for any behaviors which seem urmatural or abnormal.

Often double-coded with a verbal response.

\section{EXAMPLES}

Scratching

Tics

Leg swings

Holding arms tightly folded

Posture directed away

\section{HOT TO BE CONFUSED WITH}

DG--DISAGREE

CR--CRITICIZE

You have had a heart problem, haven't you? (PD/QU) [Headshaking to indicate No.] (DG)

Please, give me your telephone number again. (CV/CM) [Eyes roll away.] (CR) 
NO--NORMATIVE

Non-verbal behavior that is appropriate to the task at hand.

Verbal Dehavior thus coded includes the reading out loud of forms, applications, or generalized questioning from a form.

\section{EXAMPLES}

Filling out forms, writing, reading out loud. (NO)

Reading silentry. (NO)

Touching that is required as a task of one's job, i.e., taking blood pressure, pulse. (1NO)

INUT TO BE COIJFUSED WITH

TA--TALK

QU--QUESTIOIN 


\section{WR--INO RESPOINSE}

Coded when a verbal response is clearly called for from one person, and there is none for at least 3 seconds.

Coded when person $A$ asks person $B$ a direct question and $B$ doesn' $t$ respond. Code IIR for $B$.

Coded when both people stop talking in the middle of a discussion for longer than 3 seconds. Code IIR for both persons.

\section{EXAMPLES}

When will you get your check? (QU) $[\ldots 3$ seconds...] (NR)

I can go today to get it for you. (PS) $[\ldots 3$ seconds...] (INR)

Wo, let's go tomorrow. (DG/PS) $[\ldots 3$ seconds...] (NR)

$[\ldots 3$ seconds... $]$ (NR) 


\section{PA--PARENTING}

Statements where speaker addresses listener as a child (use of words like dear, honey).

Statements that foster dependence and helplessness.

Moralizing statements as in should, must, ought, always, can't, never, bad, like, let's, we could.

Tone of voice can be neutral or friendly. May be condescending, as one would speak to a child, but not openly critical.

\section{EXAMPLES}

Dear, you did such a good job getting up those steps. (PA/SS)

You mean that you don't want to talk to me? (cajoling tone) (PA/QU)

Now, let me do that for you. (PA/VO)

Now, you know how to do that, sweetie. (PA)

I'm proud of you. You did such a good job today. (PA/SS)

I wish you would eat better. (PA/PS)

I don't think you should do that. (PA/PS)

You shouldn't get yourself all riled up. (PA)

Let's go eat now. (PA/PS) 
PA--PARENTING (Continued)

NOT TO BE CONFUSED WITH

VO--VOLUNTEER HELP

SS--SUPPORTIVE STATEMENT

CR--CRITICIZE

Can I help you get up? (QU/VO)

You put a lot of effort into that. (SS)

You sure do know how to make a person feel good. (Sarcastic) (CR)

You know it's not a good idea to be late for your appointments. $(\mathrm{PA} / \overline{\mathrm{CE}})$ 


\section{PD--PROBLEM DESCRIPTION}

Statement describing present problem.

Statement of clarification, often describing past problems--explaining, elaborating.

Statements must be said in neutral tone of voice. If whining tone, double-code with COMPLAIN.

Statement can be vague or specific but at the same time must refer to a recognizable problem.

\section{EXAMPLES}

I am having difficulty with my medication. (PD)

Would you consider your living situation to be one of the reasons you've been depressed? (QU/PD)

Last week I was having some difficulty with getting up and about by myself. (PD)

INOT TO BE CONFUSED WITH

CP--COMPLAINT

CR--CRITICIZE

PS--PROPOSED SOLUTION 
PD--PROBLEM DESCRIPTION (Continued)

I really do seem to have my share of problems when it comes to regulating my medication. ( $P D / C P$ )

You really have not helped me out with deciding whether I should stay here or go into a home. (CR/PD)

You get me so upset when you talk to me like that. (CR)

We can change your medication so it will bother you less. (PS) 


\section{PP--POSITIVE PHYSICAL CONTACT}

Any positive physical contact which is not w0 (Normative) or required by the tasks of the situation.

Any time any person touches the other in a friendly or affectionate manner.

\section{EXAMPLES}

You sure did a good job. (SS/PP) [Speaker pats 1istener on back.] 


\section{PS--PROPOSED SOLUTION}

Statement where person describes somethings s/he wishes the other person to do or not to do.

Advise, inform, teach statements--or any elaboration on advising, informing, teaching.

Statements where person suggests, indicates, attempts to persuade the other person of something.

Doesn't require specific and immediate behavior.

Said in a neutral or friendiy tone of voice.

\section{EXAMPLES}

Why don't you go home and come back when you feel better? (PS/QU)

Taking a friend with you would make you feel more comfortable. (PS)

This is how to do it. (PS)

I could arrange for you to come back tomorrow. (PS)

NOT TO BE CONFUSED WITH

PA--PARENTING

CR--CRITICIZE

LA--LAUGH

CM--COMMAND/REQUEST 


\section{PS--PROPOSED SOLUTION (Continued)}

You should eat a hot lunch. (PA)

You really ought to have been here on time. (CR)

You should have worn a wet suit today, there's so much rain. (HM)

Think about it and come back tomorrow. (CM) 


\section{QU--QUESTION}

Any statement phrased as a question.

Often double-coded with (PD), (PS), and (CR).

\section{EXAMPLES}

Where are you going? (QU)

Is your difficulty in getting up the steps? (QU/PD)

Would you feel better talking to your daughter first? (QU/PS)

Why do you always make things so difficult? (QU/CR) 
SP--SELF PUT DOWIN

Statements which are negative evaluations or criticisms of one's own behavior, appearance, or characteristics.

Defeatist self-evaluations.

Apologetic statements said in a self-abasing way.

EXAMPLES

I can't do anything right. (SP)

ilo matter what I do, it is all wrong. (SP)

HOT TO BE CONFUSED WITH

CV--CIVILITY

CR--CRITICIZE

CP--COHPLAIN

I'm sorry to be late again. (CV)

You really never do anything right. (CR)

I'm so unhappy. (CP) 


\section{SM--SMILE}

Coded for each separate occurrence of a smile.

Often double-coded with HUMOR, CIVILITY, NERVOUS BEHAVIOR.

\section{EXAMPLES}

I'm glad to see you today [smile]. (CV/SM)

Will you talk to your daughter? (QU/PS) I don't want to see my daughter about that aga in [smile, scratching]. (DG/NB/SM) 


\section{SS--SUPPORTIVE STATEMENT}

Statement which indicates that the respondent personally favors something the other has said or done (does not include praising someone outside the immediate dyad).

Statements which recognize that the other has performed a desired behavior if made in a way to express approval.

Can refer to past, present, or future actions.

Can be double-coded with (PA) for statements that include both partners in the approval statement.

Code S/SS when the statement is applied to oneself.

\section{EXAMPLES}

I really like what you're doing. (SS)

You handled it beautifuliy, although you may have been upset.

We have really accomplished a lot today. (PA/SS)

That's a good idea. (SS)

Yes, you've got the jist of it. (SS)

I really do like the way you do things. (SS)

Great! (SS)

I really did it right this time. (S/SS)

NOT TO BE CONFUSED WITH

CV--CIVILITY

Thanks for the visit. (CV) 


\section{TA--TALK}

Simple yes/no responses where no opinion or agreement is indicated. Head shaking if meant to indicate yes/no responses. Responses that do not fit into any other verbal category. If coder does not understand what is being said, code TA.

\section{EXAMPLES}

Is it raining today? (QU) No, it isn't. (TA)

My daughter came to visit last week. (TA) 
Same definition as SS, except the statements are applied to oneself.

\section{EXAMPLES}

I think I did that pretty well. (S/SS) 
1. THE CLIENT YOU JUST SPOKE WITH:

a. has a positive outlook on life.......

b. is fragile........................

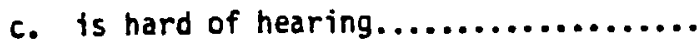

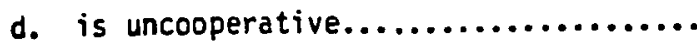

e. has a wealth of experience...........

f. refuses to help herself/himself.......

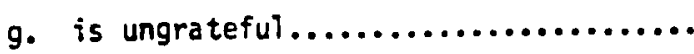

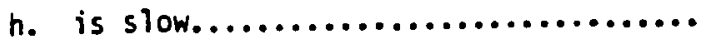

i. is considerate...................

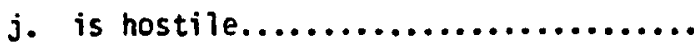

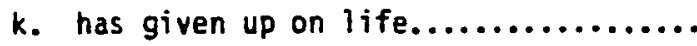

1 . is at peace with herself or himself...

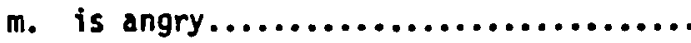

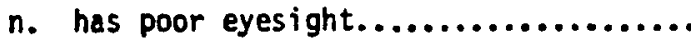

o. is appreciative of your services......

p. is overly demanding.................

q. has interesting stories to tell......

r. has serious emotional problems........

5. ts dependable......................

t. has a sense of humor

u. is a chronic complainer.

v. Is warm.

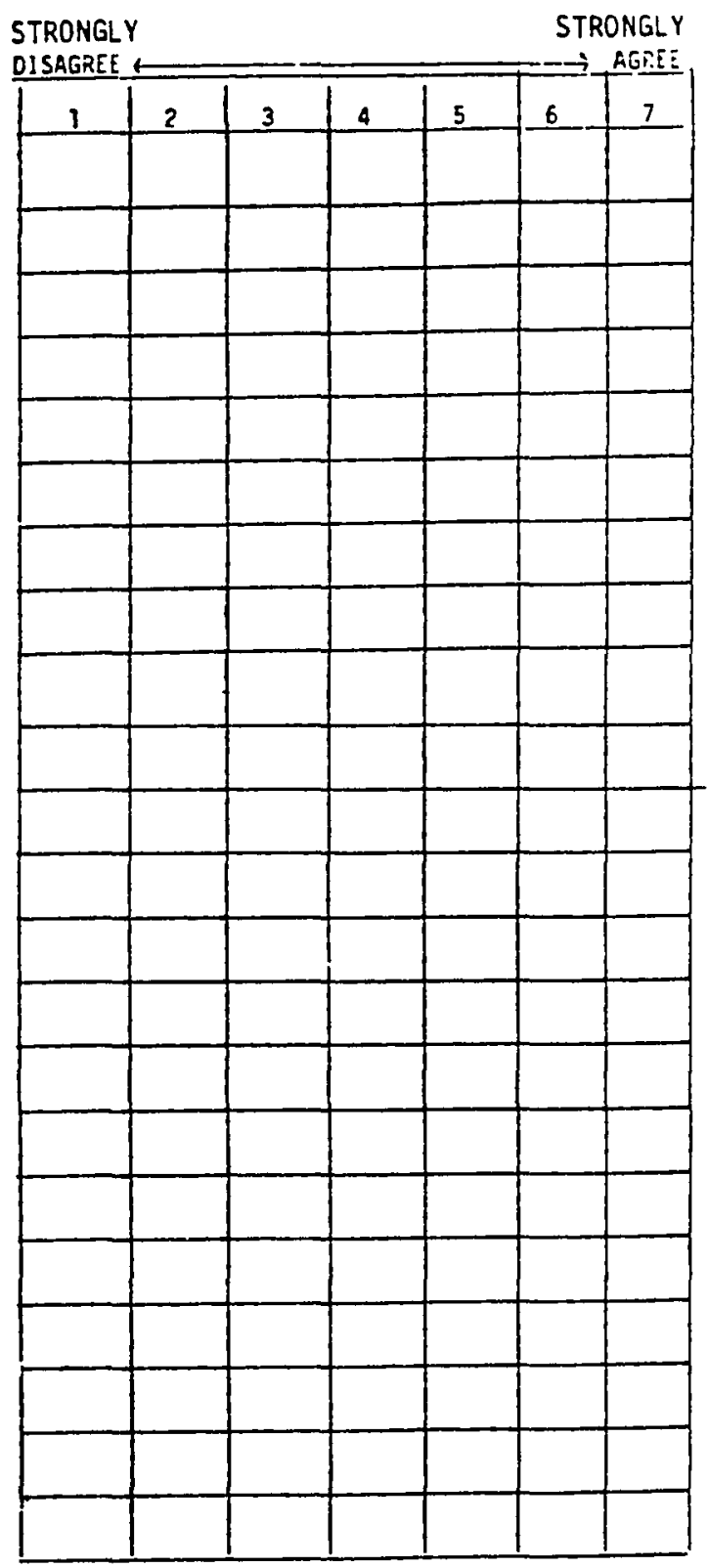


2. HOW MUCH DO YOU THINK YOUR CLIENT ACTED DIFFERENTLY TODAY THAN HE/SHE USUALLY DOES

\begin{tabular}{|c|c|c|c|c|c|c|}
\hline \multicolumn{2}{|c|}{$\begin{array}{l}\text { ACTED IN A } \\
\text { MORE NEGATIVE } \\
\text { WAY THAII } \\
\text { USUAL }\end{array}$} & \multicolumn{3}{|c|}{$\begin{array}{l}\text { CLIENT } \\
\text { ACTED AS } \\
\text { USUALLY } \\
\text { DOES }\end{array}$} & \multicolumn{2}{|c|}{$\begin{array}{l}\text { ACTED II A } \\
\text { MORE POSITIY } \\
\text { WAY THAII } \\
\text { USUAL }\end{array}$} \\
\hline 1 & 2 & 3 & 4 & 5 & 6 & 7 \\
\hline
\end{tabular}

How did he/she act differently than usual?

3. DID ANYTHING ATYPICAL TAKE PLACE DURING TODAY'S SESSIOH? YES HO.

If yes, what?

4. I ESPECIALLY ENJOY WORKIHG WITH CLIENTS LIKE THIS PERSOH.

\begin{tabular}{|l|l|l|l|l|l|l|} 
NEYER & \\
\hline & 2 & 3 & 4 & 5 & 6 & 7 \\
\hline & & & & & & \\
\hline
\end{tabular}

5. IS THERE ANYTHING IN PARTICULAR ABOUT HORKIHG WITH THIS CLIENT WHICH MIGHT SERVE AS A USEFUL ILLUSTRATION III TRAINING OTHER SERVICE PROVIDERS WORKIHG WITH OLD PEOPLE?

6. HOW LONG HAVE YOU WORKED WITH THIS CLIENT? 


\section{APPENDIX C}

\section{INTERPERSONAL CHECKLIST}

INSTRUCTIONS: This is a list of descriptive words and phrases to use in descriting yourself. Please read the items quickly and put an $X$ in front of all the items which describe you, in your own opinion. Those items which do not apply leave blank.

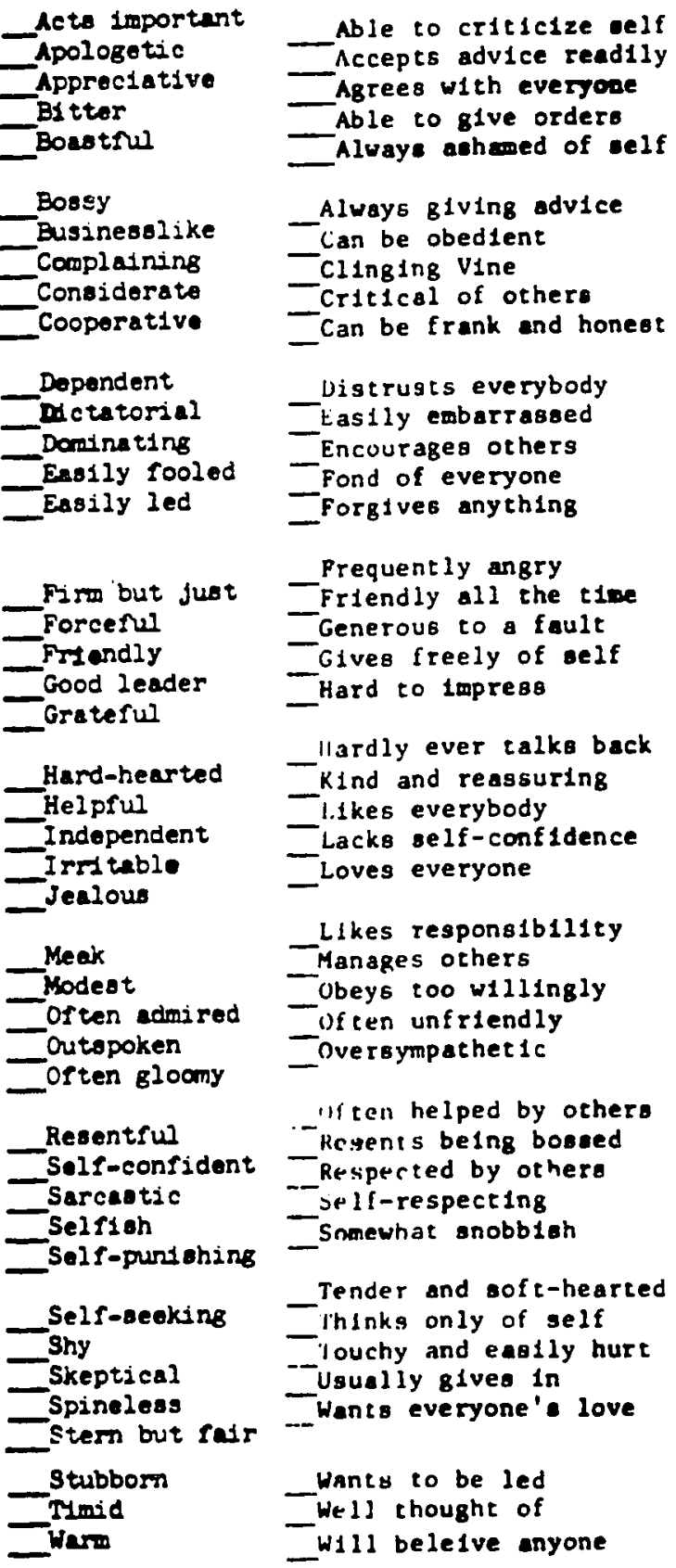

Able to take care of eelf

-Adurea and imitate others

Affectlonate and underatanding

Able to doubt others

-Alwaye pleasant and agreeable

B18-hearted and unself 1 bh

Can be Indifferent to others

Cold and unfeeling

can complain if necessaty

Cruel and unkind

Can be gtrlet if necessary

Eager to get along with others

Egotiotical and conceited

Enjoye raking care of others

Expects everyone to adelre his or her

Frequent ly disappointed

Hardbolled when necessary

Impatient with other's miotakes

Leto orhers make decialons

Likee to compete with others

Likes to be taken care of

Makes a good Impression

Overprotect ive of others

pasive and unagresalve

Proud and self-satisfied

Rebels againgt everything

Self-reliont and assertive

Shrewd and calculating

slow to forglve a wrong

Sociable and neighborly

Spo1ls people with kindneos

Straightforward and direct

Too easily influenced by friends

Triea to be too auccessful

Too lenient with others

Too willing to give to others

Tries to confort everyone

Trueting and eager to please

Very anxious to be approved of

Very reapectful to authority

Wante everyone to like him or her Will confide in anyone 
APPENDIX D

CLIENT EVALUATION INTERVIEW SCHEDULE

CLIENT EVALUATION INTERVIEN

1. Thank client for letting you be there.

2. Show coding'sheets to client, explaining "here's where you asked a question, here's where you sat down," etc.

3. Explain you're not recording what they are saying "We're here because we're interested in improving quality of help agencies like give persons like yourself."

4. "Would like to talk with you about $\underline{5}$ minutes"

5. "Important for us to know what's important to you"

6. "List of things here to renind me of what I want to ask you"

7. "Will be taking notes, to be as accurate as possible"

8. "REMEMAER, anything said is strictly confidential, won't be seen or discussed with anyone outside of our research team."

1. HOW LONG HAVE YOU BEEIN SEEIHG MRS/MR?

2. HOW DID YOU HAPPEN TO START SEEING IIER/HIM?

3. DID YOU HAVE A SPECIFIC REASON THAT LED YOU TO START SEEING HER/HIH?

PROBE: specific reasons like shopping, washing hair, hurt foot 
4. HAVE YOU RECEIVED THE SAME HELP YOU GET FROHI MRS/MR

FROHA ANYONE ELSE?

5. NOW I HAVE A FEW QUESTIONS I'M GOING TO ASK YOU TO AIISWER IN ANOTHER WAY. I'LL READ THE FIRST PART, AND YOU CAN FILL IN WHATEVER COMES TO YOUR MIND. THE THING I LIKE BEST ABOUT MY VISIT WITH MRS/MR TODAY WAS

PROBE:
Make appropriate
comments like
"Yes, I know
"hat you mean,
that is important
isn't it?"

6. "NOH, I'M GOING TO ASK YOU TO THINK BACK ON THIS VISIT AND AGAIN FILL IH WHATEVER COMES TO YOUR MIND. SINCE WE ARE INTERESTED IN IMPROVING THE QUALITY OF HELP YOU GET, WE HEED TO NNOW NOT ONLY WHAT YOU LIKE BEST, BUT WHAT YOU WOULD LIKE TO SEE CHANGED AS WELL." (CHANGED OR ADDED OR TAKEN AWAY)

THE OHE THIHG ABOUT TODAY'S VISIT THAT I WOULD CHANGE IS

TRULE: If one response, tsk "anything else," if jeveral responses, ask "which would you change first" if no response, say "it may sound like we're asking you to zriticize, but we're hot. We are interested in helping you get what you want. 
7. HHAT THINGS DID MRS/MR DO OR SAY TODAY THAT YOU DIDH'T EXPECT HER TO DO?

PROBE: that you didn't think she would do, for example, spend more time with you than usual. To get details ask "how did you feel about it, did

you like it, not ijke it?"

8. WHAT THINGS DID SHE/HE DO FOR YOU TODAY THAT YOU COULD HAVE DONE FOR YOURSELF?

9. WERE THERE ANY THINGS YOU EXPECTED MRS/MR TO DO FOR YOU TOUAY THAT DIDN'T GET DOHE? WHY?

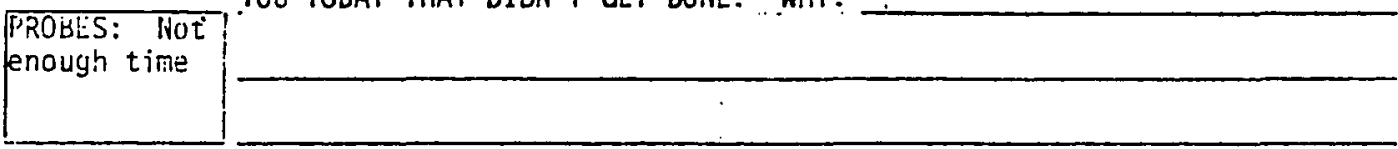

10. ARE THERE THINGS WHICH ARE HARD FOR YOU TO DO BY YOURSELF WHICH YOU WISH MRS/MR WOULD HAVE HELPED YOU DO TODAY?

PROSE: DO YOu think that is part of her job?

11. THINKING BACK OVER TODAY'S VISIT, DO YOU THINK MRS/MR ACTED DIFFERENTLY THAN SHE/HE USUALLY DOES? IF SO, HOW? 
12. COMPARED TO OTHER PEOPLE HHO HAVE HELPED YOU, HOW DO YOU.ENJOY HORKIHG

\begin{tabular}{l|l} 
PROBE: Is she \\
much better, \\
better, about \\
the same, not so \\
good, not at a17
\end{tabular}

13. IS THERE ANYTHING I DIDN'T ASK YOU THAT YOU FEEL IS IMPURTAHT TO IMPROVING THE QUALITY OF HELP YOU RECEIVE FROM AGENCIES LIKE

14. IS THERE ANYTHING ELSE ABOUT MY WORK YOU WOULD LIKE TO KHOW?

Thank client, and end interview--

leave card and thank-you note 
APPENDIX E

OBSERVER IMPRESSION SHEET

IOA:JZ: 22 May 78

Observer Impression Sheet

1. Did anything happen during the observation that was difficult to score? that you felt was omitted iy the coding system? that was distorted by the coding system?

2. Please check all the items you would use to describe the service provider from this particular observation with this particular client:

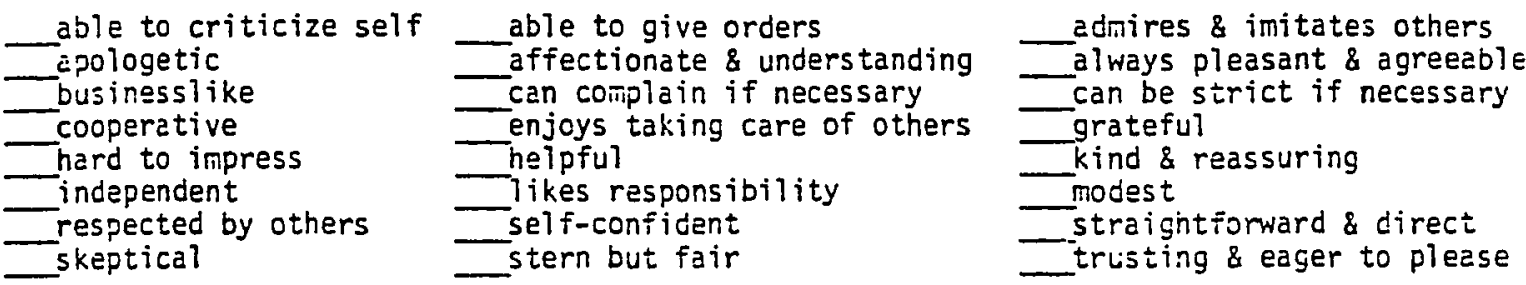

3. What are your general impressions of the service provider from this observation?

4. Did you feel that the encounter between service provider and client changed appreciably when you completed the formal 10 -minute observation? In what way?

5. How vias the encounter terminated? 
i. Please estinate the degiee to which you believe the service provider was respectful of the client.

iot

Respectfu?

\begin{tabular}{|l|l|l|l|l|l|l|}
\hline 1 & 2 & 3 & 4 & 5 & 6 & 7 \\
\hline & & & & & & \\
\hline
\end{tabular}

Indicate any specific occurrences which led to this judyment.

2. Please estimate the extent to which you believe the client participated in deciding what was to be done during the encounter.

No

Participation

\begin{tabular}{|l|l|l|l|l|l|l|}
\hline 1 & 2 & 3 & 4 & 5 & 6 & 7 \\
\hline & & & & & & \\
\hline
\end{tabular}

Emplete Parificipation

Indicate any specific occurrences which led to this judyment.

3. Please estinate the extent to which you feel the provider did things for the client which the client could have done for him/herself.

Vidn't do all

that was

\begin{tabular}{|l|l|l|l|l|l|l|}
\hline & 2 & 3 & 4 & 5 & 6 & 7 \\
\hline & & & & & & \\
\hline
\end{tabular}

Did much more necessary.

than necessary

Indicate what was done which you believe could have been done by the client: 